\title{
Middle and High School Science Teachers' Attitudes toward Nanotechnology and Intention to Implement it in Science Classrooms
}

\author{
Nadira I. Ghattas
}

Follow this and additional works at: https://researchrepository.wvu.edu/etd

\section{Recommended Citation}

Ghattas, Nadira I., "Middle and High School Science Teachers' Attitudes toward Nanotechnology and Intention to Implement it in Science Classrooms" (2015). Graduate Theses, Dissertations, and Problem Reports. 5667.

https://researchrepository.wvu.edu/etd/5667

This Dissertation is protected by copyright and/or related rights. It has been brought to you by the The Research Repository @ WVU with permission from the rights-holder(s). You are free to use this Dissertation in any way that is permitted by the copyright and related rights legislation that applies to your use. For other uses you must obtain permission from the rights-holder(s) directly, unless additional rights are indicated by a Creative Commons license in the record and/ or on the work itself. This Dissertation has been accepted for inclusion in WVU Graduate Theses, Dissertations, and Problem Reports collection by an authorized administrator of The Research Repository @ WVU.

For more information, please contact researchrepository@mail.wvu.edu. 
Middle and High School Science Teachers' Attitudes toward Nanotechnology and Intention to Implement it in Science Classrooms

Nadira I. Ghattas

Dissertation submitted to the College of Education and Human Services at West Virginia University in partial fulfillment of the requirements for the degree of

\author{
Doctor of Education \\ in \\ Curriculum and Instruction
}

Jeffrey S. Carver, Ed.D., Committee Chair

Sebastián R. Díaz, Ph.D., J.D.

James A. Rye, Ph.D. Patricia Obenauf, Ed.D.

Eva Erdosne Toth, Ph.D.

Department of Curriculum and Instruction/Literacy Studies

Morgantown, West Virginia

2015

Keywords: Attitudes, Intention, Nanotechnology, Science Teachers, Nanoscience Education Copyright 2015 Nadira I. Ghattas 


\section{Abstract \\ Middle and High School Science Teachers' Attitudes toward Nanotechnology and Intention to Implement it in Science Classrooms}

\section{Nadira I. Ghattas}

This study was designed to determine the relationship between attitudes toward nanotechnology and the intention of implementing it in science classrooms; to detect the relationship between attitudes and other influential factors (knowledge and self-confidence, professional development, professional context, personal research experience, and personal practice of bringing nanotechnology in science classrooms); to highlight the salient attitudes of science teachers toward nanotechnology and implementing its related content, materials, and activities in science classrooms; and to identify the salient factors that would facilitate the process of integrating nanotechnology in science classrooms.

Science Teachers' Attitudes toward Nanotechnology (STAT-N) survey and semi-structured interview were both used to collect data. Correlation was conducted to explore the relationship between attitudes and intention, and between attitudes and the above mentioned factors. The grounded theory approach was applied to identify science teachers' salient attitudes toward nanotechnology and implementing it in science classrooms, and to determine the facilitators that would help with the process of implementing nanotechnology in science classrooms. Regression analysis was also used to identify the facilitators that would help science teachers with integrating nanotechnology in science classrooms.

Statistical analyses revealed a statistically significant relationship between attitudes and intention, $p<.05$; statistically significant relationships between attitudes and the other influential factors (knowledge and self-confidence, professional development, professional context, personal research experience, and personal practice of bringing nanotechnology in science classrooms), $p<.05$; and that all of these factors but attitudes and research were statistically significant factors in predicting and teachers' intention of implementing nanotechnology in science classrooms. Professional development (PD) factor was the best predictor $(\beta=.32)$ among other factors.

Qualitative results unfolded that attitudes toward nanotechnology and its implementation in science classrooms are influenced by personal perspectives and by inhibiting factors that are related to school and student type, curriculum determinants, time constraints, social influences, lack of resources, lack of PD, lack of knowledge and self-confidence. Facilitators were offered to address some of these limiting factors. 


\section{Dedication}

To my husband, Raed Ghattas, and my children: Sereen, Basil, Dana, Feras, and Yousef Ghattas, the best thing happened in my life.

To my parents for their love, support, and encouragement. 


\section{Acknowledgements}

Completion of this doctoral degree would not have been possible without the support, understanding, and encouragement of many persons. My sincerest appreciation is extended to my advisor and committee chair, Dr. Jeffrey Carver, for his patience, guidance, and constant support during the course of my doctoral degree. I immensely thank you!

I would like to express my gratitude to my committee members, Dr. Rye, Dr. Diaz, Dr. Obenauf, and Dr. Erdosne Toth for their time, expertise, and guidance in this research.

I must acknowledge the help, support, and encouragement of many faculty and staff members in the College of Education and Human Services at West Virginia University.

I am so grateful to my parents, who always believed in me. Their love and encouragement gave me the strength to continue my education and achieve a goal in my life.

My loving husband, Raed Ghattas, gets the lion's share. Words cannot define how much I thank and love you. I'm deeply thankful for everything you have done for me. Thank you for your love and support.

Finally, I would like to thank my five children: Sereen, Basil, Dana, Feras, and Yousef Ghattas, for being my five little blessings. You brightened the way for me. You mean the world to me and I love you. God bless you all! 


\section{Table of Contents}

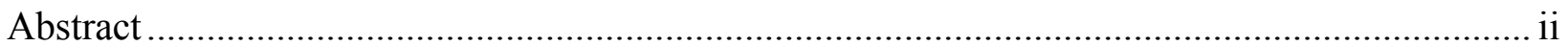

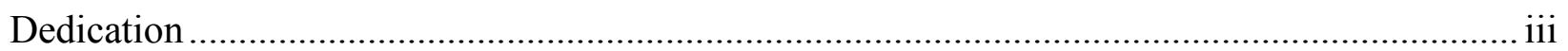

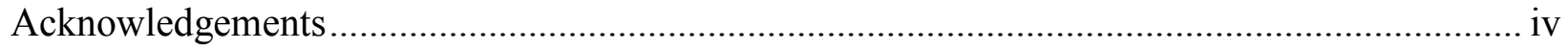

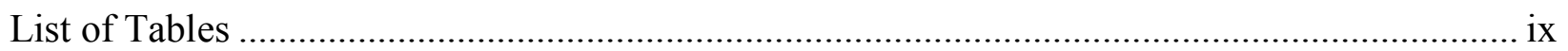

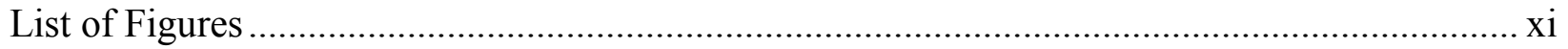

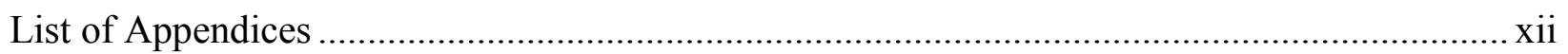

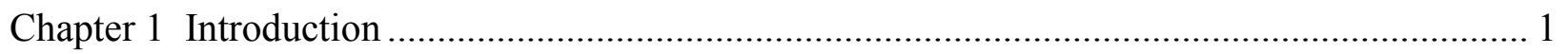

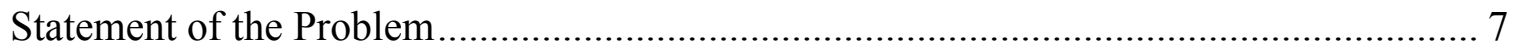

Purpose and Research Questions ............................................................................. 9

Glossary ……............................................................................................ 10

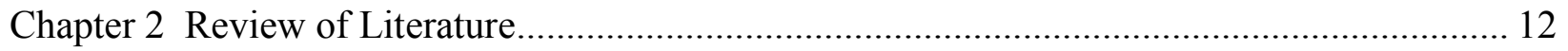

Toward a Definition of Nanotechnology ………………............................................ 12

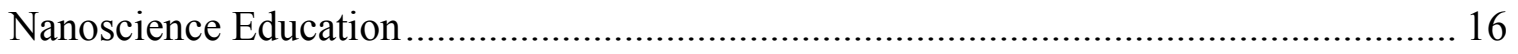

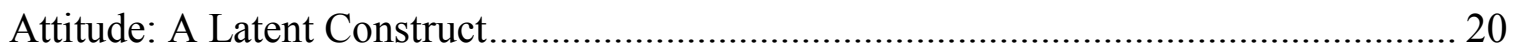

Theoretical Framework: Theory of Planned Behavior ..................................................... 23

Students' Interest in Science and Engineering................................................................. 30

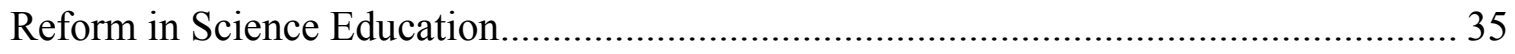

Nanotechnology Professional Development................................................................. 41

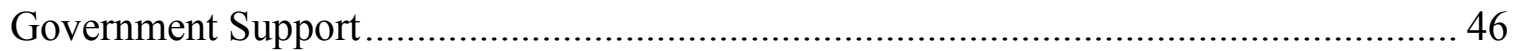

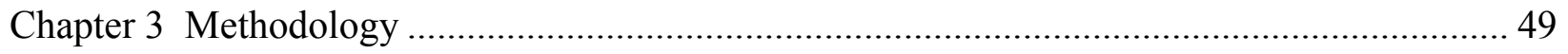

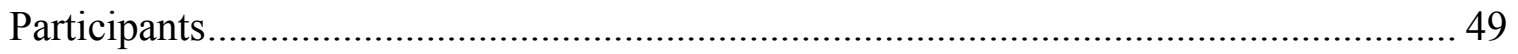

Questionnaire participants ............................................................................. 50

Semi-structured interview participants .............................................................. 51

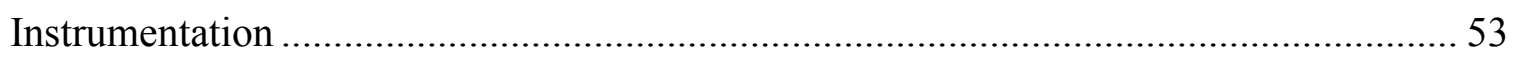

Science teachers' attitudes toward nanotechnology questionnaire (STAT-N) ..... 53

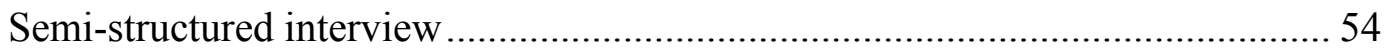

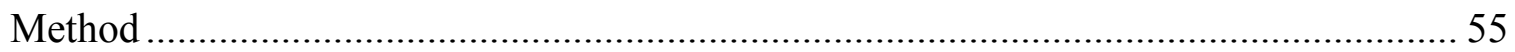




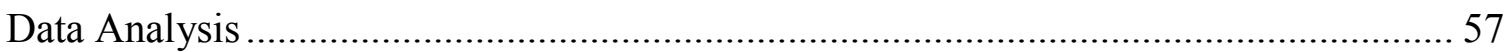

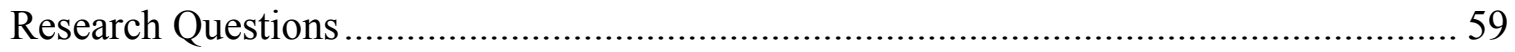

Research question one a............................................................................... 59

Research question one b................................................................................ 59

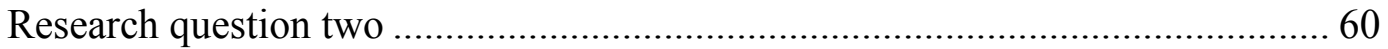

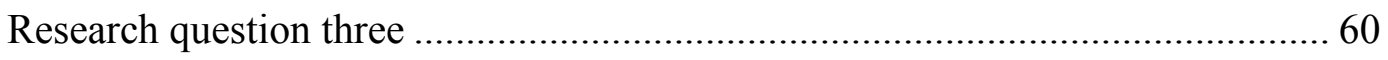

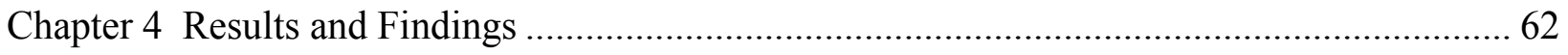

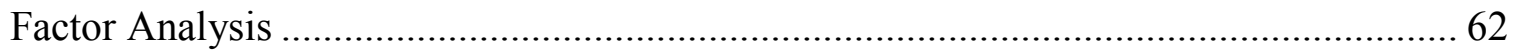

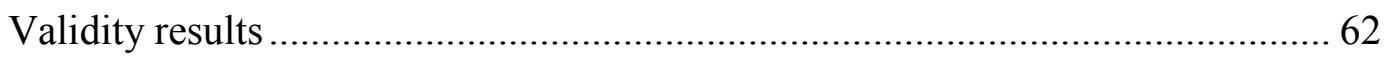

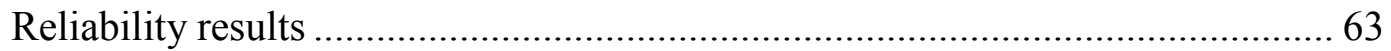

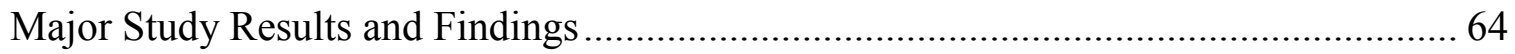

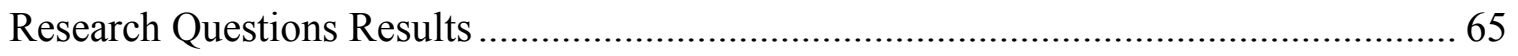

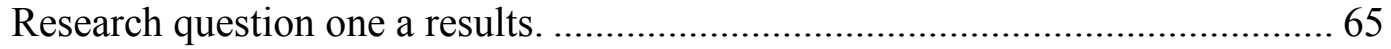

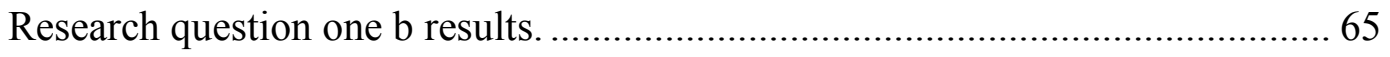

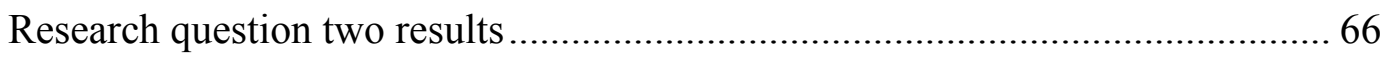

Personal Perspectives toward Nanotechnology ............................................................... 67

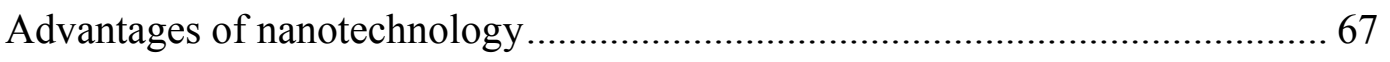

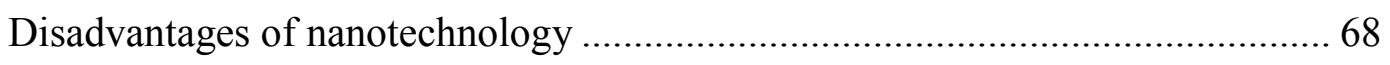

Value of Nanotechnology Implementation in Science Classrooms................................... 70

Limitations of Nanotechnology Implementation ......................................................... 73

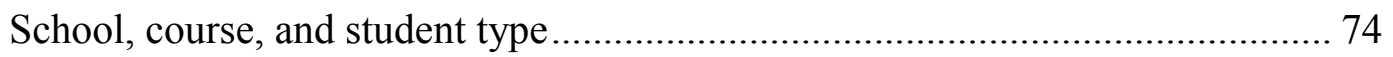

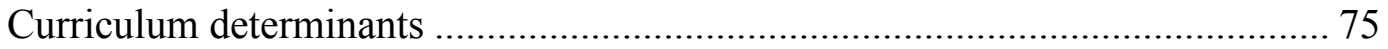

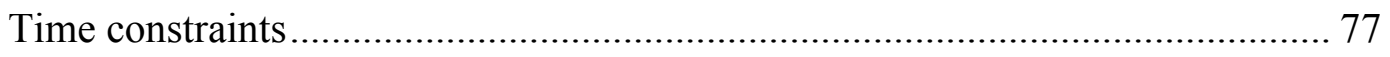

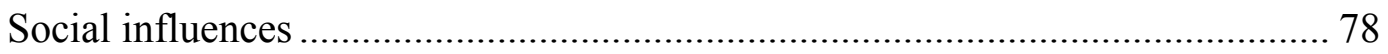

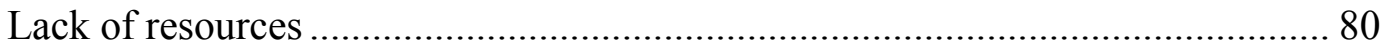

Lack of nanotechnology professional development ………………………….... 82

Lack of nanotechnology knowledge and self-confidence..................................... 83

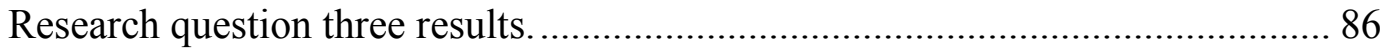

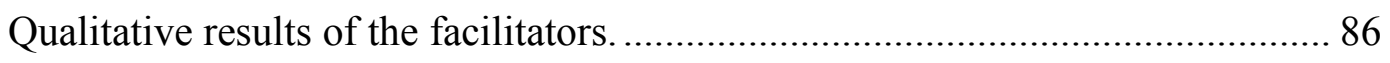

Lack of Nanotechnology Knowledge and Self-Confidence ........................................... 87

Nanotechnology professional development and workshops ................................. 87 
Partnership with researchers and local agencies ........................................... 88

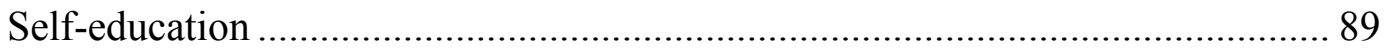

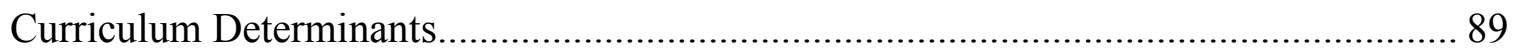

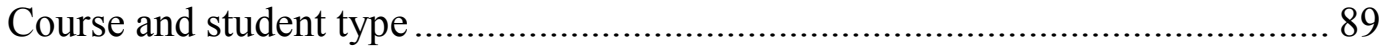

Nanotechnology placement, implementation, and lesson plans ......................... 89

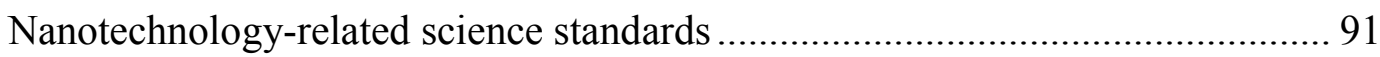

Making a shift in science teaching approach .................................................. 91

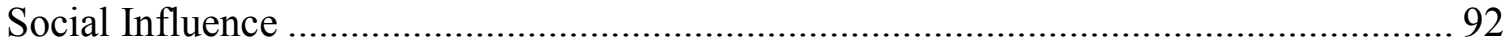

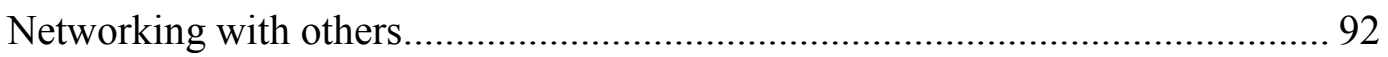

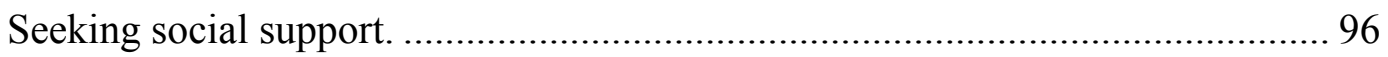

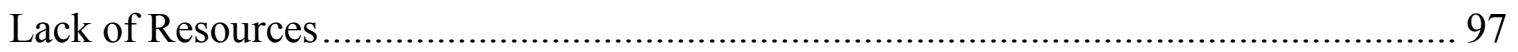

Securing funds, materials, and equipment .................................................. 97

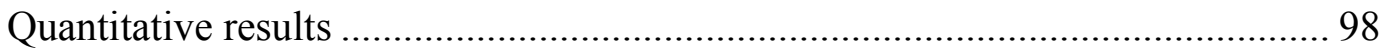

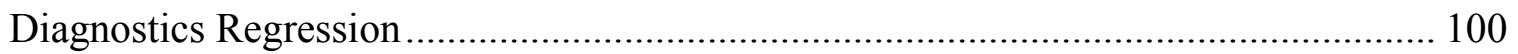

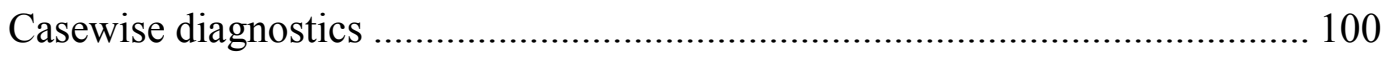

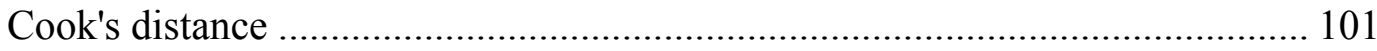

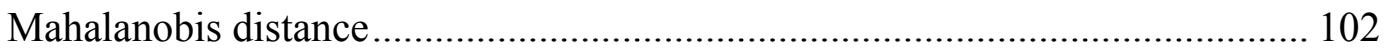

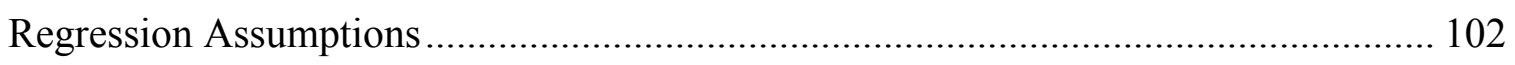

Assumption of no-multicollinearity ............................................................ 102

Assumption of homoscadasticity ........................................................ 103

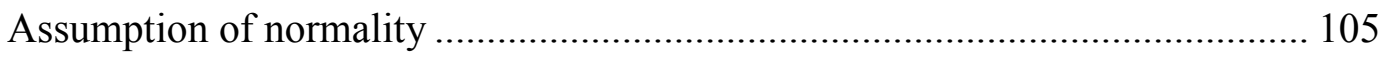

Assumption of independence of observations .............................................. 108

Chapter 5 Discussion, Conclusions, Limitations, Implications, and Recommendations........... 109

Conclusions from the Research Questions ........................................................... 110

Research question one a conclusion ............................................................. 110

Research question one $b$ conclusion ........................................................ 111

Research question two conclusion ............................................................. 112

Research question three conclusion ...................................................... 114

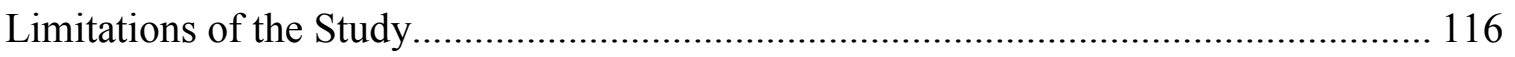

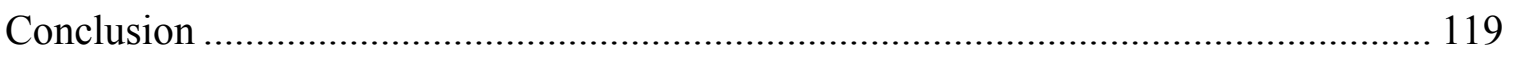

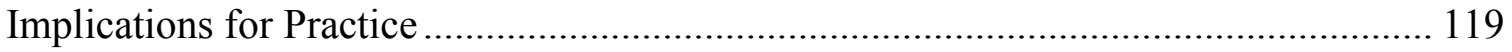


Recommendations for Future Research ............................................................ 122

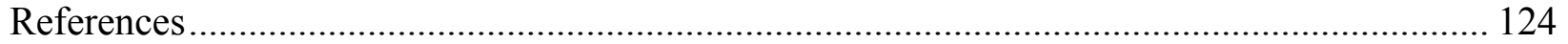

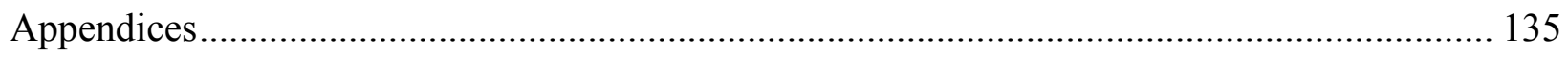




\section{List of Tables}

Table 1 Years of Teaching Experience Distribution of the Sample ......................................... 50

Table 2 Distribution of the School Teaching Level......................................................... 51

Table 3 Years of Teaching Experience Distribution of the Interviewee ................................. 52

Table 4 Distribution of the Interviewee School Teaching Level ........................................... 52

Table 5 Participation of Nano Professional Development.................................................... 53

Table 6 Research Questions with Corresponding Data Sources........................................... 55

Table 7 Alignment of the STAT-N Survey Items into Different Factors/Subscales ................. 63

Table 8 Summary of Factors/Subscales Reliability Statistics............................................... 64

Table 9 Descriptives of the Dependent Variable (Intention) and Independent Variables (Attitude, Professional Development, Professional Context, Practice, Research, and Knowledge and

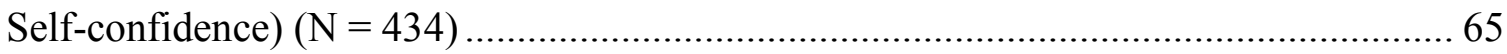

Table 10 Spearman Correlations between Attitude and Five Other Factors (Professional Development, Professional Context, Practice, Research, and Knowledge and Self-

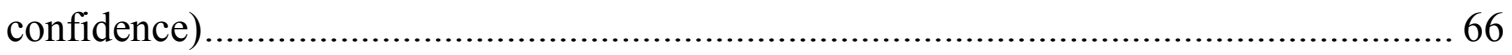

Table 11 ANOVA Test of the Regression Model............................................................. 98

Table 12 Coefficients of the Regression Model ................................................................... 99

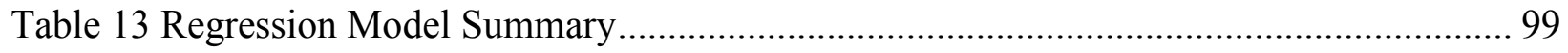

Table 14 Casewise Diagnostics for Outliers .............................................................. 101

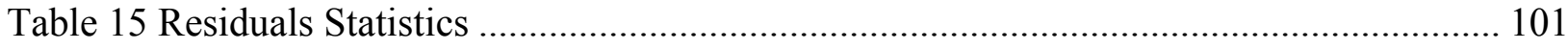

Table 16 Pearson Correlations between Intention (Outcome Variable) and Attitude, Knowledge and Self-confidence, Research, Practice, Professional Context, and Professional

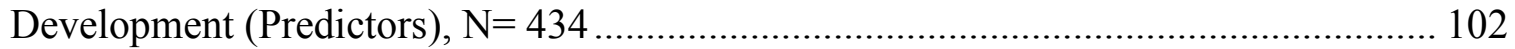


Table 17 Variance Inflation Factor of Regression Predictors.............................................. 103

Table 18 Test of Normality of the Standardized Residual .................................................... 106 


\section{List of Figures}

Figure 1. Theory of Planned Behavior............................................................................... 28

Figure 2. Percent Enrollment of All Freshmen Intending Engineering Major: Selected Years,

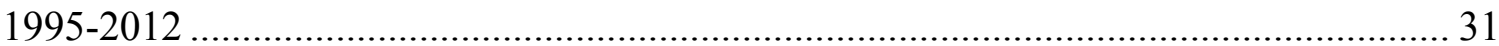

Figure 3. Percentages of All Freshmen Intending S\&E Major: Selected Years, 1995-2012....... 32

Figure 4. Intention Regression Scatter Plot of the Standardized Predicted Value vs. Standardized

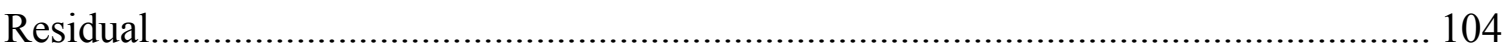

Figure 5. Intention Regression Scatter Plot of the Standardized Predict Value vs. Standardized

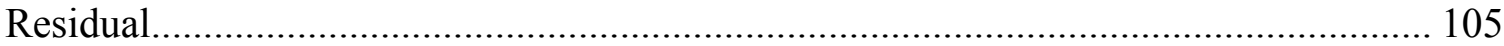

Figure 6. Histogram of the Standardized Residuals...................................................... 106

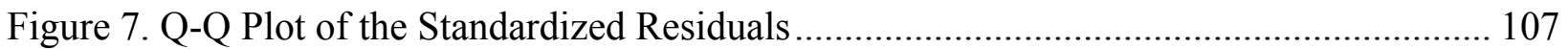




\section{List of Appendices}

Appendix A Securing Copyright Permission. 136

Appendix B Science Teachers' Attitudes toward Nanotechnology (STAT-N) Survey

Appendix C Semi-structured Interview Protocol.... 142

Appendix D STAT-N Invitation Email.......................................................................... 143

Appendix E STAT-N Survey Cover Letter ..................................................................... 144

Appendix F Interview Recruitment Survey ................................................................. 145

Appendix G Interview Cover Letter …..................................................................... 146

Appendix H IRB Research Approval ............................................................................... 147

Appendix I Correlation Matrix of All Likert-type Survey Items........................................ 149

Appendix J Total Variance Explained by Six-Factor Solution............................................. 150

Appendix K Rotated Component Matrix of the Survey Items ........................................... 151

Appendix L Detailed Alignment of the Survey Statements into Six Different Subscales ........ 153

Appendix M Reliability Statistics (Cronbach’s Alpha Coefficients) .................................... 155

Appendix N Histograms of all Variables Included in the Factor Analysis............................ 161 


\section{Chapter 1}

\section{Introduction}

Science is dynamic in its nature. It consistently embraces new changes, new technologies, and new techniques that set forth a parallel change in science curricula. Science as a subject has attracted and aroused the interests of many scientists, researchers, educators, and even the U.S. government as it seeks to make sure that the nation's competency in science, technology, engineering, and math (STEM) is at the forefront in a time that is congruent with the emergence of a novel advanced technology, i.e., nanotechnology. Nanotechnology as an interdisciplinary field of science, technology, engineering, and math (STEM) can bring the nation's economic prosperity to a higher level. So, how can this be done? This can be done through education, which is a vehicle of knowledge and practice. It is evident that education is a priority. Education plays a key role in our increased awareness of science and technology and standing at the front of technology trends and its challenges. One of the most prominent among these events was the launch of Sputnik by the Russians in 1957. This 'scitech' (science technology) innovation prompted an immediate need for an educational reform. More recently, and with the emergence of nanotechnology, our attention to education is prevalent once again.

There have been major drives that situated my focus and piqued my interest in studying the underlying effects of beliefs and attitudes, specifically, science teachers' attitudes toward nanotechnology and their intention of implementing it in science classrooms. Investigating science teachers' attitudes toward nanotechnology and its implementation in science classrooms can be located within a four-fold coherent theme that peaked my interest in studying this topic: (a) the recent emergence of nanotechnology; (b) the declining rate of students' enrollment in 
science and engineering; (c) 'failure' of educational reforms; and (d) the lack of instruments that measure attitudes toward nanotechnology.

Teachers' attitudes toward nanotechnology and the integration of its related content, materials, and activities in their science classrooms can significantly influence the intentions that shape their actual behaviors of implementing it in their science classrooms. Studies that were carried out to investigate teachers' attitudes shared a common theme and indicated that teachers' attitudes are one of the determinants that influence their intentions, which, in turn, affect their behaviors in classrooms (Haney, Czerniak, \& Lumpe, 1996; Lan, 2012; Schifter \& Ajzen, 1985; Yore, 1991). As a consequence, teacher attitudes reflected in their behaviors would affect students' attitudes as well as their academic achievements (Czerniak, Lumpe, \& Haney, 1999; Haney et al., 1996; Koballa \& Crawley, 1985; Mintzes, Marcum, Messerschmidt-Yates, \& Mark, 2013).

The first component of this dissertation study pertains to the emergence of a new and complex interdisciplinary technology, nanotechnology. Nanotechnology is an interdisciplinary field that involves the manipulation of materials at the nano-scale level. Nanotechnology has already entered mainstream industry. The concept of nanotechnology is wide and it conveys a wide range of approaches and applications in the world of industry (Roco \& Bainbridge, 2005). Roco (2003a) stated that nanotechnology is beneficial as it increases productivity, provides better healthcare, and extends the limits of sustainable development and of human potential. The $21^{\text {st }}$ century is witnessing rapid innovations and technological advancements, especially ones that are associated with nanotechnology, such as nanocoatings that provide self-cleaning surfaces; nanotubes that allow for the direct delivery of medicinal treatment, e.g., in dental implants; and nano fuel cells that allow for more efficient electrical gains on hydrogen conversions. 
Due to all of the promising outcomes that can be associated with nanotechnology, the U.S. government has increased its budget investment toward improving and sustaining this new advanced technology (Bowles, 2004; The Royal Academy of Engineering \& Royal Society, 2004; Telford, 2004). Investment in nanotechnology is worthy despite some of the unknown, and perhaps negative, impacts of nanotechnology, such as the effects on our respiratory system by inhaling nanoparticles. Furthermore, from an educational lens, nanotechnology lends itself as interdisciplinary field that requires creating a relationship between science and technology (Ghattas \& Carver, 2012).

Preparing students, even if they are not all seeking nano-related jobs in the future, to be nano-literate citizens in order to meet the demands of the $21^{\text {st }}$ century is paramount. With the influence of nanotechnology, studying teachers' attitudes and beliefs toward nanotechnology is needed, especially due to the lack of research regarding science teachers' attitudes toward nanotechnology and implementing it in school curricula. Haney et al. (1996) indicated that previous science reforms were ineffective because they ignored the influential effects of teachers' beliefs and attitudes. Prior studies have shown that the attitudinal construct was the greatest predictor of science teachers' intention of implementing new reforms that integrate new curriculum and adopt new teaching strategies that are associated with its curriculum materials (Czerniak et al., 1999; Haney et al., 1996; Koballa \& Crawley, 1985). In addition, recommendations for scientific reforms have been increasingly evident in hope of preparing a scientifically literate future workforce that is equipped and competent in an increasingly scientifically and technologically advanced industrial world (Lumpe, Haney, \& Czerniak, 2000). In order to avoid pitfalls of past educational reforms, Haney and Lumpe (1995) recommended focusing on classroom teachers as they have a very important role in the process of change. Very 
often policy makers discount teachers' attitudes and beliefs towards a new educational reform as opposed to paying close attention to their existing beliefs and attitudes before expecting them to implement new curriculum with 'cutting-edge' topics that will be of an added value in preparing scientifically and technologically literate citizens. Both attitudes and beliefs are inseparable constructs, in which attitudes can be predetermined by an individual's held beliefs. Pajares (1992) stated, “...when clusters of beliefs are organized around an object or situation and predisposed to action, this holistic organization becomes an attitude" (p. 314). Therefore, beliefs and attitudes are critical factors that influence restructuring science education (Haney et al., 1996).

There has been plenty of research done on studying science teachers' beliefs, perceptions, and attitudes. However, there is little research done on studying science teachers' attitudes toward nanotechnology as a new emerging interdisciplinary field. Therefore, "future research should seek to enhance our understanding of the relationships between teachers' attitudes and science education reform," which, in this case, promotes integrating nanotechnology in science classrooms (Czerniak et al., 1999, p. 126). Promoting nanotechnology in K-12 science education comes in response to the development of the Next Generation Science Standards (NGSS), and to the constant calls for science education reforms that aim at the development of scientific literacy on emerging technologies such as nanotechnology with its increased contributions in this society (Gardner, Jones, Taylor, Forrester, \& Robertson, 2010; Lan, 2012).

The second component that situated my focus in this study pertains to the declining rate of students who choose to pursue science and engineering disciplines; a rate that reflects that the field of science is not attracting enough students to pursue science (Fonash, 2001; Lee, Wu, Lu, \& Hsu, 2006; Osborne, Simon, \& Collins, 2003; Xie \& Achen, 2009). The declining rate of 
students who are majoring in science and engineering is well documented and inconsistent with international trends related to the increasing demands for a scientific and technical workforce. Osborne et al. (2003) stated that "the swing away from science" becomes a major concern that should be considered (p. 1050). What this calls for is to restore the "scientific appeal," in which science and engineering should be attractive enough to reverse the insufficient number of students in the science and engineering fields to fulfill the high-tech jobs. This is a necessity if we are to revise the downward trend, and it may be accomplished through educational reform. Scientific literacy has become a necessity for everyone in a world that is full of scientific inquiries (National Research Council, 1996). Efforts in science reform identify that scientific literacy is the main goal of science education to produce scientifically literate populace (National Research Council, 1996). Koballa and Crawley (1985) stated, "the first step in improving the status of science as a school subject is to establish a minimum time period during which science must be taught daily at the elementary level" (pp. 228-229). This is consistent with Haney et al. (1996) who encouraged educators to seek improving students' interests and attitudes toward science. It should take place as early as the primary school level. Enacting this course of action may have a significant effect in terms of improving students' attitudes toward science in early stages and making them recognize the importance of science and pursue it as a subject of study.

The third component is attributed to the downturn of many educational reforms that were ineffective. Education is a suitable place for transformation. In addition, it is a way to prepare the next generation of scientists and engineers. Nanotechnology as a novel technology will be a stimulus for such transformation if it is included in school education where students can learn about the new advanced technology. Lee, Wu, and Yang (2002) described nontechnology as a catalyst for transformation. It is a "catalyst to change everything...nanotechnology is performing 
a facelift on every aspect [of our lives]...from education, industrial utilization, and to research and development" (p. 385). This requires reconsidering existing curricula by not only including nanotechnology as a new content area but also changing and/or providing new pedagogical approaches that help with introducing and understanding the new content as well as to respond to the emphasis on inquiry as is capitalized in the NGSS, which are based on the K-12 Science Framework (Next Generation Science Standards, 2013; National Research Council, 1996, 2012).

The above mentioned trend regarding the declining rate of students entering science and engineering leads to a dilemma that should be addressed and taken into consideration as educational reform is developed and implemented. In addition, an effective science education reform would last if close attention is paid to teachers' beliefs and attitudes and by including their voices in the process of designing and implementing educational reforms (Keys \& Bryan, 2001).

The fourth, and final, component that comprises this study comes in response to the multitude of attitudinal instruments to measure teachers' general scientific attitudes and beliefs, yet lack measuring attitudes and beliefs about nanotechnology and the intention of implementing it in science classrooms. Consequently, the attitudinal instrument Science Teachers' Attitudes toward Nanotechnology (STAT-N) was self- developed, by me, in order to measure teachers' attitudes and beliefs toward nanotechnology and implementing it in school.

Overall, this dissertation study comes in response to what is a new prevailing trend in science and with the spread of commercial products as well as technological devices that function at the nano-scale level. This study was driven by the premise that attitudes could be used to predict observable teaching practices, and that changes in attitudes would result in changes in overt teaching behaviors (Abell \& Lederman, 2010). This study is based upon the 
theoretical framework that was developed by Fishbein and Ajzen (1975), Theory of Planned Behavior (TPB). Fishbein and Ajzen's theory of planned behavior was developed in order to predict the attitude-behavior relationship with the construct of intent as the intermediate stage that intervenes between attitudes and behaviors. Intentions are mediated by subjective norms and perceived behavioral control. The use of TPB in science education permits science teachers and researchers to identify key beliefs that play a pivotal role in influencing personal actions (Atwater, 1994). In addition, subjective norms as well as self-perceived behavioral control are two other measures that influence an individual's intention towards performing a desired action or not.

\section{Statement of the Problem}

There are many new fields that are constantly emerging as a result of successful research that shows the overlap and interconnection between individual disciplines. As a result of interdisciplinary efforts, these disciplines became an interdisciplinary field in its nature that requires expertise from different disciplines. In fact, today's interdisciplinary fields might become tomorrow's traditional disciplines. Enzymology, biochemistry, biomechanical engineering, computational biology (bioinformatics), and nanotechnology are some examples of unique interdisciplinary/multidisciplinary fields that integrate/combine different disciplines to fulfill students whose interests span different fields.

Students should be given the opportunity to attack a subject from various methods and cutting across disciplines to better understand a subject or problem. There are so many topics that should be part of today's science curricula. However, nontechnology is distinct because it is not a traditional topic in the commonly taught disciplines, such as chemistry, physics, biology, and earth science. It is an interdisciplinary field that combines science, technology, engineering, and 
math (STEM). Nanotechnology as an integral field provides an opportunity to capitalize on math and science. Thus, teaching about nanotechnology helps with increasing the academic performance of the U.S. students in math and science, where students in the U.S. recorded lower scores in math and science than students in other developed countries which has raised the concerns regarding the ability of the U.S. to compete in a global economy that demands its citizens to be scientifically and technologically literate (Chiappetta \& Koballa, 2010; Milner, Sondergeld, Demir, Johnson, \& Czerniak, 2012; National Science Board, 2012; Schank, Krajcik, $\&$ Yunker, 2007). Teaching about nanotechnology in schools is imperative because students will be growing up in an environment where nanotechnology applications will be widely used. In addition, it helps with the nation's industrial independence and competitiveness.

The problem of this research study stems out of the struggles that are facing science teachers as they attempt to implement nanotechnology-related content, materials, and activities in their science classrooms. Negative attitudes toward nanotechnology as evidenced by the behavior of not integrating nanotechnology-related content, materials, and activities in science classrooms is another contributor that adds to the problem of this study. Lack of knowledge about nanotechnology, teachers' inability and lack of confidence and readiness to integrate nanotechnology as part of science curricula, and other barriers could result in holding negative attitudes toward integrating nanotechnology in science classrooms and lead to the absence of integrating nanotechnology as the desired behavior. Science teachers should be nano-literate, hold positive attitudes toward new emerging technologies, increase their self-confidence about teaching nanotechnology, and be equipped with resources that lessen their struggles. Therefore, nanotechnology professional development opportunities should be promoted among science teachers to train and educate them about this new discipline and make them nano-literate 
teachers, and to enhance their attitudes toward nanotechnology and implementing it in their science classrooms. Nanotechnology professional development should also be able to increase science teachers' confidence and ability to integrate nanotechnology related topics in their science curricula and keep it current with the fast pace of the new scientific revolution. In addition, it should equip them with effective teaching methods and modules in nanotechnology. Based upon the TPB, this research study contributes to deeper understanding science teachers' already existing knowledge of and beliefs and attitudes toward nanotechnology and their willingness to integrate and teach nano-related material in their science classrooms.

\section{Purpose and Research Questions}

Understanding teachers' attitudes and knowledge is essential as it informs the improvement of teaching practices and facilitates professional development opportunities that not only provide teachers with content knowledge but also foster positive attitudes among teachers, and enhance educational effectiveness (Fang, 1996; Pajares, 1992). This research study will be a valuable contribution to understanding the influences and relationship between science teachers' attitudes toward nanotechnology and the intention of implementing its related content, materials, and activities in their science classrooms. The hypothesis is that there will be a direct relationship between positive levels of teachers' attitudes and their intention or willingness to integrate nanotechnology in science classrooms. That is, if there are positive attitudes toward nanotechnology, there will be a high intent to implement nanotechnology-related material in science classrooms. Alternatively, if there are low attitudes toward nanotechnology, there will be a low intent to implement nanotechnology-related material. This study was also aimed to identify different factors that could influence teachers' intentions toward implementing nanotechnologyrelated content, materials, and activities in science classrooms. Applying the theory of planned 
behavior as the theoretical framework for this study aimed to document that the three constructs of the theory of planned behavior (attitudes, subjective norms, and perceived behavior control) influence individual's intentions of carrying out a desired behavior. It is hypothesized to identify that the following six factors have a direct influence on science teachers' intentions toward implementing nanotechnology in science classrooms: professional development, professional context, personal attitudes, knowledge, personal research experience, and personal practice of bringing nanotechnology-related material into science classrooms. These factors could serve to facilitate the implementation of nanotechnology in science classrooms. Accordingly, this study was designed to answer the following research questions:

RQ 1A - What is the relationship between science teachers' attitudes toward nanotechnology and their intention of implementing it in science classrooms?

RQ 1B - In what ways do the other five factors (knowledge, professional context, professional development, research, and practice) associate to attitudes?

RQ 2 - What are the attitudes and perceptions of science teachers toward nanotechnology and implementing it in science classrooms?

RQ 3 - What helps science teachers implement nanotechnology in science classrooms?

\section{Glossary}

Although defined more extensively throughout this document, the following list provides a concise and convenient alphabetized summary of some important terms and concepts of this study:

- Attitude is a latent construct; however, it can be defined as a component of individual's belief system, and a cluster of beliefs around an object or situation form attitudes that have an affective component. 
- Nanotechnology is an interdisciplinary/multidisciplinary filed that combines science, engineering, and technology. It is the control and restructuring of matter at the nanoscale, which is about 1 to 100 nanometers, in order to create materials, devices, and systems with fundamentally new properties and functions due to their small structure.

- NGSS - (Next Generation Science Standards) - are based on the "Framework K-12 Science Education" that was created by the National Research Council. The NGSS are developed through a collaborative, state-led process managed by Achieve. The NGSS are rich in content and practice, arranged in a coherent manner across disciplines and grades to provide all students an internationally benchmarked science education (NGSS, 2013).

- $\quad$ STEM - (Science, Technology, Engineering, and Math) - field includes a wide range of disciplines: the following fields are classified as STEM: mathematics; physical sciences; biological/life sciences; computer/information sciences; engineering/engineering technologies, and science technologies.

- $\quad$ TPB - (Theory of Planned Behavior) - is a theoretical model of human behavior that identifies factors influencing intention and behavior. The TPB consists of direct measures of three constructs: attitude toward behavior, subjective norm, and perceived behavior control. 


\section{Chapter 2}

\section{Review of Literature}

A review of the literature considering teachers' attitudes toward nanotechnology resulted in identification of several areas relevant to this investigation. Major emphases were focused upon (a) defining of nanotechnology as an interdisciplinary field that integrates science, technology, engineering, and math, and as a field that works with materials at the nano-scale level; (b) nanoscience education that includes teaching topics in schools that are nano-related, and that prepares to produce nano-literate citizens; (c) attitudes as an affective construct that influences the process of integrating nanotechnology as part of the science school curricula; (d) theory of planned behavior as the theoretical framework that guides this study; (e) student's interest in science as evident by enrollment in science that reflects a declining rate in the number of students who choose to major in science and engineering; (f) reform in science education that intends to include new emerging science topics that are relevant to students' lives and how to introduce them in science classrooms; $(\mathrm{g})$ nano professional development to train and teach inservice science teachers who were not exposed to it when they were in college; and (h) government support by increasing its investment in nanotechnology research and development (R\&D).

\section{Toward a Definition of Nanotechnology}

Nanotechnology is a new emerging technology (Lakhtakia, 2006; Lin \& Allhoff, 2007; Novak, 2010; The Royal Academy of Engineering \& Royal Society, 2004). It is the "next industrial revolution" that permits building products at the nanoscale level, atom by atom, from relatively inexpensive raw materials (Jones et al, 2013, p. 1490). As an inter/multidisciplinary field of small and ultra-small materials, nanotechnology encompasses a broad principle of 
understanding related to biology, chemistry, physics, engineering principles of design, process control, and yield (Cavanagh 2009; Ernst 2009; Fonash, 2001; Gardner \& Jones 2009; Gardner, Jones, \& Falvo 2009; Jones 2009; Roco, 2003b). Nanotechnology deals with materials "where the key features are measured in a modest number of nanometers" (Kurzweil, 2007, p. 41). The emergence of this new advanced technology prompted the collaboration of researchers from the separate fields of science to share knowledge, techniques, and to control and produce tools that help with the development of the "capability of human beings to observe and organize matter at the atomic level;" an ability that was not yet achievable just a few years ago (Sweeney, 2006, p. 438).

The underpinnings of the concept of nanotechnology were first laid out by the physicist Richard Feynman in 1959, in his lecture that was titled "There's plenty of room at the bottom." In his lecture, Feynman never explicitly mentioned the idea of nanotechnology. However, he argued the possibility of arranging and manipulating atoms and molecules and even creating machines at the nano-scale level (Bennett \& Daniel, 2006; Fanfair, Desai, \& Kelty, 2005; Feynman, 1960; Lane\& Kalil, 2007). In that regard, Feynman (1960) wrote, It doesn't cost anything for materials, you see. So I want to build a billion tiny factories, models of each other, which are manufacturing simultaneously, stamping parts, and so on. As we go down in size, there are a number of interesting problems that arise...but I am not afraid to consider the final question as to whether, ultimately -in the great future - we can arrange the atoms the way we want; the very atoms, all the way down! (p. 34) Feynman (1960) explained that "atoms, on a small scale, behave like nothing on a large scale, for they satisfy the laws of quantum mechanics" (Taylor, Jones, \& Pearl, 2008, p. 30). For 
example, aluminum can be used as a safe material when producing soda cans but it turns as a harmful material when it is manipulated at the nanoscale; when it is used in fine powder form, it can explode when in contact with air (Lin \& Allhoff, 2007).

Nanotechnology is an ever-widening field, and while there is no single definition of it, an umbrella definition of nontechnology was laid out by Roco (2011), who defined it as the ability to control and restructure the matter at the atomic and molecular levels in the range of approximately 1-100 nm. ${ }^{1}$ The word nano is associated with a size about 100,000 times smaller than a human hair (Bowles, 2004). Clunan, Rodine-Hardy, Hsueh, Kosal, and McManus (2014) stated, "nanotech is not merely about size, it is about the unique physical, chemical, biological and optical properties that emerge naturally at the nanoscale and the ability to manipulate and engineer such effects" (p. 6). Nanotechnology can be considered as a special aspect of nanoscience, which is "the study of phenomena and manipulation of materials at atomic, molecular and macromolecular scales, where properties differ significantly from those at a larger scale" (The Royal Academy of Engineering \& Royal Society, 2004, p. 5).

Nanoscience helps us to develop an understanding of the effects of (e.g., surface tension or stickiness) the materials at the nano-scale level. However, on the application side of it, nanotechnology, which can be defined as "the design, characterization, production and application of structures, devices and systems by controlling shape and size at nanometer scale" aims to exploit these effects to create structures, devices and systems with novel properties and functions due to their size (The Royal Academy of Engineering \& Royal Society, 2004, p. 5).

\footnotetext{
${ }^{1} \mathrm{~A}$ nanometer is equal to one-billionth of a meter
} 
Atomic Force Microscopes (AFM) and the Scanning Tunneling Microscopes (STM) are scanning probe instruments that have led to the biggest breakthroughs in nanotechnology; they allowed scientists to view and manipulate materials that are invisible to the naked eye at the nanoscale level (Schank et al., 2007). These instruments enabled scientists and engineers to build materials and structures at the nano-scale level with novel properties that differ from those at the macro-scale level (Schank et al., 2007). Schank et al. (2007) addressed two of the biggest challenges that are likely to confront our students when introduced to nanoscience education. The first challenge is to develop a conceptual understanding of materials at the nano-scale level, given that nano particles are hard to see and visualize. Usually, the experiences of physical objects at the macro scale level can be accurately described by Newtonian physics. However, developing an understanding from the physical laws that govern behaviors of materials at the nano-scale can be the second challenge that is likely to perplex our students. At the nano-scale level different rules will pre-dominate other than the rules or the laws that govern materials at the macro level. For instance, gravity becomes negligible at the nano-scale level while charged forces, quantum mechanics, and the random thermal motion of particles become applicable at the nano-level. Such challenges can be dealt with by using the scanning probe instruments (Schank et al., 2007).

Even though we are decades away from the most dramatic nanotechnology products that have been predicted, science and engineering at the nano-scale have had significant contributions to the world of industry, such as catalysts, coatings, paints, pharmaceutical products, tire products, smart materials, sensors, magnets, and fabrication, among others (Bowles, 2004; Kurzweil, 2007; Lin \& Allhoff, 2007; Roco \& Bainbridge, 2005). Lin and Allhoff (2007) stated that nanotechnology might not only enable today's "mundane products," such as sport equipment 
and cosmetics, but also has various medical and industrial applications (p. 3). In addition, nanotechnology helps with producing clean energy (Peterson \& Heller, 2007). Roco and Bainbridge (2005) indicated that many companies in the U.S. have shown their confidence of the future of nanotechnology with its beneficial contributions. These companies have put substantial resources to the development of nanotechnology. It was estimated that almost $50 \%$ of new products in manufacturing and medical products will be affected by nanotechnology (Roco \& Bainbridge, 2005).

With all of the promising benefits that are associated with nanotechnology, as with any given technology, nanotechnology is associated with ethical controversies; the impacts of nanotechnology are associated with unforeseen and potentially underestimated dangers. Lin and Allhoff (2007) argued that innovation of new technologies has advantages as well as disadvantages and "we should come to terms that our creations can have unintended or unforeseen consequences" (p. 4). For example, they argued that our creation of such products as gunpowder, cameras, nuclear power, and computers have brought us advantageous results in individual, environmental, economics, and security; however, such innovations have created risks that changed our society in fundamental ways and caused problems, such as pollution, privacy concerns, cybercrimes, and new diseases (Lin \& Allhoff, 2007).

\section{Nanoscience Education}

According to the Organization for Economic Co-Operation and Development (OECD, 1999), scientific literacy can be defined as "the capacity to use scientific knowledge, to identify questions and to draw evidence-based conclusions in order to understand and help make decisions about the natural world and the changes made to it through human activity" (p. 60). Scientific literacy is important for all students, it is important for all citizens in order to enable 
them to make judgments and decisions about aspects of their lives that are influenced by science (OECD, 1999). Nanoscience education helps students to appreciate the importance of science and its relevancy to their everyday lives. It also produces nano-literate citizens in light of the emerging nanotechnology as an inter/multidisciplinary field that encompasses chemistry, biology, physics, math, and technology at the same time. The inclusion of nanotechnology in science curricula helps students to develop an understanding of the relationship between and among science disciplines.

Occupations in areas of science, technology, engineering, and mathematics (STEM) will be fast growing; however, the shortfall in STEM employees is likely to increase (Carnevale, Smith, \& Strohl, 2013, Next Generation Science Standards, 2013). Chang (2006) stated, "as the demand for human resources in science and engineering skyrockets, in many parts of the world fewer young people are pursuing scientific careers" (p. 6). A recent CEO perspective on STEM education and careers indicates that "there is an alarming shortage of young people pursuing careers in science and engineering" (Business Roundtable, 2013, p. 6). Currently, there are two to three million unfilled jobs in the STEM areas of science, technology, engineering and mathematics (Next Generation Science Standards, 2013). Thus, despite the growth of the careers in the STEM field, many U.S. students find STEM learning uninspiring (Business Roundtable, 2013). This could be attributed to the lack of positive student attitudes toward science.

In addition, it is believed that the divide of science into disciplines of biology, chemistry and physics and teaching them separately from math and engineering is to be responsible for the increasing disinterest in science among the younger generation (Chang, 2006). The state of science education at the high school level is primarily discipline-specific courses; science curricula are disjointed or there is only a little interplay between the science disciplines (Schank 
et al., 2007). Because "high school students typically do not experience interdisciplinary science until they enter an undergraduate institution, if at all," there is an urgent need for integrating nanoscience education that brings together concepts from across science disciplines, i.e., nanotechnology (Schank et al., 2007, p. 279). Doing so, helps with revising the reality of the current state of science in schools, especially at the high school level where students get introduced to the multiple, but disconnected, science disciplines as opposed to a more integrated holistic curriculum showing unity among different science disciplines (Lan, 2012).

Nanoscience will be a useful field of study for students to pursue, particularly given the increasing demands for nano-scientists and engineers in the market to fulfill the increasing number of jobs that nanotechnology is creating. It will be a stimulus that arouses students' interests, especially with the recent major economic decline and the increase in the unemployment rate.

Nanoscience education can be the driving force for future education in trying to fulfill the curiosity of our students, if not to decrease the divide among the different science disciplines, as well as to produce multidisciplinary citizens who can make informed decisions about scientific challenges and the purchase of nanotechnology products. Even though nanoscience is still in its infancy, its nature, as an interdisciplinary field, makes it a tool to pique the interests among our students to pursue careers in science and engineering (Lan, 2012; Novak, 2010) and "create a better pipeline for young students interested in nanotechnology" (Telford, 2004, p. 18).

With the increasing need for nano-literate citizens, many initiatives have been undertaken to train people to become nano-literate, to build a research capacity in nanotechnology, and to rebuild science education and nano workforce development from the bottom up (Chang, 2006). Achieving these initiatives will fulfill the needed nano workforce as it is expected that by 2015 
nanotechnology will have the potential to create 5 million jobs in the global market (Roco, 2003b).

Similarly, Chang (2006), the director of the National Center for Learning and Teaching (NCLT) in nano-scale science and engineering (NCLT), pointed out that "roughly two million new nano scientists and engineers will be needed worldwide in the next 10-15 years" (p. 7). In 2000, it was estimated that in that there would be 2 million nanotechnology workers worldwide by about 2015 (Roco, 2011). Indicators of nanotechnology development globally show annual growth rates worldwide of approximately $25 \%$ between 2000 and 2008 . However, the average growth rates of all indicators fell by more than half during the financial crises of 2009 (Roco, 2011). Roco (2011) stated that the estimate that was made in 2000 about the number of researchers and workers, who would be involved in one domain or another of nanotechnology would have been realized if the $25 \%$ growth had continued. However, it is expected that this growth is to continue because of new nanotechnology products that will enter the market within the next few years (Roco, 2011).

Because of the declining quality of science education in the United States, the National Science Foundation (NSF) and the National Nanotechnology Initiative (NNI) expressed its concern that the United States that will not have the workforce or intellectual capacity to compete worldwide in nanoscience, or to fully take the advantage of future career opportunities (Foley \& Hersam, 2006; National Nanotechnology Initiative Strategic Plan, 2011; Roco, 2003b; Schank et al., 2007). Roco (2003b) described education as one of the grand challenges for nanotechnology. Education "is looming as a bottleneck for the development of the field of nanotechnology" (p. 1247). 
Challenges that are facing the United States in order to stay competitive with other industrialized nations can be lessened and ameliorated through its educational system, which should correspond to the many calls that are being made by scientists, engineers, policy makers to modify the national standards or to create new standards and curriculum materials that are related to nanoscience and nanotechnology (Jones et al., 2013; Schank et al., 2007).

In 2012, the National Research Council Committee on a Conceptual Framework for new K-12 Science Education Standards, Next Generation Science Standards (NGSS), expressed a vision in science education that requires students to operate at three dimensions (scientific and engineering practices, crosscutting concepts, and disciplinary core ideas) to develop foundational knowledge in preparation for a competitive workforce (National Research Council, 2012). States should adopt the NGSS, which are designed to provide all K-12 students with internationally benched marked science education to better prepare students for college and career readiness in science and engineering (Next Generation Science Standards, 2013).

One of the problems of earlier versions of standards for science has been the absence of including engineering design practices that all citizens should learn. However, the NGSS represents a commitment to integrate engineering design as an essential element to the structure of science education at the same level as inquiry when teaching science disciplines at all levels. Inclusion of engineering design in the NGSS allows students to better engage in and solve societal and environmental problems they will face in the future (Next Generation Science Standards, 2013).

\section{Attitude: A Latent Construct}

This research study is an attempt to understand the influence of teacher belief and attitude constructs toward nanotechnology and the intention of implementing it in science classrooms. If 
we want to better prepare our students to be future scientists and engineers, these constructs must be understood. Attitude has been the subject of investigation by social psychologists for decades (Simpson, Koballa, Oliver, \& Crawley, 1994). Attitude is an abstract and nebulous construct that has myriad definitions, and cannot precisely be measured. It is a fuzzy construct that is poorly articulated and not well understood (Henderson, Morris, \& Fitz-Gibbon, 1987; Osborne et al., 2003). However, it is distinguished from other related terms, such as beliefs, knowledge, selfefficacy, intentions, etc., which are unobservable attributes/constructs (Abell \& Lederman, 2010; Cheung, 2009; Wesely, 2012).

Cheung (2009) defined attitude as "an internal state and thus not directly observable" (p. 79). Attitudes are complex in nature; they cannot be directly measured, thus one can look at relative simple indicators in trying to measure it indirectly (Atwater, 1994; Sapsford, 2007). Henderson et al. (1987) defined attitude as a "tool that serves human need to see order and consistency in what people say, think and do, so that given certain behaviors, predictions can be made about future behaviors" (p. 11). Atwater (1994) called for a need of consistency; that is when perceptions are accurate, teachers' beliefs develop systematically so that the expectations and attitudes can reflect the individual experiences.

Attitude was delineated as a measure of individual's preference and feelings towards an object; they do not necessarily reflect an overt behavior, and they can be used to predict future behavior through words and actions (Henderson et al., 1987; Osborne et al., 2003). Atwater (1994) illustrated attitudes as affective or emotional reactions to objects or people. In a similar fashion, Cheung (2009) suggested that "attitude toward nanotechnology can be conceptualized as set of...affective reactions toward, evaluative beliefs about, and behavioral tendencies to the learning of nanotechnology" (p. 88). 
Attitudes can be influenced by sub-constructs such as beliefs, knowledge, and selfefficacy. Therefore, defining these sub-constructs will help with forming an understanding of attitudes toward a given subject. In a distinction between beliefs and attitudes, Fishbein (1967) defined attitudes, on the one hand, as

...learned predispositions to respond to an object or class of objects in a favorable or unfavorable way. Beliefs, on the other hand, are hypotheses concerning the nature of these objects and the types of actions that should be taken with respect to them. (p. 257)

The term belief is "reserved for information that a person accepts to be true" (Koballa \& Crawley, 1985, p. 223). In turn, the term attitude is shaped as a "result of previously acquired beliefs" (Koballa \& Crawley, 1985, p. 225). Both components of attitude, cognitive and action, can be viewed as more related to beliefs rather than to attitude which can be judged based on the affective component part of it (Fishbein, 1967). Attitude toward an object is determined by individuals' accessible beliefs about the object (Ajzen, 2012).

In contrast with attitudes, which can be measured on a bipolar evaluative scale, e.g., good-bad, clean-dirty, beliefs can be viewed as a measure of probability that the object has a certain attributes, e.g., probable-improbable, possible-impossible, likely-unlikely, etc. (Ajzen, 2012; Fishbein, 1967). Beliefs and knowledge are distinctly different predictors of individual's attitudes (Smith \& Siegel, 2004). Beliefs are necessary but not sufficient condition of predicting individual's knowledge about an object (Smith \& Siegel, 2004). It was argued that beliefs tend to form themselves as a coherent set of ideologies that are held by a person. It is a form of “conceptual behavior" that may not predict what one will do, but what one will say (Sapsford, 2007, p. 104). 
Knowledge is important for shaping appropriate attitudes (Cossons, 1993). Smith and Siegel (2004) argued that beliefs and knowledge are two distinct terms; however, they are related. Specifically, Smith and Siegel (2004) delineated between knowledge and beliefs as the following: objective/subjective, rational/irrational, public/personal (religious beliefs), verified/unverified, certain/tentative, static/dynamic (changing), not a basis for action/a basis for action, low commitment/high commitment, verifiable/unverifiable; given that knowledge is at the left side while belief is at the right side. In relating attitude to beliefs, it can be said that attitudes have the facets of feelings and beliefs (Henderson et al., 1987). Thus, beliefs are one of the factors that constitute one's attitudes towards performing a favorable behavior. This helps predicting a relationship between attitudes and behaviors, in which attitudes can have a little value to high value for the prediction of overt behaviors (Ajzen \& Fishbein, 1977).

\section{Theoretical Framework: Theory of Planned Behavior}

The number of studies that have been done on attitudes toward nanotechnology are limited due, in part, to the lack of developed instruments on attitudes toward nanotechnology. In general, attitudes do not consist of just a single unitary construct that contributes into shaping and forming the attitudes that are held by an individual; rather, there are sub-constructs that contribute into the different ranges of individual's attitudes, toward nanotechnology in this study (Osborne et al., 2003).

In a wide range of empirical studies, the attitude-behavior relation seems to be very loose and that can be attributed to circumstance/context and history (Ajzen \& Fishbein, 1977; Sapsford, 2007). Attitude is a psychological terms that is used to predict individuals' behaviors (Ajzen \& Fishbein, 1977; Henderson et al., 1987). However, the difficulty of demonstrating a consistent attitude-behavior relationship can be a result of the nature of the attitude construct as a 
latent variable that manifests itself in the form of one or more of three types of responses: cognitive, affective (evaluative), and conative (action) (Fishbein, 1967; Pardo, Midden, \& Miller, 2002; Simpson et al., 1994).

Simpson et al. (1994) and Fishbein (1967) defined cognitive response as a reflection of beliefs about an attitudinal object, which can be a person or even a real object. In a contrary of cognitive responses, Simpson et al. (1994) defined affective responses as the type of responses that include the feelings that a person holds towards an attitudinal object. Lastly, Simpson et al. (1994) clarified conative responses as behavioral inclination and actions with respect to an attitudinal object. Conative responses may also refer to beliefs about what should be done with respect to an object (Fishbein, 1967). For example, a person's attitude toward segregation would not only include negative feelings towards segregation, but also ideas about its causes and implications as well as convictions that it should be attacked through, for instance, demonstration and legislation (Fishbein, 1967).

The multi-component conception of attitude (affect, cognitive, and action) are not always highly correlated (Fishbein, 1967). Thus, attempts of predicting behaviors from attitudes have typically based upon the notion of consistency or inconsistency of a person's attitude that is based on intuitive consideration, what they say, think and do (Ajzen \& Fishbein, 1977; Fishbein, 1967; Henderson et al., 1987; Simpson et al., 1994). That is, it is predicted that a person who holds a favorable attitude toward an object is expected to perform favorable behavior towards it. Similarly, if a person holds an unfavorable attitude toward an object, it is expected that this person will perform an unfavorable behavior (Ajzen \& Fishbein, 1977). This was the previously held notion of predicting the relationship between attitudes and behaviors. The absence of a theoretical basis for predicting such a relationship motivated Ajzen and Fishbein in developing 
and proposing a theoretical framework that predicts the nature of the relationship between attitudes and behaviors. Thus, Ajzen and Fishbein (1977) aimed to develop a model that helps with predicting an individual's behavior. Hence, they developed the theory of planned behavior (TPB), which was developed out of the theory of reasoned action (TRA) approach that was pioneered by Martin Fishbein and emerged as a dominant conceptual framework to predict, explain, and change human social behavior (Ajzen, 2012; Simpson et al., 1994).

The TRA rests upon the assumption that the individual can decide at will whether to perform the behavior of interest or not (Simpson et al., 1994). Individuals are faced with behavioral decisions that encounter barriers (either real or perceived), personal limitations, and lack of resources. In response to the limitation of the type of response in the TRA, Ajzen and Fishbein proposed TPB as a more inclusive form of TRA to include a third component, perceived behavioral control ( $\mathrm{PBC}$ ), as an additional predictor of intentions and behaviors, to the original model, which was hypothesized to have a direct impact on the formation of behavioral intention, independent of attitudes and subjective norms (Ajzen, 2012; Simpson et al., 1994). PBC represents the extent to which a behavior is complicated by internal and external factors (Simpson et al., 1994). Internal factors include existence of adequate or inadequate information, skill, or ability (Simpson et al., 1994). Given that inadequate information or skill may hinder the process of action towards a given behavior while adequate information or knowledge may activate the process of action towards a desirable behavior.

Similar expectations with the availability or lack of external factors that may include resources, opportunity, or the cooperation of others, the construct of $\mathrm{PBC}$ is equivalent to and attributed to the concept of self-efficacy that was first postulated in Bandura's (1977) social learning theory (Ajzen, 2012; Simpson et al., 1994; van Aalderen-Smeets, Walma, van der 
Molen, \& Asma, 2012). At the heart of the social learning theory, Bandura defined self-efficacy as "judgments about how well one can organize and execute courses of action required to deal with prospective situations" (Bandura, 1982, p. 122). In other words, self-efficacy is an essential motive to learn and is responsive to change (Zimmerman, 2000).

Self-efficacy is a measure of individuals' confidence and beliefs in their performance capabilities towards a particular behavior/action that may contain difficult and stressful elements rather than focusing on their personal qualities (physical or psychological characteristics) towards successfully executing a given action towards a given object (Bandura, 1977; Mintzes, 2013; Zimmerman, 2000). According to Bandura (1982), self-efficacy is an element that has motivational and influential effect on individual's choice of action; "the higher the level of induced self-efficacy, the higher the performance accomplishments and the lower the emotional arousal" (p. 122). Self-efficacy is an element that is directly relevant to the construct perceived behavior control in the TPB. That is, individuals' behavior is strongly influenced by their confidence in their ability to perform a behavior (i.e., by perceived behavior control).

A recent theoretical framework was developed by van Aalderen-Smeets et al. (2012). It illustrated that the construct of elementary teachers' attitudes toward teaching science encompass different attitudinal dimensions (perceived behavior control, individual's affective state, and cognitive beliefs) that contribute to behavioral intention, which in turn is directly related to behavior. Lumpe et al. (2000) in their study of assessing teachers' beliefs about their science teaching context found that capability beliefs were correlated with contextual factor that could hinder or foster science teachers' capabilities. It was found that number of years of experience, number of science teaching methods courses, number of science teaching strategies used, and minutes spent teaching science were significantly correlated to the teachers' context belief score 
(Lumpe et al., 2000). Thus far and according to Bandura's social learning theory (1977), van Aalderen-Smeets et al.'s (2012) theoretical framework, and Ajzen and Fishbein's theory of planned behavior (1977), perceived behavior control is related to performing a particular action. It also completes the TPB with its basic structure to include all of three constructs; attitudes, subjective norms, and perceived behavioral control.

According to the theory of planned behavior, Ajzen (2012) explained that individual's actions are guided by

...beliefs about the likely outcomes of the behavior and evaluations of these outcomes (behavioral beliefs), beliefs about the normative expectations and actions of important referents and motivation to comply with these referents (normative beliefs), and beliefs about the presence of factors that may facilitate or impede performance of the behavior and the perceived power of these factors (control beliefs). (p. 18)

In a more detailed description of the theory of planned behavior, Ajzen (1991) and Ajzen (2012) clarified that attitudes (behavioral beliefs) refer to either favorable or unfavorable evaluations toward a given behavior; subjective norms (normative beliefs) are the perceived social pressure to perform or not to perform a given behavior; and, lastly, perceived behavior control (control beliefs) refer to the perceived ease or difficulty of performing a behavior. According to Ajzen (2012), the constructs of attitudes, subjective norms, and perceived behavioral control all aggregate into the formation of a behavioral intention, which is assumed to 
be the immediate antecedent determinant of a given behavior (see Figure 1, Appendix A for copyright permission) ${ }^{2}$

Figure 1. Theory of Planned Behavior.

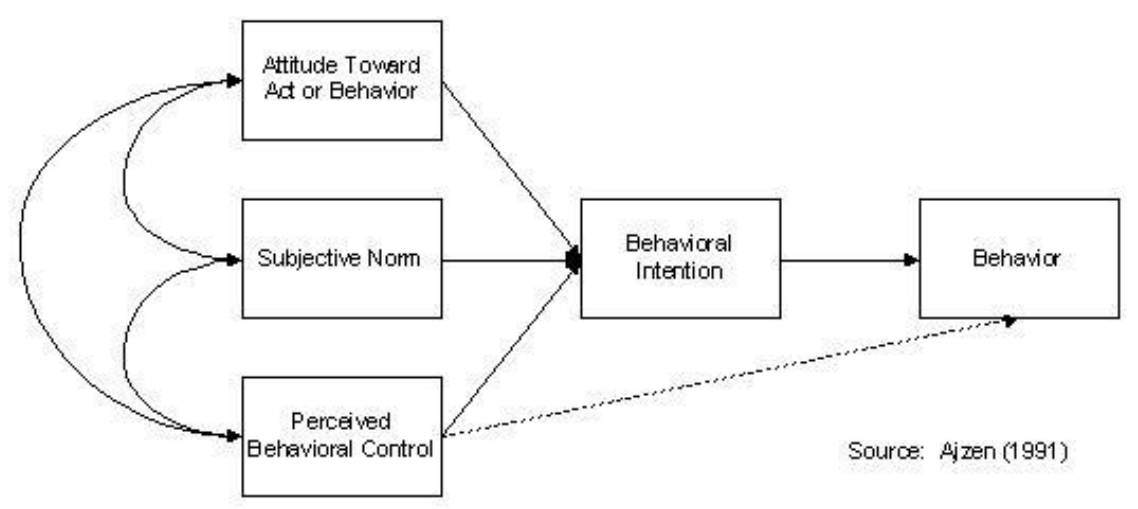

Figure 1. Illustration of the theory of planned behavior. This figure shows the relationship between the constructs that comprise the theory of planned behavior. Adapted from "The Theory of Planned Behavior," by I. Ajzen, 1991, Journal of Organizational Behavior and Human Decision Processes, 50, p. 182. Copyright 1991 by the Academic Press, Inc.

Fundamental assumption to the TPB is that behavior is guided by individual's intentions. This assumption implies that there is a strong relation between intentions and behavior, and any change in intentions is usually followed by changes in actual behavior (Ajzen, 2012). As was previously indicated, perceived behavior control of performing a desired behavior can be complicated by internal and external difficulties. In turn, it is proposed in the TPB that behavior can be guided by perceived behavior control in addition to intention (Ajzen, 2012). Perceived behavior control is a very important construct that can be promoted through professional development. Individual's increase in perceived behavior control helps with increasing intrinsic motivation, which is the desired outcome to be seen in order for effective integration and teaching of the desired behavior of integrating nanotechnology in science classrooms.

${ }^{2}$ Figure 1 is from "The Theory of Planned Behavior," by I. Ajzen, 1991, Organizational Behavior and Human Decision Processes, 50(2), 179-211. Copyright [2015] by Elsevier. Reprinted with Permission. 
In general with the TPB, it was assumed that a given behavior is more likely to be performed or engaged in with an existence of more favorable attitude and subjective norm, and greater perceived behavior control (Ajzen, 2012). The theory of planned behavior clearly distinguishes between attitudes towards an object (e.g., science or nanotechnology) and attitudes to some specific actions to be performed towards that object (e.g., integrating nanotechnology in science classrooms). The TPB helps with unfolding beliefs that can be reinforced or downplayed in order to promote a desirable positive attitude towards performing a desired given object.

The TPB has been developed to understand a wide variety of human behaviors. Studies have been conducted and found that attitude, subjective norms, and perceived behavior control are statistically significant predictors of science teachers' intent to implement new reforms or integrate new curriculum and adopt new teaching strategies that are associated with it (Czerniak et al., 1999; Haney et al., 1996; Koballa \& Crawley, 1985; Schifter \& Ajzen, 1985). In a test of the TPB, Milner et al. (2012) examined elementary teachers' beliefs-based affects influence their intent to teach science in own classrooms found that behavioral intention of the teachers was significantly linked to all of the three direct measures of the theory of planned behavior constructs (attitude toward behavior, subjective norm, and perceived behavior control). Another utilization of the TPB was in a study that was conducted by Crawley (1990) to examine the determinants of science teachers' intentions to use at least $50 \%$ of the activities and investigations that were completed as a result of their participation in a funded program by the Texas Higher Education Coordinating Board in the Institutes in Physical Science, an Education Economic Security Act (EESA), with students that teachers would teach during next school year. The study results revealed that attitudes, subjective norms, and perceived behavioral control have 
significant contributions to prediction of behavioral intention. It was found that attitude was the most important predictor of behavioral intention.

Schifter and Ajzen (1985) found that attitude, subjective norm, and perceived control are statistically significant predictors that are correlated to individual's intention, with attitude being the greatest significant predictor of intention. Similarly, Haney et al. (1996) found that attitudinal behaviors, subjective norms, and perceived behavior control to be significant contributors towards the behavioral intent for at least one of the strands of the competency based science model (inquiry, knowledge, conditions, and applications) of the Ohio state model. Specifically, Haney et al. (1996) found that attitudinal behaviors have the greatest influence on the behavioral intention to implement all four strands of the Ohio science model in their classroom instruction.

\section{Students' Interest in Science and Engineering}

At a time when the national reform focuses on science for all students, it is disturbing to see a declining trend in student enrollment in science and engineering. The "swing away from science" as it is depicted by the trend of continuing decline in the number of students who pursue science is a concerning issue (Osborne, 2003, p. 1050). Fonash (2001) debated that fewer and fewer numbers of students in the U.S. secondary educational system become interested in science, especially with the fields that deal with development and manufacturing (engineering).

Apparently, the demographic of student enrollment shows a critical decline in the number of enrolled students in engineering in the past decades of 1980s and 1990s in the industrialized countries, such as the U.S. Lee et al. (2006) pointed out that the number of undergraduate enrolled students in engineering dropped from nearly 450,000 in 1982 to about 350,000 students in 2000. According to the National Science Board (2014), the engineering enrollment rate was flat in the late 1990s, and then, fortunately, a trend of increasing and decreasing enrollment rate 
was noticed in the years from 2000 to 2009 . The undergraduate engineering enrollment rate increased from 2000-2003, declined slightly through 2006, and then has risen again about $15 \%$ for the next three years to reach 468,100 students in 2009, and then to a peak of 511,000 in 2011 (National Science Board, 2014). Figure 2 illustrates an increase in engineering enrollment after its decline in 2006 to reaching 12\% (the highest since early 1980s), and then a slight decrease in 2012 to reach 10.3\% (National Science Board, 2012, 2014).

Figure 2. Percent Enrollment of All Freshmen Intending Engineering Major: 1995-2012.

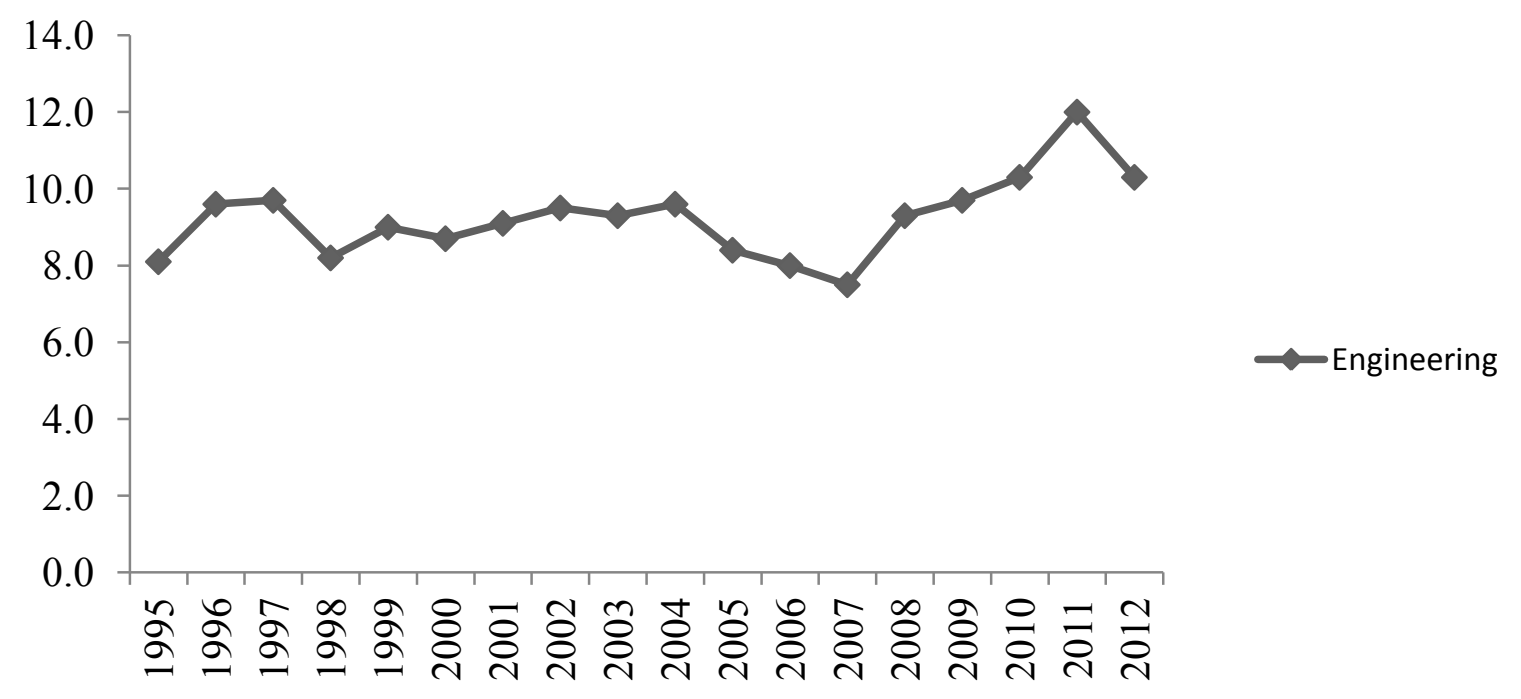

Figure 2. Percent enrollment of all freshmen intending engineering major: 1995-2012.

As shown in Figure 3, similar pattern was recorded and noticed with all U.S. freshmen intending science and engineering (S\&E) majors (National Science Board, 2012, 2014). 
Figure 3. Percentages of All Freshmen Intending S\&E Major: Selected Years, 1995-2012.

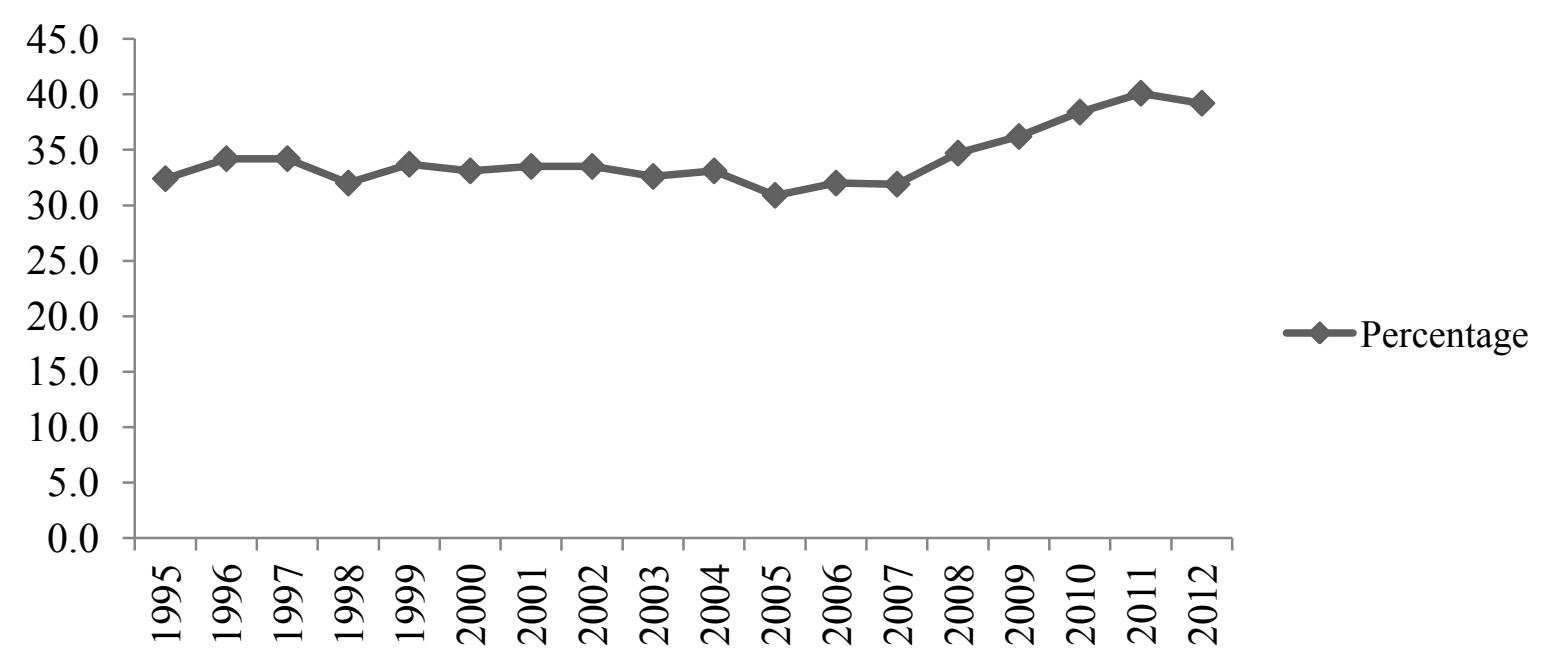

Figure 3. Percentages of all freshmen intending S\&E major: selected years, 1995-2012.

Despite the increase in the number of students who are opting to major in S\&E, this increase does not reflect the sustainability in a degree in science and engineering and even still deemed insufficient to fulfill the high demands for U.S. trained nano workforce that is associated with the relatively fast growing nano-related jobs, which made the U.S. dependent on a rising flow of foreign high-tech talent into the U.S. This inconsistency depicts a low uptake of science and engineering as majors for students (Foley \& Hersam, 2006). It was reported that the low uptake of science and engineering subjects in comparison with the increasing demand for skilled scientists and engineers can be traced back to the declining quality of STEM education, the teaching practices, the already existing traditional textbooks, and to the outdated materials that do not trigger students' interests, which in turn poses a threat to the nation's economic prosperity and to the scientific literacy of its citizens (Foley \& Hersam, 2006; Osborne, 2003; Schank, Krajcik, \& Yunker, 2007; Yore, 1991). These reasons not only contribute to the low performance of the U.S. students in science and mathematics, but also to the shortage number of students in the subjects of science and engineering. Foley and Hersam (2006) stated, "with the exception of 
Switzerland, the U.S. spends more per student than any other country, and yet, in the 2000 National Assessment of Educational Progress, less than one third of U.S. students in the $4^{\text {th }}$ and $8^{\text {th }}$ grades, and less than one fifth of U.S. students in $12^{\text {th }}$ grade performed at, or above, proficient levels in math and science" (p. 474).

Similarly, Schank et al. (2007) pointed out that "the U.S. students rank near the bottom on international studies of educational performances in science and mathematics. Their dismal performance is due partly to the science textbooks currently in use" (p. 279). Overall, the number of students who major in science and engineering creates a conflict that does not correspond to the mounting demands of preparing better students for scientific and engineering workforce especially with the emergence of the novel advanced technology: nanotechnology.

With the emergence of the advanced technology, there are more growing demands that require more scientists and engineers with perspectives beyond traditional interdisciplinary engineering and science backgrounds (Lee et al., 2002). Currently, our students are living in a technological information era where they often use their computers to gather information. However, they do not talk about nanotechnology despite considering it as one of the critical drivers which will keep the technological world evolving (Fonash, 2001).

Society faces several problems related to producing a nanotechnology literate workforce. The inability to attract students to nanotechnology education and training programs coupled to the increasing numbers of students living in poverty stricken communities where schools are not well funded or staffed prevent the flow of highly educated nanotech literate students to higher education and subsequently the higher technical careers like those in nanotechnology. School poverty level refers to the percentage of students reported by the school to be receiving free or reduced price lunch. It was found that students in urban and rural schools at the poverty level 
scored a considerably lower than their counterparts in suburban schools on subject areas of math and science (Anderson, Hollinger, \& Conaty, 1992; Foley \& Hersam, 2006). These comparisons may serve to highlight the huge funding disparities that exist between the U.S. school districts (Foley \& Hersam, 2006). Students in suburban schools enjoy a quality education, smaller classes, computers, and even higher salaried teachers, while students in urban and rural schools face larger number of students in classrooms and inadequate funding for even basic instruction (Foley \& Hersam, 2006). The challenge is to institutionalize interdisciplinary science education in K-12 science curriculum through the use of nanotechnology in these urban and rural schools, where it requires not only teacher preparation but also resources and funding to buy relatively expensive materials and equipment to successfully incorporate nanotechnology in these schools and to inspire students toward considering STEM major and professional careers.

For nanotechnology to reach its full potential and contribution to our society, we must have a trained nano workforce that corresponds to the ever-widening impact of nanotechnology and its related jobs. However, the inability to attract students to nanotechnology education and training programs is a challenging educational task that can be ameliorated if we are able to pique students interests in majoring in science and view it as immediately relevant to their daily lives and, over time, worth pursuing as a major and a career, and if the U.S. educational system is geared toward teaching a unified approach to understanding and using science and engineering (Fonash, 2001; Ringer, 2014). This will also be a challenging task if we are unable to reverse the declining number of students who are intending to major in science and engineering in 2012 as reported by the National Science Board in 2014.

There are many factors that have been found to influence students' choice of majoring in science and engineering. Culture, gender, curricula, and teachers' beliefs and attitudes are some 
of the variables that influence students' determination to pursue science and engineering (Osborne, 2003). Since students' attitudes towards science have been studied, one should instead focus on studying teachers' attitudes toward nanotechnology as a method to reveal the current attitudes and observable behaviors as they influence and predict their students' attitudes toward the same given object, nanotechnology (Abell \& Lederman, 2010; Fonash, 2001). Pajares (1992) noted that "beliefs teachers hold influence their perceptions and judgments, which, in turn affect their behavior in classrooms" (p. 307). Teachers' attitudes and beliefs about science influence many aspects of their jobs as science teachers; their influences extend to affect ranges of teaching aspects that include lesson planning, science teaching, students' learning, etc. (Abell \& Lederman, 2010).

\section{Reform in Science Education}

Education is a priority. It is a suitable place for transformation in terms of content and pedagogical methods. Through education, students can be reached and prepared to be the next generation of scientists and engineers. According to Yore (1991), the already existing curriculum textbooks tend to restrain science teachers' instructional practices, dictating that most instructional objectives will be lower level knowledge, and the instructional strategies will focus more on reciting, testing, and other traditional approaches of teaching science as a stand-alone discipline. This does not help in engaging students in direct experience, through laboratory, or actively involving them in discussing a new emerging material, such as nanotechnology, that is related to various aspects of their lives and many products that they consume. Dwelling on the educational practice that focuses on memorization explains the decreasing trend in producing scientific workforce; a practice that does not appear to produce scientifically and technologically 
literate graduates to face the new challenges that require critical thinking and problem solving (Yore, 1991).

Efforts in science education reforms identify that scientific literacy is the main goal of science education (National Research Council, 1996). The National Research Council (1996) defines scientific literacy as "the knowledge and understanding of scientific concepts and processes required for personal decision making, participation in civic and cultural affairs, and economic productivity" (p. 22). Science and technology are in a constant change. However, the U.S. has failed reversing the erosion in its K-12 STEM educational system (Foley \& Hersam, 2006). The non-competitiveness of the U.S. K-12 science education does not promise for the future of U.S. high- technology competitiveness (Foley \& Hersam, 2006). In order for the U.S to face the fierce competition in the field of nanoscience and nanotechnology, changes should be made to its educational system to keep abreast of the nanotechnological revolution; the U.S educational system needs a continual transformation that corresponds to new updates in science and technology to be able to produce scientifically and technologically literate students. The impact of novel scientific advances that are associated with the emergence of nanoscience and nanotechnology considered as an opportunity to rethink not only the content of STEM curricula but also it pedagogical strategies (Hingant \& Albe, 2010). Advancement and applications of nanotechnology establish the need for an educational transformation with nanotechnology as the catalyst for that. Lee et al. (2002) described nanotechnology as a "catalyst to change everything... nanotechnology is performing a facelift on every aspect of our lives...from education, industrial utilization, and to research and development" (p. 385). Schank et al. (2007) believed that nanoscience education can serve as a catalyst to bring about science education reform because 
...the current education system is not only failing to produce a populace scientifically literate enough to understand these scientific advances but also failing to prepare a workforce for new jobs and professions that have emerged. Moreover, as science becomes more interdisciplinary...we can no longer rely on the traditional ways of teaching science as a set of well-understood, clearly depicted, stand-alone disciplines. (p. 277)

This educational reform requires a commensurate response in the educational system in order to develop educational framework that helps with producing students with an understanding of properties and phenomena at different scales. We need to prepare students for future jobs and making sense of the world.

Developing a nanoscience education curriculum thrust can be the vehicle where nanorelated concepts can be implemented in the educational system and introduced to all students towards achieving a nano-literate generation. Nanoscience education and nanotechnology are two pertinent elements that stimulate the process of reforming science education in terms of its necessity to introduce new nano-related materials along with teaching practices to teach the new material. In educational reform, the emphasis should be put on nanoscience and nanotechnology "because nanoscience and nanotechnology are being developed in all industrialized nations, no country can depend upon foreign students for its scientific human capital, so the United States must produce an increasing number of domestic scientists and engineers" (Roco \& Brianbrodge, 2005, p. 11). Addressing nano concepts is not yet an emphasis in the currently used textbooks and science curricula because of the lack of specific reference to it in the national standards and benchmarks. Consequently, the American Association for the Advancement of Science (AAAS) is planning to include ideas, such as the change forces with the change of the scale, in its next 
revision of the Atlas of Scientific Literacy (Schank et al., 2007). Murdy (2009) stated, "while being a part of a national standard can be helpful, inclusion of nano in curricula is only guaranteed if it is in the state's learning standards" (p. 15). Including nano-related content, materials, and activities in the current school curricula help students to understand basic concepts of nanotechnology, especially the scale of it (nanometer).

Even with the current science curricula, nanotechnology can be introduced at all levels in all ages (pK-12). According to the National Nanotechnology Infrastructure Network (2014b), it was argued that nanotechnology can naturally fit in to the already existing science curricula. Integrating nanotechnology in the current science curricula can associate with it teaching to the national science education standards, its content and process. It can target areas in the physical science, life science, science and technology, science in personal and social perspective, history and nature of science, and science as inquiry (Bowles, 2004). Many nano-related activities and nano-educational modules are now made available for teachers' use to implement in science classrooms and that can fit the current science curricula (pK-12), and that can address the national science education curriculum (Bowles, 2004; National Nanotechnology Infrastructure Network, 2014a, 2014b). The purpose of introducing nano-related activities is not only to present and demonstrate important new nano-concepts, but also to engage students in activities that form their future and releasing them from more outdated curriculum activities. According to Murdy (2009), traditional science disciplines are "increasingly convergent when working at the nanoscale" (p. 9). However, focusing on nanoscience education could help with improving STEM as it integrates science, technology, engineering, and math instead of separating these into separate fields. The only initiative to be taken is to introduce science teachers to this newly 
emerging technology, nanotechnology, through thoughtfully planned and executed professional development opportunities.

Many nanoscience and nano engineering courses are being developed at national and international institutions at the undergraduate and graduate level. These courses by their nature are related to materials at the nano scale. Some of these courses are titled as nanoscience and nanotechnology, nanobiotechnology, bionanotechnology, nanoengineering, etc. (Goodhew, 2006; Roco, 2003b). While there are some existing and even increasing numbers of nanoscience courses at the undergraduate and graduate level, Schank et al. (2007) argued that there is a need for including nanoscience educational courses relevant to school science teachers at the middle and secondary school levels. To strengthen the current state of science education, students should develop a strong conceptualization of the interconnection between science disciplines: chemistry, biology, and physics. Preparing our students for future nanotechnology workforce, as well as for other future endeavors in science education, can be done in the early stages of schooling our students, particularly in middle and high school (Schank et al., 2007). They stated that this can be done through nanoscience education, which can serve as the catalyst for revamping the way of how science is taught and creating science curricula that focus on interdisciplinary approaches that help our students to think and use knowledge in an interdisciplinary fashion (Schank et al., 2007). However, Roco (2003b) argued that through nanoscience, concepts at the nanoscale level should penetrate the education system to reach more of the student population, "from kindergarten to continuing education, from scientists to non-technical audiences that may decide the use of technology and its funding" (p. 1248). In general, Roco and Bainbridge (2005) emphasized that "K-12 math and science education must be strengthened, not only through new 
curricula and educational material, but through fundamental reorganization of how technical disciplines are taught" (p. 11).

As a component of nanoscience education, there have been different controversies regarding the nature of nanotechnology discipline. Some have argued that nanotechnology is not a distinct discipline on its own; nanotechnology is interdisciplinary in its nature, it is a convergence of several existing science disciplines such as chemistry, biology, physics, engineering, information technology, etc. (Jones et al., 2013; Lin \& Allhoff , 2007). Although nanotechnology is not a distinct discipline, it broadens our understanding about the world in unprecedented ways from converging sciences (physics, chemistry, and biology) to creating new applications that can be categorized under nanotechnology (Lin \& Allhoff, 2007).

Understanding teachers' salient belief systems is a key for an effective and successful science education reform (Abell \& Lederman, 2010; Keys \& Bryan, 2001). Haney et al. (1996) illustrated that efforts of science education reforms have been unsuccessful because they failed to take teachers' beliefs and attitudes into account with respect to science education reforms. This connotes that beliefs and attitudes are critical and worthy to be investigated. Teachers salient beliefs system in regards to nanotechnology play a critical role in shaping attitudes, which can be a factor that helps with predicting teachers' behaviors of integrating nano-related materials in their classrooms or not. A good start for a successful science educational reform could be through gathering university faculty, those in the nanoscience workforce, middle and high school teachers, and policy makers to discuss the various options for how emerging topics should be introduced into classrooms and what is necessary in order to prepare individuals to enter the nanotechnology workforce (Schank et al., 2007). This allows curriculum developers and 
educators to be aware of what emerging topics should be introduced and how it should be introduced in science classrooms.

\section{Nanotechnology Professional Development}

Buczynski and Hansen (2009) argued that lack or limited scientific knowledge and insecurity result in and contribute to general disinterest in science, and form obstacles that impede teachers from teaching new materials in their classrooms. Effective professional development workshops are one of the primary methods of learning for teachers. Professional development is a pertinent means to train practicing teachers about nanotechnology who had no exposure or have not encountered taking nanoscience or nanotechnology as a part of their coursework when they were in college (Greenberg, 2009; Lan, 2012).

The novelty of nanoscience and the lack of exposure to nanoscience provide challenges for science teachers (Greenberg, 2009; Schank et al., 2007). These challenges raise pedagogical and content demands in which current science teachers are not well prepared in order to incorporate nanotechnology in science classrooms (Schank et al., 2007). Thus, the dependence on science teacher professional development will be the major vehicle for nanoscience integration until the next generation of nano-literate students become teachers.

Professional development takes various forms: mandated district sponsored staff development, workshops, summer programs, seminars/educational sessions, special courses, or even professional learning communities (PLCs). It is recommended that teachers should be engaged in professional development, which usually provides teachers with new learning opportunities, and equips them with new tools and resources that are necessary for a quality instruction amid current needed educational reforms (Buczynski \& Hansen, 2009; National Research Council, 1996; Schank et al., 2007). Professional development should not only provide 
models of practice but should also seek to change teachers' knowledge, self-efficacy, beliefs and attitudes, and habits of teaching practice as some of the attitudinal sub-constructs that influence an individual's attitudes towards a given object (Buczynski \& Hansen, 2009; Haney et al., 1996; Lan, 2012; Stein, Smith \& Silver, 1999). Lumpe et al. (2000) stated that professional development helps with changing teachers' beliefs about the nature of science and their capability of teaching science as they are "the more precise agents of change" (p. 288). Professional development helps with increasing teachers' content knowledge and self-efficacy in terms of gaining confidence in teaching science and reforms their practices in the realm of their discipline (Buczynski \& Hansen, 2009; Greenberg, 2009; Stein et al., 1999). Fostering higher teacher efficacy can be increased through professional development opportunities or during staff development experiences because self-efficacy may drive both the attitude toward the behavior and perceived behavioral control. Professional development should focus upon enhancing positive attitudes toward science and emerging technologies among science teachers. Working on developing attitude as an affective construct is crucial. Haney et al. (1996) indicated that current science reform projects, such as America 2000: An education strategy; the American Association for the Advancement of Science's (AAAS) project; the National Science Teacher Association's (NSTA) Scope recommend aim at "fostering positive attitude toward science in addition to scientific 'habits of mind,' such as skepticism and open-mindedness" (p. 972). Empirical findings showed that teacher participation in effective professional development programs results in increasing knowledge, self-efficacy, and development of positive attitudes. For example, Lan (2012) conducted a study to assess $233 \mathrm{~K}-12$ teachers' attitudes toward nanotechnology who participated in the K-12 Nanotechnology Program in Taiwan by utilizing Nanotechnology Attitude Scale for K-12 teacher (NAS-T) survey. His 
findings revealed that teachers with a higher level of program participation exhibited more confidence and enthusiasm in science teaching and willingness to promote nanotechnology than those with lower level of program participation did. In addition, their behavioral tendency to promote and teach nanotechnology was also positively related to their self-perception of their own knowledge about nanotechnology. In other words, if teachers have enough nanotechnology literacy, they will be more willing to engage in promoting K-12 nanoscience education and will have a higher science teaching efficacy (STE) (Lan, 2012). Other research showed similar results with a different form of professional development, PLC as a learning opportunity that fosters collaborative learning among colleagues within a particular field. Mintzes et al. (2013) examined the effects of PLCs with in-service elementary teachers' self-efficacy. Their study recorded that there was a change in personal self-efficacy as a result of participation in PLCs. Buczynski and Hansen (2009) reported similar results in terms of knowledge increase; they reported that some participants have transferred knowledge and skills that they have gained from the professional development into their classrooms. However, others were encountered with lack of resources, time constraints, mandated curriculum, classroom management issues, and language trainings as some of the barriers that prevented the implementation of what they have gained from the professional development (Buczynski \& Hansen, 2009).

With respect to attitudes, Lee et al. (2006) reported that the attitudes and interests in nanotechnology of the participating teachers had increased as a result of their involvement in the K-12 Nanotechnology program. Approximately, $96 \%$ of the participating teachers felt that their interest in learning about new and advanced technology had increased. About $85 \%$ became more interested in learning about their own subjects. They also indicated that the support that they have received from the program office was satisfactory. However, the support that they received 
from the school administration was not as great, especially when they needed release time from their teaching or administrative duties to attend the workshops.

Blonder (2010) studied how the Atomic Force Microscopy (AFM) model influenced high-school chemistry teachers' knowledge and attitudes toward using it in school with their students. He found that the knowledge and attitudes of the experimental group of chemistry teachers was higher than the comparison group. As a result, teachers who got exposed to the AFM model made significant progress in their nano-related knowledge and in their ability to teach this emerging topic in their courses. This positive professional development experience introduced high-school chemistry teachers to a novel topic and an effective model neither of which had been an integral part of their high-school chemistry curriculum. It enhanced their content knowledge, pedagogical content knowledge, and their attitudes and self-efficacy toward teaching nanotechnology.

Incorporating nano-related materials in classrooms can be met with difficulties that are related to teachers' negative attitudes toward nanotechnology, lack of knowledge, lack of selfefficacy, and due to the nature of nanoscience education, which is still in its infancy. Hence, the need for "effective teacher professional development programs for the inclusion of nanoscience into the curriculum are paramount" in order to help with understanding and research how to teach nano-related concepts (Greenberg, 2009, p. 766). For nanotechnology to reach its full potential, it is recommended that the reliance on the variety of forms of professional development is paramount. It is important to understand what is required to prepare a nanotechnology, scientific and engineering literate workforce (Fonash, 2001). Greenberg (2009) stated, 
...until we have a generation of science teachers who are exposed to nanoscience concepts during their college classes, we will need to rely on professional development opportunities to enable teachers to understand nanoscale concepts needed for proper implementation of nanoscience-focused educational materials. (p. 768)

The K-12 nanotechnology program (R.O.C.) was established by the National Science Council, Taiwan, in 2002. It is a good example of an effective nano-related professional development program. The K-12 nanotechnology program was established to introduce teachers to recent research and development in nanotechnology and to help teachers develop lesson plans, instructional materials, and hands-on activities to pique their students' interests in learning about the advanced technology in hope of increasing the number of students who choose to major in science or engineering and to prepare a future generation of nano-literate citizens (Lee et al., 2006). In studying the effectiveness of the K-12 nanotechnology program in Taiwan, Lee et al. (2006) found that teachers who started the program with a little knowledge about nanotechnology showed improved attitudes and interest toward learning about science and technology over the course of their participation in that program.

Recent professional development is not only created with a general initiative of promoting teachers' understanding, knowledge, and development of positive attitudes toward a desirable subject (e.g., nanotechnology) to be taught in schools, but also received governmental support and funds in order to train science teachers, and to provide them with essential instructional tools and resources with respect to the new emerging interdisciplinary field of science, technology, engineering and math (STEM) nanotechnology. 


\section{Government Support}

Nanotechnology offers advances across the fields of science and engineering that are crucial to the society (Roco \& Bainbridge, 2005). By 2015, large and small industry leaders alike have estimated that approximately $50 \%$ of new manufacturing products and pharmaceutical supplies will be influenced by nanotechnology (Roco \& Bainbridge, 2005). Roco, Mirkin, and Hersam (2010) referred that the worldwide market for products incorporating nanotechnology reached about $\$ 254$ billion in 2009, and the current values for nanotechnology-enabled products are estimated at about $\$ 91$ billion in the United States.

Trends indicate that the number of nanotechnology-based products and workers worldwide will double every three years, achieving a $\$ 3$ trillion market and 6 million workers (2 million in the U.S. only) by 2020 (Roco, Mirkin, \& Hersam, 2010). According to a recent report by Lux Research (2015), nano-enabled products reveals that the global value of nano-enabled products, nano-intermediates, and nanomaterials will reach $\$ 4.4$ trillion by 2018. Lux Research (2015) indicates that nano-enabled products has continued to grow, from $\$ 339$ billion in 2010 to \$731 billion in 2012 worth of product revenue. Nanotechnology has vast contributions to the society. At least 60 countries have put efforts and funds into the field of nanotechnology given that the United States, Japan, and the European Union are the three major economies that invest $\$ 1$ billion yearly in nanotechnology. The worldwide government investment in nanotechnology research and development (R\&D) had increased from $\$ 432$ million in 1997 to $\$ 4.1$ billion in 2005 (Lan, 2012; Roco, 2005). In Taiwan, the government had funded K-12 nanotechnology programs in order to train K-12 teachers with nanotechnology literacy to foster the next generation with sufficient knowledge with key concepts of nanoscience and nanotechnology (Lan, 2012). The U.S. government has spent billions of dollars towards nano initiatives in order 
to introduce nanoscience concepts into schools, to prepare individuals to function in the future, and to create new modules for grades 7-12 that emphasize upon "the role of nanoscale properties and structure in determining the behavior of the substances that drive our technological society" (Telford, 2004, p. 18). In the U.S., the $21^{\text {st }}$ century nanotechnology research and development (R\&D) Act that was passed in 2003 allocated a yearly expenditure of $\$ 3.7$ billion on nanoscience and nanotechnology from 2005 to 2008 , which is a tremendous increase in funding for nanotechnology research from $\$ 750$ million in 2003 (Bowles, 2004; The Royal Academy of Engineering \& the Royal Society, 2004).

The National Nanotechnology Initiative (NNI), in the U.S., was unveiled by President Clinton, who supported nano-scale science and engineering (S\&E) in a major science policy addressed at the California Institute of Technology (Caltech) early in 2000 (Lane \& Kalil, 2007). His fiscal year (FY) budget was doubled from \$270 million in 2000 to \$496 million in 2001 in support of nano-scale S\&E initiatives or programs. The National Science Foundation (NSF) has also increased its investments in support of nano-scale S\&E. Some examples of innovative initiatives that were funded to launch programs in nano-scale science and engineering (S\&E) are: the National Center for Learning and Teaching in nano-scale and engineering (NCLT), the nanosense project, the Nanoscale Informal Science Education (NISE), the defense advanced research project agency's ULTRA electronics program, etc. (Lane \& Kalil, 2007; Schank et al., 2007).

With all of the investments and initiatives that were put toward improving nanotechnology, similar investments and support should be put toward nanotechnology education. Otherwise, all of the calls for nano a literate workforce will be left unattended. Improving nanotechnology education is needed as it helps in sparking students' interests to learn about nanotechnology and become nano-literate citizens to fulfill the increasing demand for nano 
literate citizens, who can make informed decisions about nanotechnology and who can fill the increasing number of jobs in the nanotechnology marketplace. 


\section{Chapter 3}

\section{Methodology}

\section{Participants}

The population under investigation included middle and high school science teachers from the states of West Virginia (WV), Illinois (IL), Pennsylvania (PA), Texas (TX), and California (CA) whose emails were publically available via their school or district website. Tremendous amount of time and efforts were put in order to search for participants' email addresses. Science teachers' email addresses were manually obtained via search for schools websites in districts of WV, IL, PA, TX, and CA. Available email addresses were then prepared and organized in an excel sheet that was made by the researcher to facilitate the process of using it for the research study. Participants in this study were selected from among states that have had active nanotechnology professional development or teacher research programs in them. Inservice science teachers from middle to high school grades were chosen because it was suggested that nanotechnology should be introduced to students in early stages of their education; middle through high school. Participants under investigation are not nanotechnology experts or science researchers, but some have participated in nanotechnology professional opportunities or nanotechnology programs. Science teachers in states with active nanotechnology programs are more likely to be aware of nanotechnology as a concept, and the probability of implementing nanotechnology-related content, material, and activities is higher than in states with no active nanotechnology programs or teacher research. 
Questionnaire participants. A convenience sample of $(N=4,986)$ middle and high school science teachers from WV, IL, PA, TX, and CA were selected to complete the selfdeveloped Science Teachers' Attitudes toward Nanotechnology (STAT-N) survey by the researcher of this study (see Appendix B for the STAT-N survey). All participants had volunteered to participate in completing the online STAT-N survey.

At the time of sending the only one reminder email in Qualtrics on March 13, 2015, a total of 278 survey responses were collected. However, at the time of closing the survey on April 10,2015 , a total of 501 survey responses were collected. This represents $10.05 \%$ response rate.

Gender. There was 37.4\% $(\mathrm{n}=184)$ of the respondents male, $62.6 \%(\mathrm{n}=308)$ female, and 9 participants failed to report on their gender.

Years of teaching experience. The respondents' minimum number of years of teaching experience is ( $0-5$ years), and the maximum number of years of teaching experience is greater than 28 years. Table 1 indicates that $18.5 \%(\mathrm{n}=92)$ respondents are with $0-5$ years of teaching experience; $25.8 \%(\mathrm{n}=128)$ with $6-11$ years of teaching experience; $22.3 \%(\mathrm{n}=111)$ are with 12-17 years of teaching experience; $13.1 \%(\mathrm{n}=65)$ are with $18-23$ years of teaching experience; $11.5 \%(n=57)$ are with 23-28 years of teaching experience; and $8.9 \%(n=44)$ are with more than 28 years of teaching experience.

Table 1

Years of Teaching Experience Distribution of the Sample

\begin{tabular}{lcc}
\hline & $\mathrm{n}$ & Valid $\%$ \\
\hline $0-5$ years & 92 & 18.5 \\
6-11 years & 128 & 25.8 \\
12-17 years & 111 & 22.3 \\
18-23 years & 65 & 13.1 \\
24-28 years & 57 & 11.5 \\
Greater than 28 years & 44 & 8.9 \\
\hline
\end{tabular}


School teaching level. Table 2 shows that the majority of the survey respondents are science teachers who teach at the high school level; 18.1\% $(\mathrm{n}=90)$ are science teachers teaching at the middle school level while $81.9 \%(\mathrm{n}=408)$ are science teachers teaching at the high school level.

Table 2

Distribution of the School Teaching Level

\begin{tabular}{lcc}
\hline & $\mathrm{n}$ & Valid \% \\
\hline Middle School & 90 & 18.1 \\
High School & 408 & 81.9 \\
\hline
\end{tabular}

Semi-structured interview participants. The semi-structured interview was conducted using a convenience sample of $(n=13)$ middle and high school science teachers from the states of WV, IL, PA, TX, and CA. Participants of the semi-structured interview were randomly selected from the convenience sample of 4,986 and who had the opportunity to further volunteer be contacted by the researcher. All science teachers who volunteered $(n=34)$ were initially contacted and 13 of them were available for a brief 20-25 minute-interview. The random selection of participants for the semi-structure interview was made by using the random number generator to generate a sequence of numbers that lack any pattern and appear random.

Gender. There was $46.15 \%(n=6)$ of the respondents male and 53.85\% $(n=7)$ female. Years of teaching experience. The respondents' minimum number of years of teaching experience is ( $0-5$ years), and the maximum number of years of teaching experience is greater than 28 years. Table 3 indicates that $30.77 \%(n=4)$ respondents are with $0-5$ years of teaching experience; $30.77 \%(n=4)$ with $6-11$ years of teaching experience; $30.77 \%(n=4)$ are with 12 17 years of teaching experience; and 7.69\% $(\mathrm{n}=1)$ are with $23-28$ years of teaching experience. 
Table 3

Years of Teaching Experience Distribution of the Interviewee

\begin{tabular}{lcc}
\hline & $\mathrm{n}$ & Valid \% \\
\hline $0-5$ years & 4 & 30.77 \\
6-11 years & 4 & 30.77 \\
12-17 years & 4 & 30.77 \\
18-23 years & 0 & 0.00 \\
$24-28$ years & 1 & 7.69 \\
Greater than 28 years & 0 & 0.00 \\
\hline
\end{tabular}

School teaching level. Table 4 shows that almost all of the interview participants are science teachers who teach at the high school level; $92.31 \%(n=12)$ are science teachers teaching at the high school level while $7.69 \%(\mathrm{n}=1)$ are science teachers teaching at the middle school level.

Table 4

Distribution of the Interviewee School Teaching Level

\begin{tabular}{lcc}
\hline & $\mathrm{n}$ & Valid \% \\
\hline Middle School & 1 & 7.69 \\
High School & 12 & 92.31 \\
\hline
\end{tabular}

Participation in a nanotechnology professional development. Table 5 shows that $46.15 \%(n=6)$ of the interviewee have participated in a nanotechnology-related professional development and $53.85 \%(\mathrm{n}=7)$ of the interviewee have not participated in a nanotechnology professional programs or nanotechnology-related professional development opportunities. 
Table 5

Participation of Nano Professional Development

\begin{tabular}{lcc}
\hline & $\mathrm{n}$ & Valid \% \\
\hline Nano-Participant & 6 & 46.15 \\
Non Nano- Participant & 7 & 53.85 \\
\hline
\end{tabular}

\section{Instrumentation}

Science teachers' attitudes toward nanotechnology questionnaire (STAT-N). For this particular study, the Science Teachers' Attitudes toward Nanotechnology (STAT-N) survey was used for data collection. The specific behavior being studied was defined as implementing nanotechnology-related content, materials, and activities in science classrooms.

The STAT-N was developed by the researcher of this study. This survey consists of 24 statements based on a 5-point Likert scale ranging from $1=$ "strongly disagree" to $5=$ "strongly agree." The STAT-N questionnaire was developed to measure possible constructs (factors) that would impact science teachers' attitudes toward nanotechnology and their intentions regarding implementing nanotechnology-related content, materials, and activities in science classrooms. Within these constructs, the STAT-N included survey statements (SS) on professional development, professional context, personal attitudes, knowledge and self-confidence, personal research experience, and the practice of bringing nanotechnology-related material into science classrooms as possible factors that could influence science teachers' attitudes toward nanotechnology and the intention of implementing nanotechnology in science classrooms. The content and face validity of the STAT-N was established in a multi-step, iterative, review and revision process using internal experts as data sources. The content validity and face validity of the STAT-N were established and determined by a panel of science educators in the Curriculum and Instruction Department at West Virginia University. This panel was asked to provide 
feedback and input for each item and to evaluate statements quality and ambiguity with respect to content. Survey validity was also established through administering the survey to the Association for Science Teacher Education (ASTE) listserve $(N \sim 500)$. Based upon the comments that were received by the science teachers regarding the wordings and clarity of the survey statements, subsequent modifications were given to some of the survey items to extend its use to work with a larger group of science teachers at the middle and high school levels.

Semi-structured interview. In addition to the STAT-N questionnaire, a semi-structured interview was developed as an additional source for data collection (see Appendix $\mathrm{C}$ for the interview protocol). Open-ended questions were developed to elicit salient beliefs about teachers' attitudes toward nanotechnology and implementing its related content, materials, and activities in science classrooms. More open-ended questions were also developed to identify salient beliefs about facilitators that would help with implementing nanotechnology in science classrooms.

The semi-structured interview was pilot-tested with local participants from WV who have and have not participated in nanotechnology professional development. The pilot interview was recorded and based upon their responses. Therefore, no necessary revisions were made to the interview questions because the responses of the local candidates fulfilled the purpose of answering the research questions that were designed for it. A matrix aligning the interview questions to each data source was completed (see Table 6). 
Table 6

Research Questions with Corresponding Data Sources

\begin{tabular}{|c|c|c|}
\hline & Research Question (RQ) & $\begin{array}{l}\text { Data Source Comprising RQ: } \\
\text { Survey Statement (SS), } \\
\text { Interview Question (IQ) }\end{array}$ \\
\hline $\begin{array}{l}\text { RQ } \\
1 \mathrm{~A}\end{array}$ & $\begin{array}{l}\text { What is the relationship between science } \\
\text { teachers' attitudes toward nanotechnology } \\
\text { and their intention of implementing it in } \\
\text { science classrooms? }\end{array}$ & SS5, SS6, SS7, SS9 \\
\hline $\begin{array}{l}\mathrm{RQ} \\
1 \mathrm{~B}\end{array}$ & $\begin{array}{l}\text { In what ways do the other five factors } \\
\text { associate to Attitudes? }\end{array}$ & \\
\hline & $\begin{array}{l}\text { Factor 1: Professional Development } \\
\text { Factor 2: Professional Context } \\
\text { Factor 3: Practice } \\
\text { Factor 4: Research } \\
\text { Factor 5: Knowledge and Self- } \\
\text { confidence }\end{array}$ & $\begin{array}{l}\text { SS10, SS11, SS12 } \\
\text { SS13, SS14, SS15, SS16 } \\
\text { SS17, SS18, SS19, SS20 } \\
\text { SS21, SS22, SS23, SS24 } \\
\text { SS1, SS2, SS3, SS4, SS8 }\end{array}$ \\
\hline RQ 2 & $\begin{array}{l}\text { What are the attitudes and perceptions of } \\
\text { science teachers toward nanotechnology } \\
\text { and implementing it in science } \\
\text { classrooms? }\end{array}$ & IQ1, IQ2, IQ3, IQ4, IQ5, IQ6, IQ7, IQ10 \\
\hline RQ3 & $\begin{array}{l}\text { What helps science teachers implement } \\
\text { nanotechnology in science classrooms? }\end{array}$ & $\begin{array}{l}\text { SS1, SS2, SS3, SS4, SS5, SS6, SS7, SQ8, } \\
\text { SS9,SS10, SS11, SS12, SS13, SS14, SS15, } \\
\text { SS16, SS17, SS18, SS19, SS19, SS20, } \\
\text { SS21, SS22, SS23, SS24, IQ1, IQ2, IQ 5, } \\
\text { IQ6, IQ7, IQ 8, IQ9, IQ11 }\end{array}$ \\
\hline
\end{tabular}

\section{Method}

The STAT-N was developed to assess science teachers' attitudes toward nanotechnology and implementing it in science classrooms. Based on the initial instrument validity that was established, wording of some items was modified to eliminate any ambiguity and to increase the instrumental clarity. Participant science teachers from the states of WV, PA, TX, IL, and CA 
were recruited and invited to participate in taking the self-developed questionnaire (STAT-N) via sending them an invitational email in a conjunction with a cover letter that explains the purpose of this study using Microsoft Outlook (see Appendix D for the STAT-N invitational email text, Appendix E for STAT-N cover letter). These states were chosen because they have active nanotechnology initiatives and the likelihood of introducing the concept of nanotechnology and implementing its related content and activities by its science teachers is higher than in states with no active nanotechnology programs. Further validation of the STAT-N was also established after administering it with the middle and high school science teachers. Factor analysis (FA) was performed and used as an exploratory tool to determine the validity of the survey instrument by reducing a large set of variables to a smaller number of factors containing related variables. However, all statistical analyses that were conducted report the results based upon the current survey and before validating it.

Participants were also invited to take part in a semi-structured over-the-phone interview or face-to-face interview. Participants were recruited with a thank-you message after completing the STAT-N survey where they were provided with a link that took them to a short survey to provide their contact information to be reached at if they would like to be part of the semistructured interview after attaching a cover letter that explains the purpose of conducting the semi-structured interview, which was designed in an attempt to seek out and illicit deeper understanding of the salient beliefs regarding science teachers' attitudes toward nanotechnology and the behavior of integrating nanotechnology-related content, materials, and activities in science classrooms, their subjective norms, and their perceived behavior control (see Appendix F for the interview survey, Appendix G for the interview recruitment cover letter). Science teachers' attitudes, subjective norms, and perceived behavior control all directly influence 
individual intentions, which in turn predict the action of integrating nanotechnology in science classrooms. Questions for the semi-structured interview were developed to identify teachers' attitudes toward nanotechnology and implementing it in science classrooms. They were also designed to determine factors that would facilitate the process of integrating nanotechnologyrelated content, materials, and activities in science classrooms.

After recruiting participants for the interview, the semi-structured interview was conducted both ways via phone and face-to-face, audio-recorded, and then interview responses were transcribed verbatim. In order to establish 'member checking', interview transcripts and via email were sent to the interviewees who then proofed them by sending no comments on the content and their responses to the interview questions. West Virginia University's Institutional Review Board (IRB) acknowledgement of this study is on file (see Appendix H for IRB protocol approval).

\section{Data Analysis}

The collected data were analyzed via using both quantitative and qualitative methodologies. SPSS for Windows, Release Version 17.0 was used for all quantitative analyses. The grounded theory approach was used to analyze all collected qualitative data. The grounded theory is a methodology that was introduced by Glaser and Strauss in 1967 as a methodological approach for helping researchers with the process of data analysis (Corbin \& Strauss, 1990; Crotty, 1998). For this particular study, social constructivism by Vygotsky (1978), was the theoretical perspective that informed the context of this study, especially with the teachers who have participated in nanotechnology professional development opportunities or in nanotechnology programs, such as the Teacher Research Experience for the advancement of Knowledge (TREK). The theoretical perspective of social constructivism stemmed out of the 
epistemological view of constructionism as a way of understanding, constructing, and explaining how we know what we know (Crotty, 1998). Therefore, social constructivism is focused on how individuals construct meaning as they are situated in a specific social context, which influences their meaning construction.

The grounded theory was applied throughout the process of qualitative data analysis in trying to develop a theory out of the raw interview data that were collected. Sampling in the grounded theory was based on selecting groups of individuals who are representative of the phenomenon of the study. For this study, middle and high school science teachers who either have or have not participated in nanotechnology programs or nanotechnology professional development opportunities were selected.

Coding is fundamental in research that has applied the grounded theory approach where there are three basic types/levels of coding: open (level 1), axial (level 2), and selective (level 3) (Corbin \& Strauss, 1990). After deconstructing the collected qualitative data and putting it into meaningful segments, open-coding was employed as soon as the data were collected. In opencoding, concepts were extracted from the qualitative data excerpts. In axial coding, categories are established in which all related crosscutting concepts at the lower level of coding, open coding, are grouped together to form categories or patterns. The last step of the grounded theory is selective coding, where all interconnected categories are unified around a core category to form a theory that arises from and grounded in the collected data.

For this study, qualitative data analysis using the grounded theory was carried out from the start as it was used to direct the next interview. The semi-structured interview was conducted to gain a better understanding of the intricacies of science teachers' attitudes toward nanotechnology and implementing it in their science classrooms. The qualitative data that were 
collected from the semi-structured interview were analyzed employing the grounded theory approach with its coding process at its different types its different levels: open-coding, axial coding, and selective coding.

Quantitative and qualitative methodologies could be combined to use results from one method to elaborate on results from the other method. The use of both quantitative and qualitative data in this study was thought as a valuable approach in answering the research questions of this study.

\section{Research Questions}

Research question one a. What is the relationship between science teachers' attitudes toward nanotechnology and their intention of implementing it in science classrooms? The survey questionnaire data were analyzed using Spearman correlation to determine to what extent the relationship between science teachers' attitudes and their intention of implementing nanotechnology-related content, materials, and activities is statistically significant $(\alpha=.05)$. The significance level of .05 was chosen because in social science research the .05 cut-off that was originated by Fisher in 1925 is the most accepted threshold for confidence to establish statistical significance (Field, 2009).

Research question one b. In what ways do the other five factors (knowledge and selfconfidence, professional context, professional development, research, and practice) associate to Attitudes? The survey questionnaire data were analyzed using Spearman correlation to determine the relationship between each of the factors (knowledge, professional context, professional development, research, and practice) and attitude. 
Research question two. What are the attitudes and perceptions of science teachers toward nanotechnology and implementing it in science classrooms? The qualitative data for research question two were analyzed utilizing the grounded theory analysis process as described above.

Research question three. What helps science teachers implement nanotechnology in science classrooms? A combination of both qualitative and quantitative methodologies was used in exploring the different facilitators that could help in implementing nanotechnology-related content, materials, and activities in science classrooms. Regression analysis was conducted to identify factors that could help with implementing nanotechnology-related content, material, and activities in science classrooms. A set of semi-structured interview questions were also developed and asked about the salient beliefs about the facilitators that might help with implementing nanotechnology-related content, materials, and activities in science classrooms. The data that were collected from this set of interview questions were qualitatively analyzed using the grounded theory approach at its three different coding levels as described above.

Data that were collected and analyzed in this research study will help us in verifying the constructs that comprise the theory of planned behavior (attitudes, subjective norms, and perceived behavior control) with possible factors (e.g., knowledge, professional development, professional context, research, and practice), that influence science teachers' salient attitudes, which directly impact their intentions of implementing nanotechnology-related content, materials, and activities as the desired behavior to be conducted in science classrooms. Findings of this study will help researchers and educators in designing educational programs or in-service professional development that are specifically designed to help middle and high school science 
teachers overcome challenges and their attitudes in order to enact their planned behavior of integrating nanotechnology-related content, materials, and activities in science classrooms. 


\section{Chapter 4}

\section{Results and Findings}

For this study, factor analysis (FA) was conducted and all statistical analyses reflect statistical results of the current survey before conducting the validity and reliability analyses. However, findings of research questions: one $a$, one $b$, and three were relevant to FA.

\section{Factor Analysis}

Validity results. After all negatively phrased Likert-type items were reversed, factor analysis (FA) was carried out in order to establish the validity of the STAT-N survey. Correlation matrix was generated showing all possible correlation coefficients among all of the 24 Likert-type survey items (see Appendix I). It represents that items were correlated with each other but not highly correlated with each other (no correlation greater than .8 ). This suggests that there was not a lot of overlap between the Likert-type items. Thus, no multicollinearity (no correlations greater than .80 ) was found in the output data for the factor analysis. Therefore, no items were deleted.

According to the total of variance explained (Appendix J), SPSS distributed survey items to fit six factors. The principal component extraction method was used and the criterion for factor extraction was based on eigen values greater than 1.0. Varimax rotation was also used supposing that the factors are unrelated. For the six-factor solution, before rotation, the first factor accounted for a variance of $31.90 \%$ compared to $9.97 \%, 7.61 \%, 5.93 \%, 4.79 \%$, and $4.27 \%$, respectively, but after rotation it accounted for only $16.44 \%$ of variance (compared to $16.23 \%, 12.24 \%, 7.13 \%, 6.61$, and $5.81 \%$, respectively). The six-factor solution, total variance table (Appendix J), illustrates that $64.31 \%$ of the variability was explained by these six factors and that was based upon the initial eigen values. Rotation component matrix (Appendix K) 
shows that Liker-type items were loaded in each of the six factors. Based on the researcher's rational when created the survey, Appendix L show the alignments of all 5-point Likert scale survey items but statement \#9 (intention) that were initially loaded to fit six factors and the alignments of the survey items differ from the loadings of the items that were produced by SPSS. Table 7 illustrates a brief alignment of the STAT-N survey items into six different factors.

Table 7

Alignment of the STAT-N Survey Items into Different Factors/Subscales

\begin{tabular}{lcl}
\hline Factor & No. of items & Survey statements included \\
\hline Professional Development & 3 & SS10, SS11, SS12 \\
Professional Context & 4 & SS13, SS14, SS15, SS16 \\
Practice & 4 & SS17, SS18, SS19, SS20 \\
Research & 4 & SS21, SS22, SS23, SS24 \\
Knowledge and Self-confidence & 5 & SS1, SS2, SS3, SS4, SS8 \\
Attitude & 3 & SS5, SS6, SS7 \\
\hline
\end{tabular}

Reliability results. The reliability of the six-factor analysis was dependent on both correlation coefficients across items and on sample size. According to Field (2009), the common rule that there has to be at least 10-15 participants per variable. For reporting reliability of the survey scales, Cronbach's alpha coefficients were calculated for all of the Likert-type survey items used for analysis and for each of the six subscales (factors). The Cronbach's alpha coefficients were reported for internal consistency reliability of items in each subscale. Cronbach's alpha coefficient ranges between 0 and 1. The closer Cronbach's alpha coefficient to 1 is the greater internal consistency of items in the subscale it is and vice versa. While there is no general agreement regarding the acceptable level of Cronbach's alpha coefficients, George and Mallery (2003) provided the following rules of thumb: " $>.9$ excellent; $>.8$ good; $>.7$ acceptable; $>.6$ questionable; $>.5$ poor; and $<.5$ unacceptable" (p. 231). Appendix M provides detailed SPSS outputs of the reliability statistics. Table 8 provides a summary of the Cronbach's 
alpha reliability statistics for all of the items used for analysis as well as for each of the six subscales.

Table 8

Summary of Factors/Subscales Reliability Statistics

\begin{tabular}{lcll}
\hline Factor & No. of items & Survey statements included & $\alpha$ \\
\hline Professional Development & 3 & SS10, SS11, SS12 & .82 \\
Professional Context & 4 & SS13, SS14, SS15, SS16 & .76 \\
Practice & 4 & SS17, SS18, SS19, SS20 & .62 \\
Research & 4 & SS21, SS22, SS23, SS24 & .56 \\
Knowledge and Self-confidence & 5 & SS1, SS2, SS3, SS4, SS8 & .87 \\
Attitude & 3 & SS5, SS6, SS7 & .65 \\
\hline
\end{tabular}

Note. $\alpha=$ Cronbach's Alpha Coefficient

Table 8 demonstrates that the knowledge and self-confidence factor was found to have the highest Cronbach's alpha coefficient $(\alpha=.87)$. However, research was the weakest subscale with Cronbach's alpha coefficient of $(\alpha=.563)$.

\section{Major Study Results and Findings}

According to the descriptive of all factors (Table 9), it was found that attitude was the most independent factor with the highest mean $(M=3.78)$ with a $S D$ of .65. For the intention as the dependent factor, the mean was 2.54 with a $S D$ of 1.10 . 
Table 9

Descriptives of the Dependent Variable (Intention) and Independent Variables (Attitude, Professional Development, Professional Context, Practice, Research, and Knowledge and Self-confidence) $(N=434)$

\begin{tabular}{lcc}
\hline & $M$ & $S D$ \\
\hline & & \\
Attitude & 3.78 & .65 \\
Professional Development & 3.49 & .85 \\
Professional Context & 2.67 & .74 \\
Practice & 2.89 & .67 \\
Research & 3.37 & .75 \\
Knowledge and self-confidence & 2.56 & .98 \\
Intention & 2.54 & 1.10 \\
\hline
\end{tabular}

Appendix $\mathrm{N}$ includes histograms that show the distribution of the responses of the dependent variable (intention) and all other independent variables (attitude, professional development, professional context, practice, research, and knowledge and self-confidence).

\section{Research Questions Results}

Research question one a results. What is the relationship between science teachers' attitudes toward nanotechnology and their intention of implementing it in science classrooms? Spearman correlation was conducted and the result showed that the correlation between intention and attitude was a significant weak positive correlation $[r s(438)=.38, p<.05]$. This indicates that about $14.44 \%$ of the variability in intention was related to attitude and vice versa.

Research question one b results. In what ways do the other five factors (knowledge and self- confidence, professional context, professional development, research, and practice) associate to Attitudes? Spearman correlations pointed that there was a significant correlation between attitude and each of the other factors. Table 10 shows that there is a significant moderate positive correlation between the factor of attitude and knowledge and self-confidence factor $\left[r_{s}(438)=.47, p<.05\right]$; a significant little positive correlation between attitude and 
research $\left[r_{s}(435)=.18, p<.05\right]$; a significant weak positive correlation between attitude and practice $\left[r_{s}(435)=.35, p<.05\right]$; a significant weak positive correlation between attitude and professional context $\left[r_{s}(435)=.28, p<.05\right]$; and a significant moderate positive correlation between attitude and professional development $\left[r_{s}(435)=.46, p<.05\right]$. The Spearman correlations results show that attitude was mostly correlated with knowledge followed by professional development and least correlated with research.

Table 10

Spearman Correlations between Attitude and Five Other Factors (Professional Development, Professional Context, Practice, Research, and Knowledge and Self-confidence)

\section{Factors}

1. Professional development

2. Professional context

$$
.46^{* *}
$$

3. Practice

$.55^{* *}$

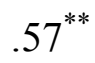

4. Research

$.21^{* *}$

$.23^{* *}$

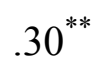

5. Knowledge and self-confidence

$.39^{* *}$

$.30^{* *}$

$.47^{* *}$
$-$

6. Attitude

Note. $* *$. Correlation is significant at the 0.01 level (2-tailed).

Research question two results. What are the attitudes and perceptions of science teachers toward nanotechnology and implementing it in science classrooms? Participants were contacted and interviewed to investigate their personal attitudes toward nanotechnology, in general, and toward its implementation in science classrooms, in particular. The interview data revealed that there are different factors that influence individuals' attitudes toward a targeted behavior. For this study, data were coded and themes had emerged to explain the influential factors and limitations that could influence teachers' attitudes and prevent or hinder them from integrating nanotechnology in science classrooms as part of their science curricula. The themes that were formed out of the data were related to personal perspectives toward nanotechnology 
and its implementation in science classrooms. Teachers shared their views of nanotechnology as both advantageous and disadvantageous technology at the same time. They also shared their perspectives toward the value of implementing nanotechnology in science classrooms as well as some of the limitations or inhibitors that are real and perceived and related to: school, course, and student type; curriculum determinants; time constraints, social influences; lack of resources; lack of nanotechnology professional development; and lack of nanotechnology knowledge and self-confidence. Below is a detailed description of each of these themes along with supportive excerpts that were directly taken from the interviewed participants who are current middle and high school science teachers.

\section{Personal Perspectives toward Nanotechnology}

Advantages of nanotechnology. Overall, participant science teachers expressed their attitudes and personal beliefs about nanotechnology as an advanced technology, in general, and toward implementing and introducing it to students in science classrooms, in particular. All participants but only one participant (Katie) shared same or similar perspectives about nanotechnology and viewed it as an important technology that has multiple industrial and medical applications, and considered it as a technology that opens up various job opportunities for individuals. The only one participant who did not reflect upon the advantages of nanotechnology was because she had no idea of even what nanotechnology is. In an honest way, Katie (2015) said, "honestly, most of it coming from me because I do not know even what nanotechnology is." However, the potential of nanotechnology was viewed by all other teachers. For example, Tina (2015) mentioned that exposing students to nanotechnology gives them an idea of some of the working fields in science, "nanotechnology increases the scope of what they 
could possibly want to do when they leave high school." Melissa (2015) shared a similar perspective by stating,

...because I think that there is a lot of job opportunities that are now available if students are aware that nanotechnology is present, they need to know what it is and they need to be able to make decisions whether be for college or if they are going into the manufacturing industry at least if they are presented with the idea of nanotechnology they have an opportunity to get a job where before they might not had that opportunity if they did not know anything about it.

Furthermore, Richard (2015) contributed by saying that nanotechnology not only opens up more job opportunities but also applies to different fields. Richard said,

I know it has tremendous future... it has great future for the growth of our economy. I think it has a lot of employment opportunities. It applies to everything; manufacturing, to mining to health... anything that you can think of that would need a machine, nanotechnology can probably be applied in some capacity.

Tina (2015) contributed by saying,

I think nanotechnology has a lot of possibilities, especially when you look at the different levels of applications that it has, not only in terms of industrial applications, but when you look at it in terms of medicine and preventative health. I think there are a lot of opportunities to research.

Disadvantages of nanotechnology. Overall, most of the participants pointed that the advantages of nanotechnology outweigh its disadvantages. However, despite all of the potentials of nanotechnology, participants had their own reservations about nanotechnology. They shared concerns and issues related to nanotechnology, such as ethical issues, fear of nanotechnology, 
environmental issues, and privacy issue. Tom and Tina (2015) expressed their concerns that are related ethical issues that are associated with nanotechnology. Both Tom and Tina pointed to ethical questions on the practical applications of nanotechnology. Tina (2015) said, ...a lot of ethical questions that people mostly have to answer when it comes to nanotechnology what people be doing and disputing nanotechnology versus...the ethical question with genetic engineering I think comes up when you're dealing with nanotechnology as well.

Tina (2015) went on and talked out her fear of using particles at the nano-scale level in medicine and inserting them in the human body. In that regard, Tina (2015) indicated that "it is kind of controversial in terms of using this for medical purposes like you know creating small particles which will be inserted in your body so people are kind of worry about that." Similarly, Jack (2015) expressed his concerns about the practical application. He stated, "I think it's very interesting from an intellectual perspective but as far as a practical application is concerned, I have a lot of reservations about it."

Particles at the nano-scale level not only raise questions that are ethical or related to health but also cause environmental pollution. Among all of the interview participants, only Jack (2015) was skeptical and aware of the negative effects of nanotechnology and its role as environmental pollutants. He stated,

I definitely do have the concern about their role as environmental pollutants. I think that's a major concern if we are ever going to implement carbon nanotechnology as a main state for our devices. I think that's going to be something that's going to take serious consideration in that. My speculation is that a lot of carbon nanotechnology based technologies will have serious environmental pollutant concerns to be addressed. 
A few participants held conflicting views about nanotechnology; they talked about some of the potentials of nanotechnology but they talked about their fear of it. Melissa (2015) best described this by stating,

...there is a lot of people I think might be afraid of nanotechnology. Anything with technology attached to it, they can have a certain I think fear of there is certain part of population that has that sense of fear so I just think I don't know being able to make people aware of what really is nanotechnology, just not the content but also equating the term nanotechnology with the content will go a long way to having people understand that these are technologies that we're already aware of something like lead glass and things that have been in existence since medieval times that people don't realize that, Oh, that's nanotechnology. We just didn't call it nanotechnology. We call it art.

In addition to the above mentioned concerns with regard to nanotechnology, Lynne was the only participant who pointed out to the privacy issue that comes out as a result of using nanotechnology. Lynne (2015) said,

...the only thing I could see as a disadvantage would be that with the setup of our insurance and stuff like that, and that's why the privacy act is in place, but knowing more information that could leak out would be not an advantage to people that are trying to get covered with insurance and whatnot.

\section{Value of Nanotechnology Implementation in Science Classrooms}

With respect to attitudes toward implementing nanotechnology in science classrooms, participants shared competing opinions in that regard; they talked about the value of implementing nanotechnology in science classrooms as well as about its limitations. 
Participants viewed nanotechnology as an important cutting-edge subject that should be integrated into the traditional science curricula, as stand-alone subjects, (e.g., biology, chemistry, physics, earth science, etc.) that hardly ever changed and that do not include crosscutting concepts such as nanotechnology. The integration of nanotechnology helps students to see the interrelatedness of various science disciplines; how they are connected rather than separate and disconnected disciplines. This view was shared by a few participants. For example Tom (2015) said,

...nanotechnology is the cutting-edge, and cutting that out of the curriculum not providing students with the cutting-edge and exposure to what is currently going on in science would be no different than teaching a history class and not allowing them to know anything about current events. Failing to connect the science that they are learning with the science that is going on right now would be the same as teaching about the civil war and not talking about civil rights. So it is very, very important.

Similarly, Ron (2015) commented on the importance of exposing students to other disciplines that integrate more than one discipline, such disciplines as nanotechnology, as it shows students how disciplines are connected and it helps them to pursue disciplines other than the traditional disciplines, such as chemistry, biology, or physics. Ron (2015) said,

I think it is important for students to get exposure to nanotechnology because there is a lot of students only know about...chemistry and physics. They do not realize that there is all these sub-disciplines within their science classrooms. If we do not expose them to these sub-disciplines, they do not know about them, they are not going to pursue them in college. Giving them some exposure, I think, is very important to change the thinking about other fields that we are trying, such as nanotechnology. 
Furthermore, Marie (2015) pointed out to the importance of veering off what is in the current text book with the traditional content and teaching topics that are new and relevant to students' lives, such as nanotechnology. She stated,

I think it [nanotechnology] will be very important you know in the future for us to start expanding on some of the things that we've been teaching for the last 30 years that haven't really changed much in science, or even longer than 30 years. We're just so behind the curve when it comes to teaching about technology in our classrooms because it's just number one, the technology is not available at in case of schools and second it just hasn't been a focus of the state.

Voluntarily participant science teachers shared a common thought that nanotechnology is important for students' preparation for the actual industry even if they are not going into the science field. Tom (2015) stated,

Simply, the fact that it prepares them for the actual industry. If anyone goes in then, if they are related to science and they lack an understanding of current nanotechnology they will be a step behind other students who are....Now, someone who is not going into a scientific field needs to know just as much so that some politician or advertiser cannot trick them so they need to be equipped to deal with what other people will present to them. Ignorance is not a good option.

Tina (2015) expressed her opinion toward implementing nanotechnology in science classrooms as a technology that increases the scope of what students can pursue studying and doing science related fields. In that regard, she stated,

I think exposure to nanotechnology and exploring that from a technology perspective, I think gives the kids an idea of some of the working fields that are out there in science. 
One of the hardest things that I know we see as science teachers is how we can make the connections between what being a scientist means. A scientist isn't just something like working in a lab with bottles of chemicals around you. There's so many different career paths that science offers that we don't often get to focus on some of those things. With technology focusing on how nanotechnology can be used in medicine, it can be used in structural design, like materials engineer, things like that. I think it increases their scope of what they could possibly want to do when they leave high school.

Interestingly and in agreement with Tom, when Melissa (2015) talked about the classroom applications of nanotechnology she looked to the education of the community. She implied that nanotechnology is not only necessary for students who would like to pursue science fields, it is also necessary for other students who would like to pursue non-scientific fields as they could exert some power in the future. Melissa commented,

So, I look at my students and I just say, Okay, well hopefully, someone will be a politician in my classroom and they will have had the opportunity to at least become knowledgeable and aware...so I see as being able to craft, to invest in my future and at least have my students who are future leaders be knowledgeable about nanotechnology.

\section{Limitations of Nanotechnology Implementation}

Middle and high school science teachers contributed with their perspectives with respect to the real and perceived inhibitors and challenges that could impede and prevent the implementation of nanotechnology in science classrooms. These inhibitors have a huge impact on their attitudes. The inhibitors that were identified by science teachers were related to school, course and student type; curriculum determinants; time constraints; social influences; lack of 
resources; lack of nanotechnology professional development opportunities, lack of nanotechnology knowledge and self-confidence.

School, course, and student type. One of the challenges that would face science teachers and prevent them from implementing nanotechnology in their classrooms is the school type (rural and low-income vs. urban schools) as well as students type (standard level students vs. advanced placement [AP] level students) especially when their conceptual understanding is at a level that only and barely processes the conceptualization of basic concepts and not advanced concepts like nanotechnology. In that matter, Katie (2015) provided her honest opinion about the impossibility of introducing any advanced technology at her school in a rural district because of the miserable school level that she is teaching at. She stated, "I teach in a ghetto school, I teach in a tiny school and it is not going to happen...we do not let different things happen or teach other than basic chemistry. This could be in an advanced course." With this challenging aspect, teachers expressed contradictive opinions. Some teachers viewed that nanotechnology should be only introduced to students in high grades in high school or at a higher academic level and not to the average or below average students as it is hard for students to conceptualize and visualize something that is at the nano-scale level. However, others expressed that nanotechnology should be introduced to all students regardless of their academic level or whether they are or not pursuing science and scientific career opportunities for their future. For instance, Kevin (2015) clearly stated, "I teach upper level seniors and lower level sophomores and the lower level sophomores are not at the level that would be conducive for a lot of nanotech work on it." Similarly, Lynne (2015) shared her opposing opinion of teaching nanotechnology because of the level of students that she is currently teaching. She said, 
In my present classrooms right now, I don't see an advantage because I don't think that my students that are not academically inclined have enough base knowledge to understand what's really going on on that level. I would love to see it in the honors program in the AP biology. Any of the students that are going on in their career for science, I think it's very much of an advantage to have it in a high school year. I think it's a waste of time for the students that could care less about biology and you're just trying so hard to pull them through and get them engaged and get them excited. It's the toughest job when you have a class like that.

Lynne (2015) added more by saying,

I think that everybody is trying to get a broad spectrum of teaching everybody everything, but I think that's where we fail somewhat because there are students that aren't mentally mature enough to go with this more abstract thinking in the micro world than other students. I think it really needs to be concentrated for more the higher level academic students. That's just my personal opinion.

Consistent with Lynne's opinion, Katie (2015) indicated, Children do not have the ability to think abstractly at that level until they are 16 years old. They cannot imagine the scale of nano until...that part of brain does not develop until they are 16 so they would have to be 16 or older to begin to understand.

Curriculum determinants. With respect to the issue of curriculum determinants, participants mostly commented on curriculum determinants that challenge and eventually prevent them from teaching nanotechnology. They shared common concerns that are related to the requirements of the state and national science standards, the load of curriculum material, 
absence of lesson plans and classroom activities that are related to nanotechnology, how and where to fit and teach nanotechnology as part of the current curriculum, and the time issue.

Science standards. Teachers reported that they are not mandated to teach something that is not addressed in the standards requirements. The following quotes illuminate the curriculum factors that influence teachers' attitudes toward integrating and implementing nanotechnology in the current curriculum. With respect to the requirements of the science standards, participants indicated that nanotechnology is not part of the state requirements, and they are not required to cover something that is not guided by the standards. The following excerpts support this idea. For example, Richard pointed to the absence of the nanotechnology in the standards by saying that "there's no national standard in education that addresses nanotechnology out in the field." Additionally, Katie shared that nanotechnology ...is not part of our required curriculum, we cannot deviate from the curriculum. It is not part of the State requirement. The State says we teach $\mathrm{X}, \mathrm{Y}$ and $\mathrm{Z}$ and nanotechnology is not one of the State...we are to teach.

Also, Melissa contributed by saying.

...whether it is required by whatever standards that we are teaching to that would be the most influential decision. So, if it were included on our national standards then, I would definitely include it but it is not. It would be probably you know further down on the list of topics to cover.

Overloaded curriculum. Regarding the overloaded curriculum that teachers are required to teach and covered by the standards, Linda referred to the challenge of the existing overloaded curriculum with traditional topics to cover where there is no more room to bring in and cover more topics beyond the mandated ones, she provided that "the curriculum in science classrooms 
already overloaded... and it will be hard just to weave in another topic." In addition to the state standards and overloaded curriculum, teachers pointed to the curriculum issue of fitting and relating nanotechnology into the already existing curriculum; they expressed their concern and inability to fit in and teach a topic that is out of the curriculum that they are required to teach. Tina considered fitting a new topic into the current traditional curriculum as a limiting factor as she stated, "show the teachers how they can weave nanotechnology into curriculum." Sharing the same concern, Ron indicated, “... show me how we can apply it and how it is relevant... and how students will benefit from it."

Time constraints. Time definitely is another limiting factor that was addressed by some of the interview participants. Teachers stressed that time is a big issue for covering the required curriculum material and they do not have the extra time to cover additional topics such as nanotechnology especially since it is not outlined in the national and state science standards along with the already overloaded curriculum. Marie (2015) commented that time is an issue to fit nanotechnology into her schedule, she said,

...fitting [nanotechnology] into the curriculum schedule, finding time in your plan to implement an entire unit on nanotechnology or even if it is within a lesson time is usually the factor and having time to plan for it so if I did not have that time to move, then I would probably not implement nanotechnology lesson.

Tina (2015) on the time as an issue referred, ...time could also be an issue. If you're looking at trying to integrate new topics to a new subject area, it will make any teacher apprehensive because they still have specific materials they have to cover for the state exams as well. 
Social influences. In addressing the challenge of social influences on attitudes, science teachers reported on the pressure and influence of administrators, science teacher colleagues, parents, and decision makers on their attitudes toward implementing nanotechnology in science classrooms. Supportive administration could be beneficial and helps with developing positive attitudes; however, opposition from unsupportive administrations, parents, and government officials could be detrimental and at the same time develops negative attitudes toward performing a desired behavior. In that regard, Robert (2015) indicated, "administration has been kind of aha...they're not willing to go the extra mile. Administrative interference there can be beneficial but at the same time it can also be detrimental." The social pressure was viewed as an issue especially if people who are involved are unsupportive and adhere to teaching to the standards, worried about test scores, do not have the background of the subject to be taught, and deny the learning opportunities for other teachers through participating in professional development and workshops. Tom (2015) noted, “... some of my administration would worry that it is not exactly outlined in the content standards." Melissa (2015) stated,

Because it's not part of the core curriculum. I think that we have administrators who do not have science backgrounds that they do not understand the importance of implementing some of....I think we have politicians who, the last time I checked, very few have any knowledge of science and they are the ones who are making major decisions for us as educators in our communities and for our nation and they don't know the first thing about science.

The following quotations best detail having resisting and unsupportive administrators and parents who would be uninterested in having their students and kids learn about nanotechnology, especially when it comes to test scores. 
If the test scores slip or if parents were worried that this is not in the content standards and is not what their lovely little children need. Parents might especially like may be an honor's parent who is worried about their kid getting in a well-paid school, they may be would worry that this is too hard or that is not exactly what they need. (Tom, 2015)

In a similar fashion, Richard (2015) commented on the unimportance of including nanotechnology as it does not appear in the tests by saying,

Well, of course in this world of testing that we live with and secondary education and all education sort of you know college, I think that some of the resistance would be it is not in the test and we are not teaching it because many people's careers and job performances and evaluations are based upon test scores and if is not on the test scores, they are probably not going to be interested.

Below are two distinctive quotations by Melissa (2015) who shared that her administrators were unsupportive as they denied her the opportunity to attend nanotechnology professional development despite the benefits that she will get for her school. Melissa contributed by saying that her administrators and parents oppose teaching anything that is out of the curriculum as it does not help their kids and students to do well in the exam. She stated, If I can attend a workshop, I do but I've been denied the opportunity to attend a nanotechnology workshop from my administrators because it fell on a day that I wasn't allowed to take off at school even though the school was going to get $\$ 2,000$ worth of materials for participating.

Melissa (2015) added, ...well, I think that if learning about nanotechnology is not on the state exam, I think the push back could come either from parents or from administrators who would say 
something like, "well, my child didn't score proficient," or "your students didn't score proficient because you're busy teaching them something about nanotechnology.” They might misunderstand that nanotechnology is related to what's on the exam but they wouldn't have that understanding of the relationship.

Interestingly, Marie and Tina are some of the participant science teachers who reflected upon the influence of other science teacher colleagues who might discourage the idea of including and teaching something new that is not in the traditional curriculum that they have been teaching for a long time. For example, Marie (2015) speaking about old teachers who might be standing against, opposing, and discouraging that "all the teachers who have been teaching for 20 years and don't want to change anything. For 30 years and don't want to change anything. There is always a ney sayer in the crowd when it comes to change." Along the same lines, Tina (2015) reflected, Unfortunately, most of the resistance is probably going to come from other teachers. I think teachers that having been teaching or more veteran teachers that have been teaching for a long time and are resistant to change. Or that don't have a very high level of confidence in their own teaching abilities if they don't have a complete understanding of the topic. Unfortunately, we still have teachers that use the same material year after year without integrating new things. I think that, as a teacher, because you see your colleagues so much more often than you do anyone else, I think that other teachers are probably going to be one of the biggest barriers.

Lack of resources. The deep investigation with middle and high school science teachers provided informative data that illustrate that the lack of resources was one of the biggest issues among others that could determine science teachers' attitudes toward implementing 
nanotechnology in science classrooms and stand as a stumbling block that impede the process of implementing nanotechnology in science classroom. Lack of resources include: lack of materials and equipment, lack of lab facilities, and limited budget. Teachers see no point of introducing nanotechnology only at the intellectual level if no hands-on activities are associated with it, especially the teachers who are supportive demonstrating practical applications and classroom activities. The lack of classroom materials, equipment, and lab facilities prevent teachers to perform nanotechnology classroom activities that help students with developing a conceptual understanding of what nanotechnology is all about. Besides that, limited budget is also a big influential challenge for teachers that inhibit their ability of introducing nanotechnology. Some schools do not have even the budget to purchase the materials to cover the basic concepts that are in the current curriculum. Allocating or even securing the amount of money to purchase materials and equipment to teach about nanotechnology is nearly impossible at the middle or high school level because equipment to teach about nanotechnology is prohibitively expensive. On that, Tina (2015) indicated that "when you are talking about anything technology wise, you are usually using [the Internet] with it. At least in public schools, we are limited in the amount of money that we have access to be able to purchase more advanced materials." Jack is another science teacher who stated,

I don't see it being useful at any time in the future. I mean, so many schools have very, very limited budgets to keep traditional chemistry-based laboratory materials. I mean, many schools don't even have budgets to have proper chemicals and glassware. I think it's going to be a long, long time than ever before to be a major component in a chemistry classroom. At least at the high school level or early stages of someone's chemical education even at the college level. 
Lack of nanotechnology professional development. Lack or absence of nanotechnology professional development was one of the most common challenging issues that were addressed by all of the interviewed participants. What was interesting is that the participants who participated in nanotechnology professional development reported that the opportunity of participating in nanotechnology professional development was not funded and offered through their schools; it was through funded research projects where they get paid for their participation and/or college credit. Tom was one of the participants who was involved in a nanotechnology professional development reported that he participated in [name of nanotechnology program] and said that "I would consider that as a professional development not something through my school or smaller scale but that large scale research project through [name of the university]...it helped it was a paid position not only the credits were paid for" (Tom, 2015). In addition, nanotechnology participants reported that their involvement in a nanotechnology professional development was a one-time opportunity. Overall, the availability of nanotechnology professional development was reported as fairly limited or absent. Tina (2015) as one of the non-participants in any of the available nanotechnology professional development opportunities commented,

I think up until very recently the professional development that was offered was fairly limited. I know actually, just recently, learned of one that's going to be offered this summer at Rice University here in Houston. Prior to that, there really wasn't very many offerings for professional development that was related to nanotechnology in the classroom.

Tina (2015) added more by saying, 
I think the availability of resources, not only the equipment itself, but being able to find personal development close by that is convenient and doesn't cost very much either for myself or for my school. That's another obvious limitation to it is that if you're going for your school, you have to pay for the professional development out of pocket or your school has to have money to pay for the professional development for you. Then the availability of training for it I think would definitely be a major factor influencing it. Linda (2015) commented that nanotechnology professional development "was not offered. I did not see any professional development in nanotechnology."

Lack of nanotechnology knowledge and self-confidence. In addressing the challenge of individual's knowledge and self-confidence, interview data revealed that discrepancies exist between and among science teachers in their level of nanotechnology knowledge and selfconfidence; some have limited and vague understanding of what nanotechnology is and some others are familiar with the concept of nanotechnology, knowledgeable about its different medical, industrial, and educational applications. Teachers with limited knowledge level consider that besides the above mentioned challenges their lack of understanding of nanotechnology is another challenging issue that influences their attitudes and self-confidence which prevent them from integrating nanotechnology in classrooms. Tom, Lynne, and Tina reported their familiarity with nanotechnology and their confidence in teaching it in their classrooms. In that regard, Tom (2015) stated that his confidence is pretty high...mostly because I have 18 hours of graduate level work in implementing nanotechnology in the classroom which I would say very helpful at this small point, I have only dipped into the integrating nanotechnology in the classroom but I would say, I'm very confident in those labs. But because I have invested a very large amount of time 
and the [name of organization] invested a very large amount of money both in my training and materials.

Similarly, Lynne (2015) described that she is confident in teaching her students about nanotechnology by saying,

I'm fairly confident. I mean I certainly do not portray myself that I'm an expert in the field because I'm not, but I tell my students that it is a learning process for both of us. I would say in confidence level, fairly, fairly confident.

Tina too described that she feels comfortable teaching about new things, such as nanotechnology. Tina (2015) stated that "I've always considered myself to be very innovative in teaching. I love teaching new things and I feel comfortable teaching about things that I'm not totally comfortable with.”

Surprisingly, some of the science teachers who reported that they are not expert in the field of nanotechnology but familiar and knowledgeable explained that they did not include nanotechnology as part of their science curricula because of their lack of ability or confidence in teaching nanotechnology itself. Jack (2015) was an example of a science teacher who is familiar with nanotechnology and even worked in a post-doctoral fellowship with a project that deals with carbon nanotubes and yet reported his lack of confidence in teaching about nanotechnology. Jack (2015) stated,

I definitely have more of a grasp of what's going on more than I think the average chemistry teacher would have, definitely at the high school level....As far as teaching goes, that would be a hard thing to nail down definitively.... I can give a bigger exposure to things than what many students would be getting, but I really don't know how effective I am at communicating it....As far as bringing it up and my own confidence, as far as 
talking about it is concerned, I think that, I mean, I really don't know where it's going to go. I really wouldn't say I have a whole lot of confidence in my ability to teach it, but it's definitely the new frontier. There are new things to learn with it for sure.

In contrast to Jack, Robert (2015) — despite his unfamiliarity with nanotechnology_ commented that he has the ability of teaching new things, such as nanotechnology, if he got the needed knowledge and training for that. Robert (2015) stated,

I think I have the ability to absorb the...you know enough at least at the level that I teach. I think I have ability to learn enough and be very confident at teaching it [nanotechnology] just would not want to be considered as an expert by any stretch but I would be quite comfortable but I would need to be trained....I will be confident in teaching pretty much anything I think I have developed the ability to learn to teach anything if is in the science really you know I just need the information and let me apply it.

Jackie, Marie, Robert, and Jack are among other teachers who lack self-confidence to introduce nanotechnology to their students due to their lack of knowledge about nanotechnology. Jackie who is unfamiliar with nanotechnology said that "right now not very able I'd have to learn some more about it before I can pass that on...once I have the basics you know I will be confident with it." Similarly, Marie (2015) expressed that "well, at this point because I do not have much background with nanotechnology I do not know that I would be very successful in teaching it in my classroom." In addition, Robert (2015) honestly shared his fear of teaching nanotechnology because of his lack of knowledge, he stated that "my limitations probably one is my own ignorance because there is a lack of understanding, limited understanding," then he 
added that "my first year would be a learning curve... will be a little apprehensive because you know because of my lack of knowledge."

Research question three results. What helps science teachers implement nanotechnology in science classrooms? This question was addressed through both qualitative and quantitative approaches. Qualitatively, it was addressed through conducting face-to-face and over-the-phone interview for approaches that would elicit some of the real and perceived barriers that impede science teachers to implement nanotechnology in science classrooms. Quantitatively, it was addressed through conducting regression analysis to predict some of the facilitators that would help science teachers to implement nanotechnology in their science classrooms.

Qualitative results of the facilitators. Through the interview qualitative data, facilitators that would help with implementing and developing positive attitudes toward nanotechnology were identified and explored through asking participants to address real and perceived challenges that would not only limit or hinder their ability to implement nanotechnology in science classrooms but also influence their attitudes toward the actual implementation of nanotechnology in science classrooms. Proposed approaches and suggestions were offered by participants to overcome or alleviate the challenges that were related to the lack of nanotechnology knowledge and self-confidence, curriculum determinants, social influences, and lack of resources. Lack of nanotechnology knowledge and self-confidence could be solved through offering and engaging science teachers in nanotechnology professional development and workshops, partnering up with experts in the nanotechnology field, and self-education initiative. Suggestions that were offered to solve issues that are related to curriculum were addressed through thinking about the course and student type (e.g., AP course level); nanotechnology placement, implementation, and lesson plans; science standards; and shift in the science teaching approach. To address the challenge 
that is related to social influences, participants offered the solution of seeking social support from school administration, parents, school principle, science teachers colleagues, legislators, etc., and interacting, communicating, and partnering up with community members, experts in the field of nanotechnology, and local agencies with nanotechnology programs in it. Lastly, participants addressed the issue of the lack of resources by referring to securing funds, equipment, and learning materials.

\section{Lack of Nanotechnology Knowledge and Self-Confidence}

Nanotechnology professional development and workshops. One of the challenging issues that was addressed by science teachers is the lack of knowledge and self-confidence with respect to nanotechnology. The common suggestion that was shared between all participants was to expose science teachers to nanotechnology that could be through nanotechnology professional development or workshops as it provides learning opportunities for science teachers and increases their knowledge about nanotechnology as well as promotes their self-efficacy by giving them guidance on how to fit and implement nanotechnology in science classrooms as part of the current curriculum. In that regard, Linda (2015) indicated that "very small steps but first of all the science teachers have to be exposed to nanotechnology themselves." As Kevin (2015) suggested exposing science teachers to nanotechnology could be through giving them an access to labs and nanotechnology-related activities through nanotechnology professional development. Kevin said that "other things that influence is access to labs and activities that actually have them [students] do things with nanotechnology and then also access to professional development that would help me implement it in my classroom." Similarly, Tina (2015) expressed that "having the exposure, having an idea of where to take the nanotechnology lessons and... knowledge from the 
professional development would be the biggest thing to help me feel supported." More specifically, Robert (2015) pointed out,

...the ideal the best situation I can envision is you know, one, me taking a workshop of some sort and...just some kind of workshop for a class or a lecture of some sort so I can just experience it myself and then share what I've learned and pass it on to the students. So, I'd be happy to attend a workshop for training of some sort so then I can just say, alright kids, here, this is what I've learned, you know and I can help you with learning the same thing.

In addition, Tom asked for more training despite his participation in one of the nanotechnology professional development that was offered to him. Tom (2015) suggested, Support more support of this sort I mean if I were to increase my knowledge in nanotechnology. So if I want to say double the amount of nanotechnology that I was integrating into my classroom and double it, I would say I would need probably another worth of work working with professionals in the field to build the curriculum, to build the labs, to test the labs, and to prepare that. I think I would need the monetary support to build the supplies...so training and supplies those be the two main things.

Partnership with researchers and local agencies. Besides attending nanotechnology professional development and workshops, building partnerships with researchers and professionals in the field of nanotechnology and establishing alliances with local universities or companies that have nanotechnology programs in them was another approach that was suggested by some participants as it would help science teachers to increase their knowledge about nanotechnology and embed it along with classroom activities in their current curriculum. Marie (2015) shared that "university program during the summer are great for giving teachers more 
knowledge about nanotechnology. I think that's probably the best way to start." In addition, Melissa (2015) suggested working with professors or researchers who work with nanotechnology by noting, "...it is so worth it to make those connections and have professors available to you or researchers available to you who are using that technology."

Self-education. Self-education was another suggestion that was provided by few participants who were interested in learning about nanotechnology and to increase their own knowledge about nanotechnology. They suggested that this could be done through reading literature that is related to nanotechnology.

\section{Curriculum Determinants}

Course and student type. Regarding the challenge of curriculum determinants (e.g., course type, students type, standards, lesson plans, activities, overloaded curriculum), some participants suggested introducing nanotechnology in a higher course level, i.e., advance placement (AP) course and to students 16 years and older so they can conceptualize the concept of nanotechnology as Katie (2015) stated, "this has to be at the high level course or at a rich school."

Nanotechnology placement, implementation, and lesson plans. More of what would help implementing nanotechnology is to show science teachers where nanotechnology fits the current curriculum and science standards, how to implement it, and to provide them with lesson plans and classroom activities that will spark students' interests. In that regard, Jack, Kevin, and Richard expressed their opinions regarding linking nanotechnology to the current curriculum and science standards. What would be helpful as Jack suggested is show him how nanotechnology is "relatable to something they [students] already know about or they are already learning about" 
(Jack, 2015). What would be helpful for Kevin is provide him with lesson modules, where to fit them in the current curriculum, and how to teach them. Kevin (2015) stated,

I think if we had more curriculum module or things that are you know kind to help implement it that is a big push by anybody then that would definitely help...you know like that oh this is where I could fit it in. you know really how I would fit it in my current curriculum where would be financial connect, it will be a big help.

In addition, Richard (2015) explicitly said,

...well, I think if we can show how students benefit from it, I think if we could show how teaching nanotechnology fulfill the need of the standards that teachers have to meet or administrators have to meet and I think if you can help with any sources of resources you know if we have to invest in a lot of equipment...but show how nanotechnology fit content and the standards that we have to meet.

Working with others who have already implemented nanotechnology in their science classrooms would facilitate implementing nanotechnology for the ones who are interested in implementing nanotechnology and have not had done so. Robert spotted the light upon the benefits of attending professional development as it helps with increasing someone's knowledge but he also pointed out to the importance of transitioning the learned material in nano-related workshops and connecting it back to classrooms by stating that "workshop but how can I adapt it from workshop into a professional learning, the transition that would be just my only." In that reference, Marie (2015) pointed out to the importance of working with other science teachers who have successfully implemented nanotechnology in their science classrooms already and use them as role models to inspire other novice teachers to implement nanotechnology by stating that "some professional development with others who have been implementing nanotechnology 
lessons in their classrooms would be the biggest thing." So, opportunities like nanotechnology professional development could be beneficial for learning science teachers about nanotechnology as it could provide them with connections and experiences with scientists or even with expert teachers who have enacted nanotechnology lessons and activities in their classrooms.

Participants suggested that providing them with nanotechnology modules and lesson plans along with activities that could be implemented in science classrooms would be helpful especially if it corresponds to the grade level (e.g., $8^{\text {th }}$ grade, $9^{\text {th }}$ grade, $10^{\text {th }}$, etc.). On providing teachers with nanotechnology lesson plans, Ron suggested, "the best thing you could do is give teachers examples of lessons. Very simple demos.” He added, “...yeah, just giving teachers examples of simple chemical reactions they can do to demonstrate different products that involve nanotechnology. Basically, experiments that the students can do and examples of them."

Nanotechnology-related science standards. Science standards are part of the science curricula. In fact, they guide the curriculum to be introduced to students. Almost all participants pointed to the absence of specific standards that are related to nanotechnology which are posed as one of the major issues to teach nanotechnology as part of the current curriculum. Therefore, participants plainly stated that nanotechnology has to be explicitly mentioned in the national science standards in order to implement it. Kevin suggested that nanotechnology "has to be part of the curriculum and that is forced in there you know it has to be something that is in the national outreach of the curriculum."

Making a shift in science teaching approach. As a passionate science teacher who has implemented nanotechnology in his classroom and would like to see it implemented in other classrooms, only Tom critically suggested that there should be a fundamental shift in the current way of teaching profession and how teachers teach science. Tom (2015) said, 
...if you think science is just a collection of fun little artsy crafty labs, then you are not

teaching science. If you think that it is science is current and now and exploding everyday then you are teaching science. If you are not teaching them what is happening right now, you are not teaching science. You are teaching science trivia.

As an advocate of teaching current topics such as nanotechnology, Tom stressed that teaching should witness including more current topics, i.e., nanotechnology and that can be accomplished after making a shift in the teaching profession. At the same time, he expressed his concerns regarding teaching to the tests when he argued,

More integration of things like nanotechnology and other emerging sciences unless we see a major shift in the teaching profession in the United States. In general, we are moving away from that type of teaching, especially right now. We are seeing a very strong push towards tests, test, tests, and very standardized, very tiny little box just put it into a little chicken Mc. Nuggets box and ship it off.

\section{Social Influence}

Networking with others. With respect to the challenge of social influence, participants reported different views on their administration and parents of students. Some had supportive administration and parents; however, some others reported having unsupportive administration and parents. For example, Tina (2015) was fortunate to have supportive administration that encouraged her to implement innovative ideas in her science classroom. She stated, “...fortunately, my administration is actually very supportive of innovative ideas and trying to find different ways to engage students in the classroom." Not only administrators with science background could help but also parents with science and engineering backgrounds as they could be involved and used as guest speakers and appreciate the integration of nanotechnology in 
science classrooms even if it is not specifically mentioned in the standards as Melissa (2015) contributed by saying,

I think my parents are scientists, who do have science backgrounds, and I live in an area that we have a diverse...educational levels, so I'm very lucky in that respect. Those parents would appreciate the fact that they appreciate the guidance that I can give their students.

Melissa (2015) added more by saying,

I think any time a parent says to my administrator, 'Oh, I'm so happy with the school because they are teaching my student about something that's new,' that's where it definitely benefits me. It benefits the administrators and the parents. Those, who I think are already knowledgeable and working in the field, appreciate what I am able to provide. In a similar response Robert (2015) stated, Oh, my administrators are very supportive on new ideas. And the other science teachers that you know, the other grade level science teachers are very supportive of ideas and stuff like that. And parents can potentially be an untapped resource; parents are always the untapped resource. Some parents have science and engineering backgrounds, to have them help as guest speakers or they can come in and maybe, I've had parents donate some of the materials.

Some other science teachers commented on having unsupportive administration; therefore, they suggested that having support from people, as an external factor, in the career environment is pivotal. They noted that seeking support from school principal, administrators, curriculum directors, and other science teacher colleagues would provide an environment where teachers could feel comfortable in implementing current topics, such as nanotechnology. At a 
higher level of social support, they noted that getting support from superintendent and legislators would definitely ease the process of implementing nanotechnology. A few participants and as a result of their teaching experience, in general, and out of their teaching experience of nanotechnology recommended seeking social connections with universities and companies that have nanotechnology programs in them as well as with professionals and researchers in the community who are working with nanotechnology, and even with parents who have science or engineering background as this would facilitate the process of integrating nanotechnology in science classroom. Below are some of the distinctive quotations that reflect participants' suggestions on how to overcome the issue of lack of social support that would limit or prevent science teachers from implementing nanotechnology in science classrooms.

Kevin (2015) stated that seeking assistance from other science teacher colleagues or getting another science teacher assistant on board especially with large classrooms or sections. He clarified that "I teach in a large high school so I have you know there is 17 sections of regular chemistry. If I teach one or two of them and I want to take a week unit, another teacher kind of have to be on board with me."

Robert (2015) emphasized the role parents. They can play in science classrooms as guest speakers,

Parents are always an untapped resource. So, I'm always looking for you know parents who have a science background so we can use them as a guest speaker or they a friend of a friend type, they might know someone who can open up other avenues. So parents are always another administrative help. 
In addition, participants suggested making social connections with local universities and businesses with nanotechnology programs in them to bring in the needed equipment in order to successfully implement nanotechnology in the classroom. Tina (2015) suggested,

I think creating situations where schools can develop partnerships with businesses and local corporations that are either interested in or participate in nanotechnology research. We do oftentimes try to build community partners to increase access to those types of resources....I think one of the things that could be used would be developing some of those community partnerships to either borrow and or loan equipment to teachers to have them teach about nanotechnology or even personnel themselves to come and do group instructions with teachers that are interested in teaching it.

Intriguingly, Kevin made his efforts in contacting a company to borrow equipment for the classroom in order to help students understand the scale of nanotechnology and actually experience it in his own classroom. Kevin (2015) declared,

I looked at a company that talked to me about lending an electron microscope to the classroom that they bring it in to you and that sounds great. I mean I was able to get a complicated machine that get down to you know a very small level and be able to get that into a classroom...there are other labs that I know of that if you take a class then you can have an access to like there umm anything like that and you can work them remotely but it is difficult you know if you are at claim doing it just to show them pictures and what not you know.

Obviously, making connections with local universities or business would alleviate the issue that concerns the lack of equipment and other needed resources. As a science teacher who implemented nanotechnology in her classroom, Tina (2015) said, "I think creating situations 
where schools can develop partnerships with businesses and local corporations that are either interested in or participate in nanotechnology research. We often try to build community partners to increase access to those types of resources."

The suggestion of building social connections beyond the career environment seemed to be an effective approach as it was emphasized by a few participants. Lynne (2015) stated, I think it'd be very important to have an alliance with a local university that...has the equipment to test nanotechnology...so if there was some type of alliance between the school the public school and the college level so that the students could come in to a college lab and actually see nanotechnology being done because really, the kids, it's the hands-on and we don't have the equipment for any of the hands-on stuff.

In stressing the importance of building a partnership between local universities with nanotechnology programs in them and a local school, and connecting with professors and researchers, Melissa (2015) stated that "It's so worth it to make those connections and have professors available to you or researchers available to you who are using that technology [nanotechnology]... and see what's appropriate for making those and bringing those connections into the classroom."

Seeking social support. On a higher level of seeking social support, Melissa (2015) thoughtfully suggested seeking the understanding of nanotechnology to government officials as they have their influence on administrators:

I would need our government officials to understand the importance of nanotechnology and have that filter down to our administrators because they don't know how long they've been... our educational system but my administrators haven't been in a classroom in well over 15 years. Most of my administrators, whether it's my direct administrators or 
administrators that are running the district, certainly do not have a science background. In fact, most of them have a special ed. background and that special education background goes back to the time when they taught in self-contained classrooms where their kids were separated from the rest of the population. I think we're talking not only a knowledge issue with nanotechnology but we're also talking a culture in the people who are administrators who really are completely and totally out of touch with what the classroom is like today because they're involved in their administrative duties as well because I think that they might want to come in and have a better understanding of what's happening in the classrooms but they just can't and part of it goes to our government officials who are making these decisions not understanding how education works.

\section{Lack of Resources}

Securing funds, materials, and equipment. Regarding the challenge of lack of resources that was shared by all participants, they offered their opinions on how to overcome it. They suggested securing the needed materials, equipment, funding, and grant applications. As was shared by participants, seeking grant funding opportunities would help with implementing nanotechnology in science classrooms along with its related classroom activities as it would help with purchasing the necessary materials for such activities. Robert (2015) suggested that taking a grant writing class would help to get funded on nanotechnology related activities. He said,

One thing I've always wanted to do is to take a class about grant money, about writing grants to help efforts, you know, if the potential activity is a bit pricey, cost wise, is to be able to maybe write some grants, you know, class of grants can help offset the cost of getting materials to help implement nanotechnology. 
The availability of resources especially the learning equipment hold a promise for helping students with developing a conceptual understanding of what nanotechnology is all about. Marie (2015) said, "I mean definitely if we had some kind of equipment that students would actually manipulate things and getting understanding of what the possibilities are for nanotechnology."

Quantitative results. In order to predict what factors facilitate the implementation of nanotechnology in the classroom, regression analysis was conducted. Based upon the ANOVA test results as shown in Table 11, the overall regression model was statistically significant, $p<.05[F$ $(6,427)=86.04, p<.05]$

Table 11

ANOVA Test of the Regression Model

\begin{tabular}{lccc}
\hline Model & $d f$ & $F$ & $p$ \\
\hline Regression & 6 & 86.04 & $<.0001$ \\
Residual & 427 & & \\
\hline
\end{tabular}

The coefficients regression table (Table 12) illustrates that knowledge and self-confidence, practice, professional context, and professional development were all statistically significant $(p<$ .05) predictors of science teachers' intention to implement nanotechnology in science classrooms. However, attitude and research were not statistically significant predictors of science teachers' intention of implementing nanotechnology in science classroom. Of these predictors, Beta values $(\beta)$ show that professional development was the best (highest beta value, $\beta=.32$ ) predictor to predict intention followed by knowledge $(\beta=.29)$, then professional context $(\beta=.18)$, practice $(\beta$ $=.16)$ comes next, followed by research $(\beta=.02)$, and lastly by attitude $(\beta=-.01)$. 
Table 12

Coefficients of the Regression Model

\begin{tabular}{llccc}
\hline Model & & $\begin{array}{l}\text { Unstandardized } \\
\text { Coefficients }\end{array}$ & $\begin{array}{c}\text { Standardized } \\
\text { Coefficients }\end{array}$ & Sig. \\
\hline \multirow{2}{*}{1} & (Constant) & -1.22 & Beta & $P$ \\
& Attitude & -.02 & & $<.0001$ \\
& Knowledge and Self-confidence & .33 & -.01 & .73 \\
& Research & .03 & .29 & $<.000$ \\
& Practice & .27 & .02 & .64 \\
& Professional Context & .26 & .16 & .001 \\
& Professional Development & .42 & .32 & $<.0001$ \\
& & & & $<.0001$ \\
\hline
\end{tabular}

Overall Regression Model

$y=-1.22-.02($ attitude $)+.33($ knowledge and self-confidence $)+.03($ research $)+.27($ practice $)+$ .26 (professional context) +.42 (professional development)

To examine the generalizability of the overall regression model, Stein's adjusted $R^{2}$ was calculated. Then it was cross-validated against the actual value of the adjusted $R^{2}$ of the overall regression model as indicated in Table 13.

Table 13

Regression Model Summary

\begin{tabular}{lcccc}
\hline Model & $N$ & $R$ & $R$ Square & Adjusted $R$ Square \\
\hline 1 & 434 & .74 & .55 & .54 \\
\hline
\end{tabular}




\section{Stein's equation.}

Stein's Adjusted $R^{2}=1-[(n-1 / n-k-1)(n-2 / n-k-2)(n+1 / n)]\left(1-R^{2}\right) ; n=$ sample size, $k=$ number of predictors, $R^{2}=R$-squared.

Stein's Adjusted $R^{2}=1$ - [(434-1/434-6-1) (434-2/ 434 -6 -2) (434+1/434)] (1- .55)

Stein's Adjusted $R^{2}=1-(1.01 * 1.01 * 1.00 * 0.45)=0.54$ (for population)

Adjusted $R^{2}$ for the regression model that is dependent on the predictors is 0.54 and the Stein's adjusted $R^{2}$ is .54 . So, there is no difference between Stein's adjusted $R^{2}$ and the adjusted $R^{2}$ for the regression model. It can be said that the regression model is likely be representative and derived from the population from which the sample was taken.

A further step was taken in order to check for the generalizability of the regression model and that was through performing regression diagnostics tests to examine for outliers and whether these outliers are influential or not. The outliers were looked at through the casewise diagnostics, and then through Cook's distance and Mahalanobis distance to test for influential outliers. After the regression diagnostics tests were checked, checking for regression assumptions was performed. The regression assumptions that were checked for included: multicollinearity, homoscadasticity, normally distributed errors, and independence of observations.

\section{Diagnostics Regression}

Casewise diagnostics. For the diagnostics regression, the casewise diagnostics was checked to examine for extreme cases. Table 14 illustrates that there were 19 cases as potential outliers. To examine whether these outliers were influential or not Cook's distance as well as Mahalanobis distance were calculated. 
Table 14

Casewise Diagnostics for Outliers

\begin{tabular}{lc}
\hline Case Number & Std. Residual \\
\hline 14 & 2.074 \\
42 & 2.005 \\
69 & -2.627 \\
79 & 2.230 \\
108 & -2.349 \\
185 & 2.546 \\
193 & -2.068 \\
221 & -2.352 \\
230 & -3.138 \\
244 & -2.115 \\
261 & 2.050 \\
263 & 2.000 \\
349 & 2.044 \\
385 & 2.117 \\
394 & 2.129 \\
445 & -2.210 \\
449 & 2.139 \\
469 & 2.069 \\
470 & -2.980 \\
\hline
\end{tabular}

Cook's distance. Cook's maximum value should not exceed 1. According to Cook's distance as illustrated in Table 15, the outliers were not influential outliers. The maximum value was .04 $(<1)$.

Table 15

Residuals Statistics

\begin{tabular}{lcc}
\hline & Min. & Max. \\
\hline Mahal. Distance & .57 & 26.21 \\
Cook's Distance & .00 & .04 \\
\hline
\end{tabular}


Mahalanobis distance (Cutoff is 25). According to residual statistics (Table 15),

Mahalanobis distance maximum value is 26.21 , which exceeds the cutoff value of 25 . This means that there are some cases that influence the regression model.

\section{Regression Assumptions}

Assumption of no-multicollinearity. Pearson correlations (Table 16) demonstrate that there were no high correlations between predictors. This concludes that there was no multicollinearity. Therefore, the assumption of multicollinearity has been met.

Table 16

Pearson Correlations between Intention (Outcome Variable) and Attitude, Knowledge and Selfconfidence, Research, Practice, Professional Context, and Professional Development (Predictors), $N=434$

\begin{tabular}{lllllll}
\hline & 1 & 2 & 3 & 4 & 5 & 6 \\
& & & & & & \\
\hline 1. Intention & & & & & & \\
2. Attitude & .41 & & & & & \\
3. Knowledge and Self-confidence & .56 & .48 & & & & \\
4. Research & .29 & .18 & .37 & & & \\
5. Practice & .61 & .42 & .51 & .33 & & \\
6. Professional Context & .52 & .33 & .33 & .26 & .58 & \\
7. Professional Development & .61 & .50 & .38 & .21 & .61 & .49 \\
\hline
\end{tabular}

In addition, the variance inflation factor (VIF) in Table 17 confirms that there was no multicollinearity where there were no VIF values greater than 10 . 
Table 17

Variance Inflation Factor of Regression Predictors

\begin{tabular}{ll}
\hline & $V I F$ \\
\hline Attitude & 1.53 \\
Knowledge and Self-confidence & 1.62 \\
Research & 1.21 \\
Practice & 2.19 \\
Professional Context & 1.59 \\
Professional Development & 1.85 \\
\hline
\end{tabular}

Note. VIF= Variance Inflation Factor

Assumption of homoscadasticity. Figure 4 represents the scatter plot of regression standardized predicted variable vs. regression standardized residual where that there was no obvious pattern. In other words, the points are randomly dispersed throughout the plot. This pattern is indicative of a situation in which the assumption of homoscadicity has been met. 
Figure 4. Intention Regression Scatter Plot of the Standardized Predicted Value vs. Standardized Residual.

\section{Scatterplot}

Dependent Variable: I intend to integrate nanotechnology-related content, activities, and materials in my science classroom within the next one or two years.

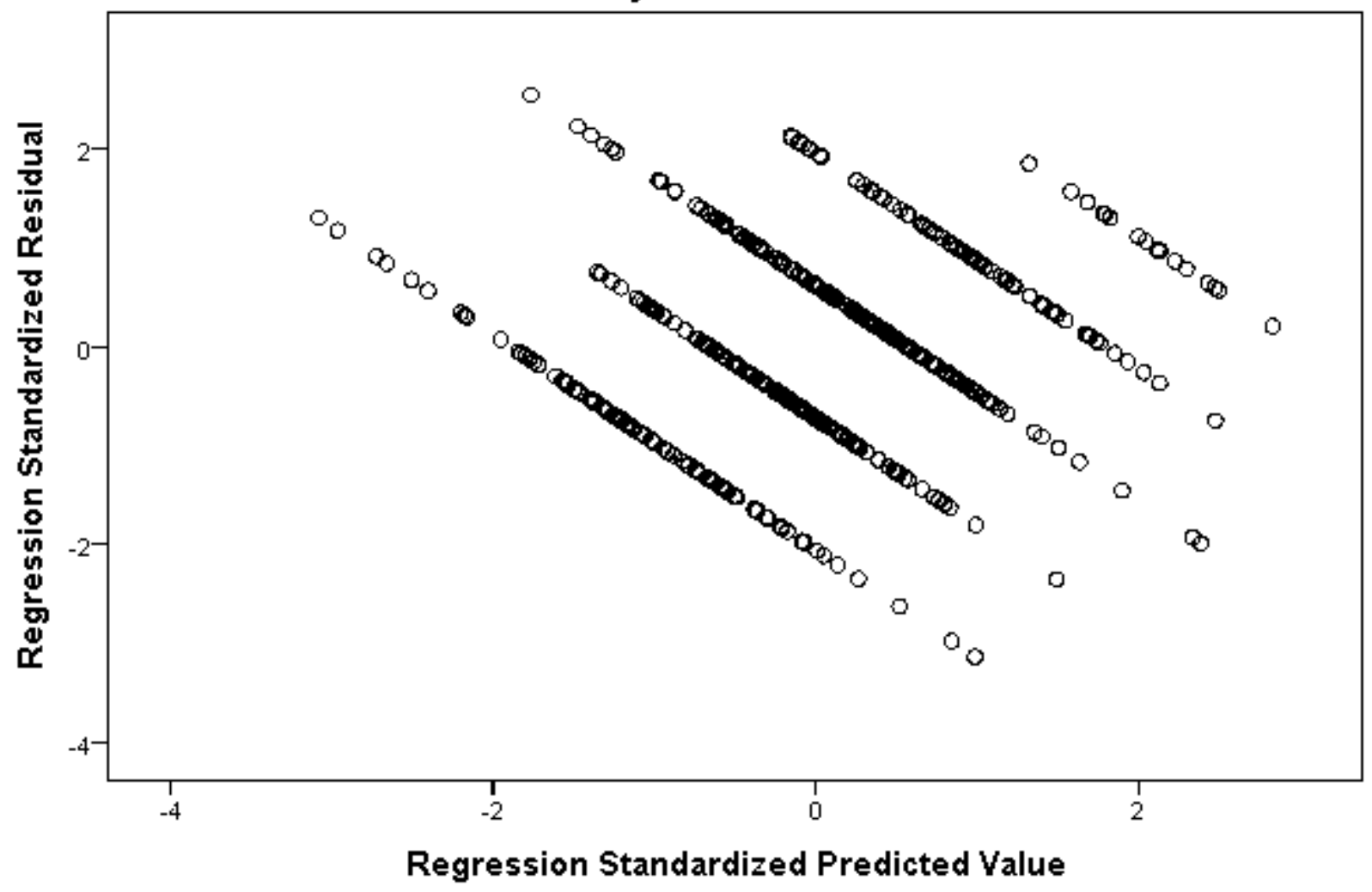

Figure 4. Regression standardized predicted value scatter plot shows no visual observation of a pattern. 
Figure 5. Intention Regression Scatter Plot of the Standardized Predict Value vs. Standardized Residual.

\section{Scatterplot}
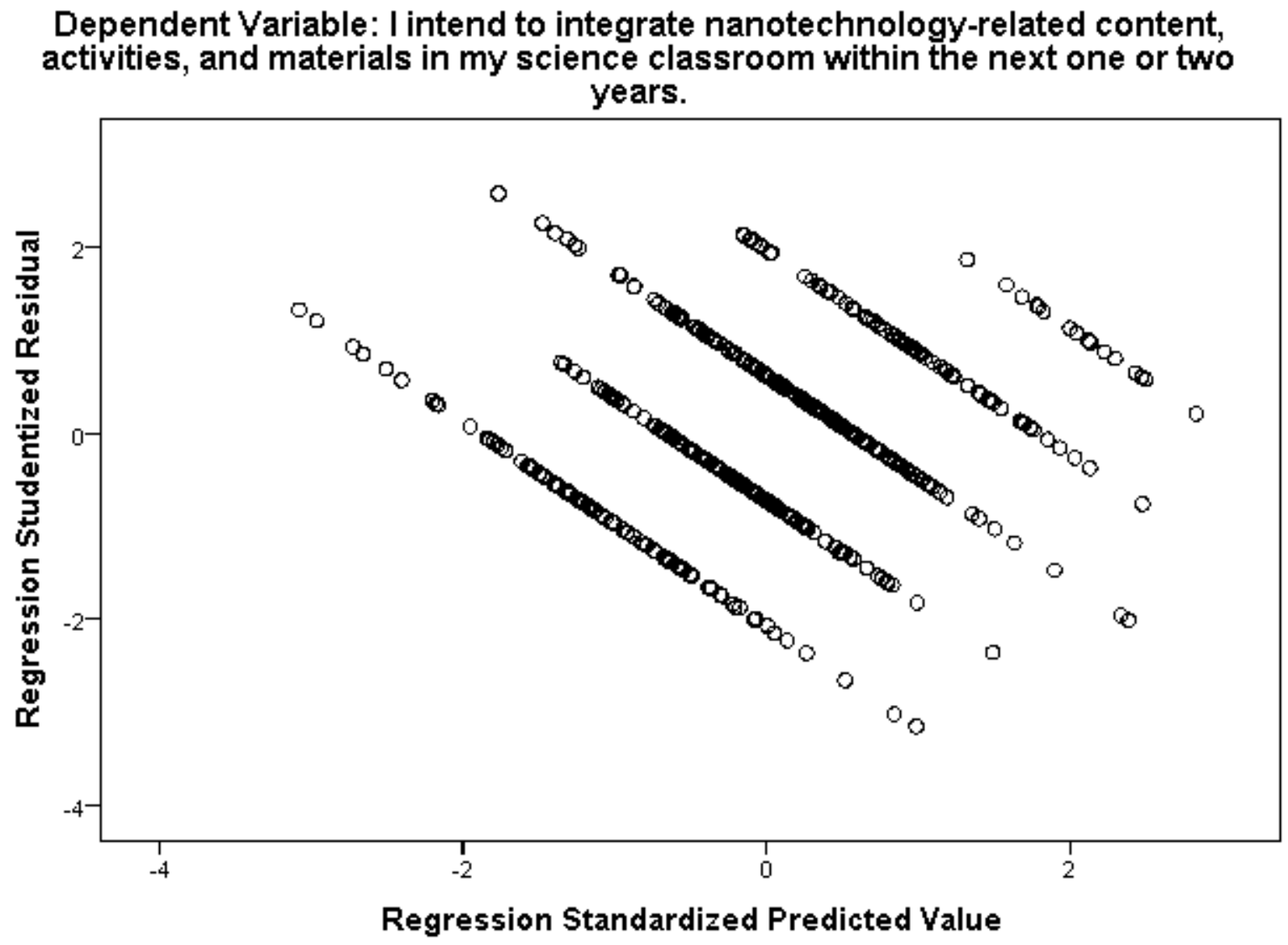

Figure 5. Regression standardized predicted value scatter plot that shows no visual observation of a pattern.

The scatter plot of regression standardized predicted value vs. regression standardized residual (Figure 5) reflects no noticeable pattern/lack of pattern to be found. That is the assumption for homoscadasticity has been met.

Assumption of normality. The K-S test of normality as shown in Table 18 indicates that our standardized residuals were not significant $[D(434)=.023, p>.05]$. Therefore, the assumption of normality has been met. 
Table 18

Test of Normality of the Standardized Residual

\begin{tabular}{lccc}
\hline & \multicolumn{3}{c}{ Kolmogorov-Smirnov $^{\mathrm{a}}$} \\
\cline { 2 - 4 } & Statistic & $d f$ & Sig. \\
\hline Standardized Residual & .023 & 434 & $.200^{*}$ \\
\hline
\end{tabular}

According to the histogram of the standardized residuals (Figure 6), the standardized residuals were normally distributed; three standard deviations above the mean and 3 standards deviations below the mean.

Figure 6. Histogram of the Standardized Residuals.

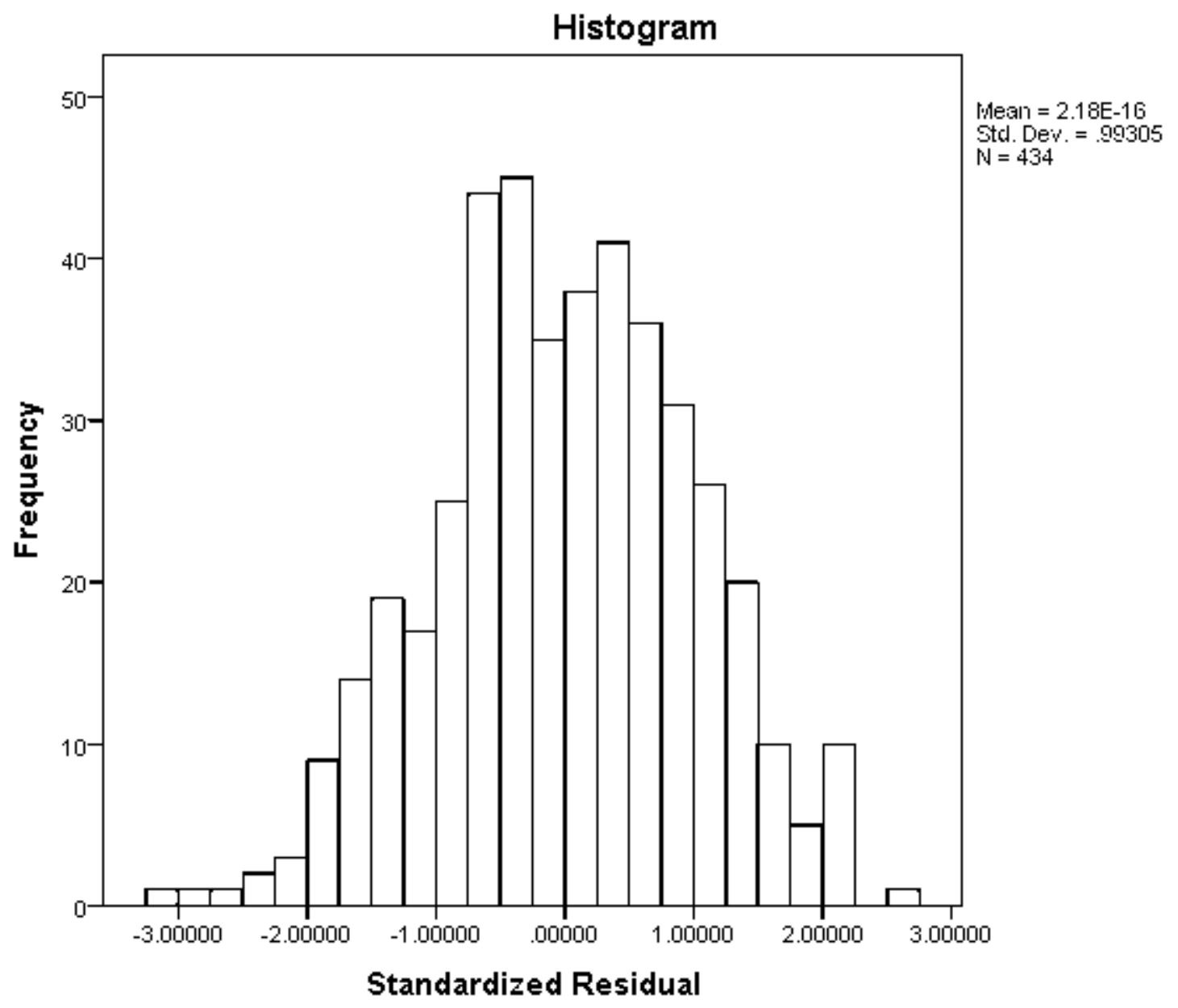

Figure 6. Histogram shows a normal distribution of the standardized residuals. 
According to the Q-Q plot of standardized residuals (Figure 7), the standardized residuals were normally distributed since almost all the dots are close to the line. That is the assumption of normality has been met.

Figure 7. Q-Q Plot of the Standardized Residuals.

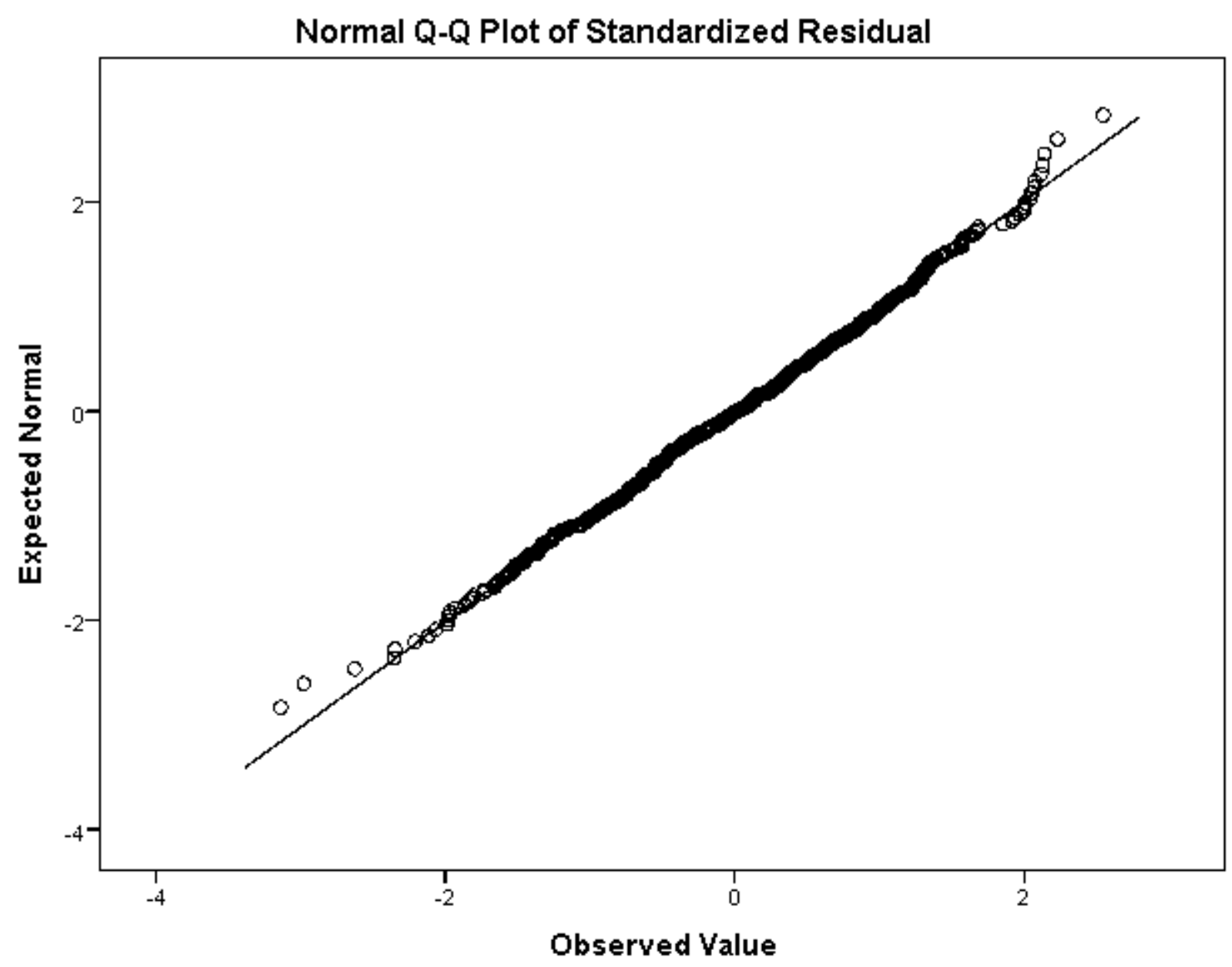

Figure 7. The Q-Q- plots show a normal distribution of the standardized residuals. 
Assumption of independence of observations. While there is no statistical test to check

for this assumption, it is assumed that each of the recorded responses belongs to a different individual. Therefore, the assumption of independence has been met.

The results of the regression assumptions that were checked for show that all of the regression assumptions have been met. However, generalization should be made with caution due to the existence of influential outliers with Mahalanobis value. 


\section{Chapter 5}

\section{Discussion, Conclusions, Limitations, Implications, and Recommendations}

The research questions of this study sought to understand science teachers 'attitudes toward nanotechnology and toward implementing it in science classrooms; detect the relationship between the influential subscale of attitude as was identified by the theory of planned behavior (TPB) and intention; and to determine the relationship between attitude and other influential factors (professional development, professional context, practice, research, and knowledge and selfconfidence) that could fall under the identified subscales of the TPB (subjective norms and perceived behavior control) on attitudes. This study was also conducted to identify real and perceived factors as barriers or inhibitors that contribute to the development of an individual's attitude. Finally, this study served to predict the facilitators that could ease the desired action of implementing nanotechnology in science classrooms. Study results were collected via administering an online survey to 4,986 participants and via conducting face-to-face and over-thephone interview to 13 participants, some of whom have had experiences with nanotechnology.

As was clarified by the TPB, overall individuals' attitudes influence intention, which in turn predicts their behavior. Identifying barriers explain the variance in individuals' attitudes, which in turn can be used to predict individuals' intention to conduct an actual behavior. Identifying these barriers suggest that the impact of these barriers is important as it hinders the implementation of a desired action; nanotechnology implementation in science classrooms. 


\section{Conclusions from the Research Questions}

Research question one a conclusion. In addressing the research question of what is the relationship between science teachers' attitudes toward nanotechnology and their intention of implementing it in science classrooms, the correlation analysis detected a significant positive but weak relationship between attitude and intention. This finding indicates that the overall relationship between attitudes and intention is important and that the attitudinal construct is one key factor that plays a significant role in shaping and understanding science teachers' intentions of implementing a desired behavior.

The positive relationship between the attitudes toward nanotechnology and its implementation in science classrooms and the intention of actually implementing indicates that as attitudes toward nanotechnology and its implementation in science classrooms increase, the intention of actually implementing it increases as well. Conversely, as attitudes toward nanotechnology decrease, the intention toward implementing it decreases. The weak association between science teachers' attitudes toward nanotechnology and its implementation in science classrooms and their intention of implementing it could be due to the lack of internal consistency among the survey items that constituted the attitudinal subscale as was indicated by Cronbach's alpha value of attitude $(\alpha=.65)$. In addition, the weak association between science teachers' attitudes toward nanotechnology and its implementation in science classrooms and their intention of implementing it could be as a result of considering the factor attitude as a latent construct where there are many other factors that are accounted for more variability than attitude and should be considered. This implies that the attitudes construct is not the strongest variable that is related to intention and there are other constructs that play a stronger influence on individual's intention than attitudes. Overall, the finding of the correlation between attitude and intention 
seems to support the predicted hypothesis as well as the TPB where attitudes serve as a significant construct to influence science teachers' intention of implementing nanotechnology in science classrooms and that should be considered before expecting or forcing teachers to implement a desired behavior, such as implementing nanotechnology in science classrooms.

Research question one b conclusion. In addressing the research question of in what ways do the other five factors (knowledge and self-confidence, professional context, professional development, research, and practice) associate to attitudes, the correlation results revealed significant correlations between attitude and each of the factors; knowledge and self-confidence, research, practice, professional context, and professional development. These findings conclude that the internal factor (knowledge and self-confidence) and the external factors (professional development opportunities, professional context, practice, and research) contribute to and influence individuals' attitude toward nanotechnology and about its implementation in science classrooms. Internal factors can be defined as inner factors that reflect individuals' ability, skill, and knowledge. These inner factors could reveal the strengths and weaknesses of an individual. They might be seen as strengths if they have a favorable influence on individual's attitude. However, they might be seen as weaknesses if they have negative impact on individual's attitude. External factors could be considered as the influence of things that motivate or justify the characteristic of the attribute or construct to be measured. Results indicate that knowledge and self-confidence as an internal factor enacted the highest influence that constitutes individuals' attitudes due to its high Cronbach's alpha value of .87, which indicates an internal consistency among items of the knowledge and self-confidence subscale.

This finding aligns with Cossons (1993) and Smith and Siegle (2004) who found that knowledge as a potent predictor of attitude. This implies that it is important to equip science 
teachers with the knowledge that is needed in order to trigger their acceptance and actual behavior of teaching and implementing nanotechnology in science classrooms. This can be done through involving science teachers and offering them with more nanotechnology-related professional development opportunities especially since the availability or lack of the professional development opportunities play as the second factor that has an important impact on individuals' attitudes. Offering nanotechnology-related professional development opportunities not only provide science teachers with knowledge but also with learning experiences. Such opportunities could include learning experiences with scientists or other expert teachers who have implemented nanotechnology lessons. Professional development opportunities could also provide teachers with educational materials that introduce them to nanotechnology-related concepts and lesson plans.

Correlation findings indicate that individual's research experience has the least impact on individual's attitude. This might be because of the low Cronbach's alpha value $(\alpha=.56)$, which indicates a low internal consistency of the items of the research subscale. In addition, low impact of research on individual's attitude concludes that prior research experiences during school or college years play a minimal impact on teachers' attitudes. It is expected that teachers' field/research experience through professional development opportunities will play more significant and influential effect in shaping their attitudes about implementing nanotechnology than their research experience during school or college years.

Research question two conclusion. In addressing the research question of what are the attitudes and perceptions of science teachers toward nanotechnology and implementing it in science classrooms, despite the scarcity of studies with respect to nanotechnology education, the results of this research question unfolded conflicted findings regarding nanotechnology as 
advantageous and disadvantageous technology. In addition, this research study revealed that several factors contribute to and impact individuals' attitudes: school, course, and students type; curriculum determinants; time constraints; cultural factors such as social influence or cooperation with others; resources; nanotechnology professional development opportunities; and nanotechnology knowledge and self-confidence were identified as factors. The internal factor (nanotechnology knowledge and self-confidence) and external factors (school, course, and students type; curriculum determinants; time constraints; cultural factors such as social influence or cooperation with others; resources; nanotechnology professional development opportunities) impact the identified subscale of attitudes, in the TPB, which are impacted by the two other identified subscales social norms and perceived behavior control in the same theory. These subscales aggregate and contribute to forming the overall individual's behavior.

These influential factors were consistent with the findings of Simpson et al. (1994) who found that same or similar factors were identified as inhibitors that impede or obstruct the behavior of implementing nanotechnology. Knowledge and perception of one's own confidence as was argued by Ajzen (1991) is an important factor in predicting individual's intention. These findings are in alignment with Buczynski and Hansen (2009) who argued that lack of knowledge and lack of self-efficacy result in an over disinterest in science, as an obstacle, that impede teachers from teaching new materials in their classrooms.

These qualitative results help to explain why some teachers have reservations and negative attitudes toward nanotechnology, introducing it to students, and incorporating it in science classrooms. Furthermore, it helps provide administrators, curriculum developers, educators, and government officials with some of the constraints that challenge science teachers, influence their belief system, and prevent them from implementing nanotechnology in science 
classrooms. One should be cognizant that these inhibitors can be considered as the underpinnings of the negative attitudes that are held by science teachers and impede the process of implementing nanotechnology in science classrooms.

Intriguingly, the qualitative results of this study were more inclusive than other studies as it included more detailed influential factors that were not shared by other studies. That is due to the nature of the research method that was conducted in order to reveal an answer to this research question. The qualitative approach that was conducted through interviewing participants helped with getting a deeper understanding of why teachers hold an attitude toward a targeted behavior of a given object. The study findings shed some light on the type and level of students who should be introduced to and taught nanotechnology. In addition, it refers to the social influence or cooperation with other individuals, researchers, universities or companies with nanotechnology programs in them.

Research question three conclusion. In addressing the question of what helps science teachers implement nanotechnology in science classrooms, qualitative results revealed that the existence of knowledge and self-confidence, availability of nanotechnology professional development opportunities, curriculum-related solutions, social support, and securing resources were identified as facilitators that would help with overcoming challenges and contribute to increasing individual's attitude toward nanotechnology and the intention of implementing it in science classrooms.

In order to triangulate data that is related to research question three that addresses the facilitators that may help science teachers with implementing nanotechnology in science classrooms as was collected through the STAT-N survey and semi-structure interview, quantitative approach was used. It revealed that all of the extracted factors (knowledge and 
self-confidence, practice, professional context, and professional development) but attitude and research experience were significant predictors of science teachers' intention to implement nanotechnology in science classrooms, $p<.05$. From a quantitative perspective, this study results identified that professional development was the predictor with the highest beta value $(\beta=.32)$. The study finding indicates that it is evident that professional development was the best predictor to predict intention. This means that professional development plays a pivotal role in individuals' intention to perform a desired behavior.

This finding is consistent with the qualitative data that was collected for this study which indicated that professional development is paramount for science teachers to get training and gain knowledge about nanotechnology. This finding contradicts Schifter and Ajzen (1985) as well as Haney et al. (1996) in their studies that found attitude was the best predictor of behavioral intention. However, it is consistent with Buczynski and Hansen (2009), National Research Council (1996), Schank et al. (2007) who recommended providing teachers with professional development opportunities amid current educational reforms. This is necessary for a successful educational reform with current topics such as nanotechnology. Similarly, participating in nanotechnology professional development agrees with Lan's study (2012) that revealed that participation in nanotechnology programs results in increasing knowledge, selfefficacy, and development of positive attitudes toward nanotechnology.

These quantitative findings are also confirmed by studies that were conducted by Czerniak et al. (1999), Haney et al. (1996), Koballa and Crawley (1985), and Schifter and Ajzen (1985). These studies revealed that attitude, subjective norms, and perceived behavior control are statistically significant predictors of science teachers' intent to implement new topics such as nanotechnology. 
The support from others as suggested by participants indicated that possessing the knowledge, positive attitude and self-efficacy alone is not enough to implement nanotechnology. Teachers must have the support and encouragement from people who matter to them, e.g., administrators, parents, community members, local businesses and industry representatives, etc. The insignificance of attitude and research as predictors could be referred to the lack of internal consistence of the survey statements that constitute both factors as was indicated by Cronbach's values, $\alpha=.65$ and $\alpha=.56$, of these two subscales, respectively. As was indicated above, the insignificance of attitude and research as predictors could also be referred to the nature of the term attitude as a latent construct, which could not be directly measured. The insignificance of research as a predictor on individual's intention could be because of participants' past research experience through high school and college years that did not include research experience that is directly related to nanotechnology. This could have changed if their high school and college years past research experience included research experience particularly related to nanotechnology. This would have likely turned research as a significant predictor of individual's intention toward implementing nanotechnology related content, materials, and activities in science classrooms.

\section{Limitations of the Study}

This research study was primarily limited due to the following reasons:

- The response rate of the survey was lower than expected. More contact between the researcher and the participants may have increased the participation rate by sending out more than one reminder email.

- This is an exploratory study and the generalizability of the findings to other groups should be done with caution and extensive analysis. 
- The validity and reliability of the survey imposed a limitation on the findings of this study because the survey instrument was developed by the researcher, and no pre-existing valid and reliable measures were available at the time of administering the survey. In an attempt to minimize this limitation, content and face validity was established through a procedure of expert validation and getting feedback from individuals who are science educators and science teachers.

- Categorization of the survey statements into different factors/subscales. Based upon the researchers rational, survey items were categorized to fit six scales; however, SPSS loaded survey items in a different way of the researcher.

- Researcher's subjectivity. One aspect of the subjectivity in this study pertains to the rotation options; varimax was chosen assuming that there is no relationship between factors. Another aspect of the researcher's subjectivity of this study is related to the alignment of survey items; survey items were categorized into different subscales based on the researcher's rational. The researcher's organization of survey items into different subscales differ from the SPSS loading of the different survey items into different subscales. Furthermore, researcher's subjectivity is also relevant to data interpretation, what was chosen to share, and to what the researcher felt as important to share relevant for this study. In general, researcher's perceptions of any experience are influenced by past experience; it is important to disclose that the researcher's past history that lacks being positioned as a science teacher in an actual classroom might influence the perceptions and the interpretations of the data in this study. The last aspect of the researcher's subjectivity in this study is related to researcher's bias toward nanotechnology and past research experience with science teachers. The researcher is an 
advocate of integrating the concept of nanotechnology in science classrooms and as a graduate research assistant, the researcher had the opportunity to meet and interview science teachers who had a nanotechnology research experience through the Teacher Research Experience for the advancement of Knowledge (TREK) program that was funded by the National Science Foundation (NSF). Researcher's past research experience with science teachers who were part of the NSF funded program aimed at identifying real and perceived barriers that would impede integrating nanotechnology-related content, materials, and activities in science classrooms. Having had the opportunity to interact with science teachers before conducting this study gave the researcher an idea to focus on and coding common challenges that were shared between and among science teachers.

- Since collection of data was limited to West Virginia, Pennsylvania, California, Illinois, and Texas, the generalization of the study results to other groups should be done only with caution and extensive analysis.

- Accuracy of attitudes is a limiting factor. Attitude is a latent construct and many factors could influence it.

- The theory of planned behavior (TPB) has its own limitations. It does not account for other variables that factor into behavioral intention, such as past experience, mood, knowledge, time, professional development, resources, etc. While it does consider normative influences, it still does not take into account environmental or economic factors that may influence a person's intention to perform a behavior. In addition, it does not address the timeframe between intention and behavior. TPB assumes that the person has obtained the opportunities and resources to perform the desired behavior regardless of the intention. 
- Inter-rater reliability was lacking because of the qualitative data analysis was only conducted by the researcher of this study. No one was involved in analyzing the data other than the researcher. More themes could merge out of the qualitative data if someone else other than the researcher was involved in analyzing the qualitative data.

- Additional open-ended questions could lead into richer qualitative results.

\section{Conclusion}

This dissertation study has demonstrated that there is a significant relationship between attitude and intention. In addition, there is a significant relationship between each of the other independent variables (knowledge and self-confidence, research, practice, professional context, and professional development) and attitude. This study also helped with identifying real and perceived factors that could be facilitators for its availability and inhibitors or barriers for its lack or absence. Finally, this study used regression analysis and showed that knowledge and selfconfidence, practice, professional development, and professional context are important predictors of an individual's intention. However, attitude and research were not important predictors of an individual's intention of performing a given behavior.

\section{Implications for Practice}

This study revealed many challenges that are facing science teachers and hinder the process of integrating nanotechnology in school education, such as lack of time, lack of instructional materials, lack of explicit connection to state science standards, etc. Despite these considerable challenges, it is possible to introduce and integrate the concept of nanotechnology and its related content, materials, and activities at the middle and high school levels. Introducing a cutting-edge subject can be used to engage students, give them a better idea of how science disciplines are linked together, prepare them to be educated and responsible generation for 
making scientifically literate decisions, and provide them with insights into job opportunities where the use of nanotechnology is prevalent.

With the numerous applications of nanotechnology in consumer products, cosmetics, electronic devices, self-cleaning toilets, medical and industrial applications, etc., there is a need to incorporate nanotechnology concepts in science curricula and teaching in order to prepare learners to understand the different aspects that are associated with this technology. This is an invitation for educators and curriculum designers to design an effective integrated nanotechnology curriculum and pedagogies to teach nanotechnology.

Introducing the concept of nanotechnology could be challenging at the conceptual and practical levels. Helping students to understand concepts at the nanoscale could be hard to conceptualize and visualize. However, introducing students to different scales could help prepare them to understand materials at the nano-scale level. Learning technologies, such as Atomic Force Microscopes (AFM), the Scanning Tunneling Microscopes (STM), or any other modeling scaling tools hold promise to help learners to develop a conceptual understanding of materials at the nanoscale as it helped scientists to visualize and manipulate materials at the nano-scale level. It helps students to come to understand how properties change as the size scale changes. At the practical level, introducing nanotechnology as part of nanoscience education motivates teachers and educators to explore new pedagogies of introducing nanotechnology.

A further implication of this study is that it helps researchers and educators in designing educational programs or in-service professional development especially since professional development is associated with attitudes and it was found to be the best predictor among others in predicting teachers' intention of implementing nanotechnology-related materials, content, and activities in science classrooms. Nanotechnology professional development should be designed 
to enhance or develop positive attitudes toward nanotechnology in order to enact the planned behavior of integrating nanotechnology-related content, materials, and activities in science classrooms. Researchers and educators can offer nanotechnology professional development to help middle and high school science teachers with to overcome challenges that impede the process of implementing nontechnology in science classrooms by providing science teachers with nanoscience educational materials, guidance on designing and integrating nanoscience activities that provide opportunities for critical thinking, provide nanoscience modules or lesson plans, modeling tools, pedagogical approaches to teach nanoscience, etc. Problem-based learning and inquiry learning tools, as it is emphasized in the NGSS, could be used as strategies to teach about nanotechnology as they develop critical thinking skills and help students transfer knowledge from across the STEM disciplines. Educational videos on nanoscience materials are another tool that could be used by science teachers to provide students with a background on nanomaterials.

In a literature review that was done by Ghattas and Carver (2012) with respect to integrating nanotechnology into school education, they offered a variety of school activities, such as stain testers, magic sand, antimicrobial agents, etc., that are related to nanotechnology and that could be facilitated at all educational levels; pre-school through graduate school (p-20).

The NGSS weave together three dimensions: disciplinary core ideas, science and engineering practices, and cross-cutting concepts. Though it is not specifically mentioned in the NGSS, nanotechnology is a suitable concept to be integrated in science curricula especially since the NGSS has a focus on integrating STEM curriculum that is grounded in cross-cutting concepts. Nanotechnology, as a cross cutting-concept, would be suited because of its real world relevance as it is emphasized in the NGSS. Integrating nanotechnology would inspire students to 
think differently about STEM and see the integration between STEM fields. It helps students to understand STEM concepts and apply them in different situations. Overall, integrating different subjects strengthens science learning for all students (NGSS, 2013).

As a controversial topic, nanotechnology has social implications. Nanotechnology has benefits as well as risks; it has many medical and industrial applications but it has societal impacts at it is a threat to the environment and health, although nanotechnology effects on environment and health are still uncertain. Introducing nanotechnology at the middle and high school levels is a good opportunity for students to construct explanation and gain experience debating current controversial issues that require scientific information and scientific ways for informed decision making about environmental implications of nanomaterial use in products; how to safely handle, dispose, and store nanomaterials. In order for nanotechnology to be part of science education, this requires collaboration between researchers and educators and all stakeholders, including policymakers and the federal government.

\section{Recommendations for Future Research}

As discussed in the previous section, this study was limited due to different factors. Some of the limitations of this study provoke additional future research to validate, and refine the survey instrument and the subscales used in this study. For example, Factor Analysis (FA) should be performed on all of the survey items to determine what subscales empirically exist among the items. There was only one survey item that is related to intention as the dependent variable in the survey of this study, future research could be conducted by adding more survey statements to form a subscale on intention instead of relying on only one survey statement to measure individual's intention toward a given behavior and that could be done in a similar fashion to what was done to other STAT-N survey subscales (professional development, 
professional context, research, practice, knowledge and self-confidence, and attitude). These new survey statements on intention can be part of the FA of the entire survey. After looking at the validated Attitudes Toward Handheld Computers Survey (ATHCS) that was done by Gado, Ferguson, and Van 'T Hooft (2006), three of the survey statements (5, 11, and 12) could be adapted after securing a permission for the use and included as part of the intention subscale in the STAT-N survey. In addition, since Cronbach's alpha value of the attitude subscale in STAT$\mathrm{N}$ was low, other ATHCS statements $(3,4,6,7$, and 8$)$ could be adapted and be part of the attitudinal subscale of the STAT-N survey. Further research to validate the STAT-N survey, modifying the research subscale statements should be considered especially with its low Cronbach's value $(\alpha=.56)$ or taking out all of the survey statements that are related to the research subscale in order to keep the STAT-N concise.

This study may also need a better, more inclusive, model or theory to understand and predict factors that contribute to an individual's attitudes toward a given object and intention toward implementing a desired behavior than the theory of planned behavior. The study results revealed factors that are influential on individual's intention beyond the three subscales of attitudes, subjective norms, and perceived behavior control that were identified by the theory of planned behavior.

Lastly, although data was triangulated in this study by collecting data through the STAT$\mathrm{N}$ survey and through the semi-structured interview, more data could be collected and triangulated from other sources, such as classroom observations, action research journals, administrator's interview, and even more personal interviews with more science teachers to illicit deeper rich information from different sources, perspectives, and attitudes other than what was shared by the middle and high science teachers who were part of this study. 


\section{References}

Abell, S. K., \& Lederman, N. (2010). Science teacher attitudes and beliefs. In G. M. Jones \& G. Carter (Eds.), Handbook of research on science education (pp. 1067-1104). New York, NY: Routledge.

Ajzen, I. (1991). The theory of planned behavior. Organizational Behavior and Human Decision Processes, 50(2), 179-211.

Ajzen, I. (2012). Martin Fishbein's legacy: The reasoned action approach. The ANNALS of the American Academy of Political and Social Science, 640(1), 11-27.

Ajzen, I., \& Fishbein, M. (1977). Attitude-behavior relations: A theoretical analysis and review of empirical research. Psychological Bulletin, 84(5), 888-918.

Anderson, J., Hollinger, D., \& Conaty, J. (1992, April). Poverty and achievement: Re-examining the relationship between school poverty and student achievement: An examination of eighth grade student achievement using the National Education Longitudinal Study of 1988. Paper presented at the annual meeting of the American Educational Research Association, San Francisco, CA.

Atwater, M. M. (1994). Research on cultural diversity in the classroom. In D. L. Gabel (Ed.), Handbook of research on Science teaching and learning (pp. 558-576). New York: Macmillan Publishing Company.

Bandura, A. (1977). Self-efficacy: Toward a unifying theory of behavioral change. Psychological Review, 84(2), 191-215.

Bandura, A. (1982). Self-efficacy mechanism in human agency. American Psychologist, 37, 122147. 
Bennett, I, \& Daniel, S. (2006). Too little, too late? Research policies on the societal implications of nanotechnology in the United States. Science as Culture 15(4), 309-25.

Blonder, R. (2010). The influence of a teaching model in nanotechnology on chemistry teachers' knowledge and their teaching attitudes. Journal of Nano Education, 2(1-2), 67-75.

Bowles, A. (2004). Teaching nanotechnology in the high school curriculum: A teacher's guide. Retrieved from http://www.tntg.org/documents/Teaching\%20Nanotechnology $\% 20 \mathrm{in} \% 20$ the $\% 20 \mathrm{High} \% 2$ 0School\%20Curriculum.pdf

Buczynski, S., \& Hansen, C. B. (2010). Impact of professional development on teacher practice: Uncovering connections. Teaching and Teacher Education, 26(3), 599-607.

Business Roundtable, Taking Action on Education and Workforce Preparedness. (2013). Report of the Business Roundtable, Taking Action on Education and Workforce Preparedness. Retrieved from http://businessroundtable.org/resources/taking-action-on-educationworkforce-preparedness

Carnevale, A. P., Smith, N., \& Strohl, J. (2013). Recovery: Job Growth and Education Requirements through 2020. Georgetown Public Policy Institute, Center on Education and the Workforce. Retrieved from http://cew.georgetown.edu/recovery2020

Cavanagh, S. (2009). Nanotechnology slips into schools. Education Week, 28(27), 1. Retrieved from http://www.lexisnexis.com.www.libproxy.wvu.edu/hottopics/lnacademic

Corbin, J., \& Strauss, A. (1990). Grounded theory research: Procedures, canons, and evaluative criteria. Qualitative Sociology, 13(1), 3-21.

Chiappetta, E. L., \& Koballa, T. R., Jr. (2010). Science instruction in the middle and secondary schools $\left(7^{\text {th }}\right.$ ed.). Boston: Allyn and Bacon. 
Clunan, A., Rodine-Hardy, K., Hsueh, R., Kosal, M., \& McManus, I. (2014). Nanotechnology in a globalized world: Strategic assessments of an emerging technology. Project on Advanced Systems and Concepts for Countering WMD (PASCC Report No. 2014 006). Retrieved from http://www.nps.edu/Academics/Centers/CCC/PASCC/Publications/2014/2014\%20006\% 20Nanotechnology $\% 20$ Strategic $\% 20$ Assessments.pdf

Cossons, N. (1993). Let us take science into our culture. International Science Reviews, 18(4), $337-342$.

Crotty, M. (1998). The foundation of social research: Meaning and perspective in the research process. Thousand Oaks, CA: Sage.

Czerniak, C. M., Lumpe, A. T., \& Haney, J. J. (1999). Science teachers' beliefs and intentions to implement thematic units. Journal of Science Teacher Education, 10(2), 123-145.

Chang, R. P. H. (2006). A call for nanoscience education. Nano Today, 1(2), 6-7. doi:10.1016/S1748-0132(06)70028-7.

Cheung, D. (2009). Students' attitudes toward chemistry lessons: The interaction effect between grade level and gender. Research in Science Education, 39, 75-91.

Crawley, F. E., III. (1990). Intentions of science teachers to use investigative teaching methods: A test of the theory of planned behavior. Journal of Research in Science Teaching, 27(7), 685-97.

Ernst, J. V. (2009). Nanotechnology education: Contemporary content and approaches. Journal of Technology Studies, 35(1), 3-8.

Fang, Z. (1996). A review of research on teacher beliefs and practices. Educational Research,38(1), 47-65. doi:10.1080/0013188960380104 
Fanfair, D., Desai, S., \& Kelty, C. (2005). The early history of nanotechnology. The Connexions Project. Retrieved from http://cnx.org/content/m14504/latest/

Feynman, R. P. (1960). There's plenty of room at the bottom. Engineering and Science, 22-36. Retrieved from http://calteches.library.caltech.edu/1976/1/1960Bottom.pdf

Field, A. (2009). Discovering statistics using SPSS. ( $3^{\text {rd }}$ ed.). Thousand Oaks, CA: Sage Publications, Inc.

Fishbein, M. (1967). A consideration of beliefs and their role in attitude measurement. In M. Fishbein (Ed.), Readings in attitude theory and measurement (pp. 257-266). London: John Wiley \& Sons, Inc.

Foley, E. T., \& Hersam, M. C. (2006). Assessing the need for nanotechnology education reform in the United States. Nanotechnology Law and Business, 3, 467.

Fonash, S. J. (2001). Education and training of the nanotechnology workforce. Journal of Nanoparticle Research, 3, 79-82.

Gado, I., Ferguson, R., \& Van 'T Hooft, M. (2006). Using handheld-computers and probe ware in a science methods course: Preservice teachers' attitudes and self-efficacy. Journal of Technology \& Teacher Education, 14(3), 501-529.

Gardner, G., \& Jones, G. (2009). Bacteria buster: Testing antibiotic properties of silver nanoparticles. American Biology Teacher, 71(4), 231-234. Retrieved from http://www.jstor.org/stable/27669416

Gardner, G., Jones, G., \& Falvo, M. (2009). New science and societal issues. Science Teacher, 76(7), 49-53. 
Gardner, G., Jones, G., Taylor, A., Forrester, J., \& Robertson, L. (2010). Students' risk perceptions of nanotechnology applications: Implications for science education. International Journal of Science Education, 32(14), 1951-1969.

George, D., \& Mallery, P. (2003). SPSS for Windows step by step: A simple guide and reference. 11.0 update $\left(4^{\text {th }}\right.$ ed.). Boston: Allyn \& Bacon.

Ghattas, N. I., \& Carver, J. S. (2012). Integrating nanotechnology into school education: A review of the literature. Research in Science \& Technological Education, 30(3), 271-284.

Goodhew, P. (2006). Education moves to a new scale. Nano Today, 1(2), 40-43. doi:10.1016/S1748-0132(06)70047-0.

Greenberg, A. (2009). Integrating nanoscience into the classroom: Perspectives on nanoscience education projects. ACS Nano, 3(4), 762-769.

Haney, J. J., Czerniak, C., \& Lumpe, A. T. (1996). Teacher beliefs and intentions regarding the implementation of science education reform strands. Journal of Research in Science Teaching, 33, 971-993.

Haney, J. J., \& Lumpe, A. T. (1995). A teacher professional development framework guided by science education reform policies, teachers' needs, and research. Journal of Science Teacher Education, 6, 187-196.

Henderson, M. E., Morris, L. L., \& Fitz-Gibbon, C. T. (1987). How to measure attitudes. New York: Sage Publications.

Hingant, B., \& Albe, V. (2010). Nanoscience and nanotechnologies learning and teaching in secondary education: A review of literature. Studies in Science Education, 46(42), 121152. 
Jones, M. G., Blonder, R., Gardner, G. E., Albe, V., Falvo, M., \& Chevrier, J. (2013).

Nanotechnology and nanoscale science: Educational challenges. International Journal of Science Education, 35(9), 1490-1512.

Keys, C. W., \& Bryan, L. A. (2001). Co-constructing inquiry-based science with teachers: Essential research for lasting reform. Journal of Research in Science Teaching, 38(6), 631-645.

Koballa, T. R., \& Crawley, F. E. (1985). The influence of attitude on science teaching and learning. School Science and Mathematics, 85(3), 222-232.

Kurzweil, R. (2007). On the national agenda: U.S. congressional testimony on the societal implications of nanotechnology. In F. Allhoff, P. Lin, J. Moor, \& J. Weckert (Eds.), Nanoethics: The ethical and social implications of nanotechnology (pp. 40-56). Hoboken, NJ: John Wiley \& Sons, Inc.

Lakhtakia, A. (2006). Priming pre-university education for nanotechnology. Current Science, $90(1), 37-40$.

Lan, Y.-L. (2012). Development of an attitude scale to assess K-12 teachers' attitudes toward nanotechnology. International Journal of Science Education, 34(8), 1189-1210.

Lane, N., \& Kalil, T. (2007). In the beginning: The U.S. national nanotechnology initiative. In F. Allhoff, P. Lin, J. Moor, \& J. Weckert. (Eds.), Nanoethics: The ethical and social implications of nanotechnology (pp. 40-56). Hoboken, NJ: John Wiley \& Sons, Inc.

Lee, C.-K., Wu, T.-T., Liu, P.-L., \& Hsu, S. (2006). Establishing a K-12 nanotechnology program for professional development. IEEE Transactions on Education, 49(1), 141-146. 
Lee, C. K., Wu, M. K., \& Yang, J. C. (2002). A catalyst to change everything MEMS/NEMS-A paradigm of Taiwan's nanotechnology program. Journal of Nanoparticle Research, 4, $377-386$.

Lin, P., \& Allhoff, F. (2007). Nanoscience and nanoethics: Defining the disciplines. In F. Allhoff, P. Lin, J. Moor, \& J. Weckert. (Eds.), Nanoethics: The ethical and social implications of nanotechnology (pp. 3-16). Hoboken, NJ: John Wiley \& Sons, Inc.

Lumpe, A. T., Haney, J. J., \& Czerniak, C. M. (2000). Assessing teachers' beliefs about their science teaching context. Journal of Research in Science Teaching, 37, 275 292.

Lux Research. (2015). Nanotechnology update: Corporations up their spending as revenues for nano-enabled products increase. Retrieved from https://portal.luxresearchinc.com/research/report excerpt/16215

Milner, A. R., Sondergeld, T. A., Demir, A., Johnson, C. C., \& Czerniak, C. M. (2012). Elementary teachers' beliefs about teaching science and classroom practice: An examination of pre/post NCLB testing in science. Journal of Science Teacher Education, 23(2), 111-132.

Mintzes, J., Marcum, B., Messerschmidt-Yates, C., \& Mark, A. (2013). Enhancing self-efficacy in elementary science teaching with professional learning communities. Journal of Science Teacher Association, 24, 1201-1218.

Murdy, J. (2009). Partnership for nanotechnology education. NSF Workshop report under NSF reward EEC, Vol. 805207. Retrieved from http://www.nsf.gov/crssprgm/nano/reports/educ09_murdyworkshop.pdf 
National Nanotechnology Initiative Strategic Plan. (2011). National nanotechnology initiative strategic plan. Retrieved from http://www.nano.gov/sites/default/files/pub_resource/2011_strategic_plan.pdf

National Research Council (NRC). (1996). National science education standards. Washington, DC: National Academies Press.

National Research Council (NRC). (2012). A framework for K-12 science education: Practices, crosscutting concepts, and core ideas. Retrieved from http://www.nap.edu/catalog.php?record_id=13165\#

National Science Board (NSB). (2012). Science and engineering indicators 2012. NSB 12-01. Arlington, VA: National Science Foundation. Retrieved from http://www.nsf.gov/statistics/seind12/

National Science Board. (2014). Science and engineering indicators 2014. NSB 14-01. Arlington, VA: National Science Foundation. Retrieved from http://www.nsf.gov/statistics/seind14/index.cfm/chapter-2/c2s2.htm

Next Generation Science Standards (NGSS) Lead States. (2013). Next Generation Science Standards: For States, By States. Washington, DC: The National Academies Press. National Nanotechnology Infrastructure Network (NNIN). (2014a). Nanotechnology classroom activities and curriculum materials. Retrieved from http://www.nnin.org/educationtraining/k-12-teachers/nanotechnology-curriculum-materials

National Nanotechnology Infrastructure Network (NNIN). (2014b). Nanotechnology in curriculum: Nanotechnology and the national science education standards. Retrieved from http:/www.nnin.org/education-training/k-12-teachers/nanotechnology-curriculum Novak, J. (2010). Learning, creating and using knowledge (LCUK). (2nd ed.). NY: Routledge. 
Osborne, J., Simon, S., \& Collins, S. (2003). Attitudes towards science: A review of the literature and its implications. International Journal of Science Education, 25(9), 1049-1079.

Organization for Economic Co-Operation and Development (OECD). (1999). Measuring student knowledge and skills: A new framework for assessment. Retrieved from http://www.oecd.org/edu/school/programmeforinternationalstudentassessmentpisa/33693 997.pdf

Pajares, F. (1992). Teachers' beliefs and educational research: Cleaning up a messy construct. Review of Educational Research, 307-332.

Pardo, R., Midden, C., \& Miller, J. D. (2002). Attitudes toward biotechnology in the European Union. Journal of Biotechnology, 98, 9-24.

Peterson, C., \& Heller, J. (2007). Nanotech's promise: Overcoming humanity's most pressing challenges. In F. Allhoff, P. Lin, J. Moor, \& J. Weckert (Eds.), Nanoethics: The ethical and social implications of nanotechnology (pp. 57-70). Hoboken, NJ: John Wiley \& Sons, Inc.

Ringer, M. (2014). Toward integrating nanotechnology in the K-12 science curriculum: A note of hope in the State of the Union. International Journal of Theoretical and Applied Nanotechnology Journal, 2, 1229-1248.

Roco, M. C. (2003a). Broader societal issues of nanotechnology. Journal of Nanoparticle Research, 5, 181-189.

Roco, M. C. (2003b). Converging science and technology at the nanoscale: opportunities for education and training. Nature Biotechnology, 21(10), 1247-1249.

Roco, M. C. (2011). The long view of nanotechnology development: The national nanotechnology initiative at 10 years. Journal of Nanoparticle Research, 13, 427-445. 
Roco, M. C., \& Bainbridge, W. S. (2005). Societal implications of nanoscience and nanotechnology: Maximizing human benefit. Journal of Nanoparticle Research, 7, 1-13.

Roco, M. C., Mirkin, C. A., \& Hersam, M. C. (2010). Nanotechnology research directions for societal needs in 2020: Retrospective and outlook. WTEC Panel Report. Retrieved from http://www.wtec.org/Nano Research Directions to 2020.pdf

Sapsford, R. (2007). Survey research. ( $2^{\text {nd }}$ ed.). Thousand Oaks, CA: Sage Publications, Inc.

Schank, P., Krajcik, J., \& Yunker, M. (2007). Can nanoscience be a catalyst for educational reform? In F. Allhoff, P. Lin, J. Moor, \& J. Weckert (Eds.), Nanoethics: The ethical and social implications of nanotechnology (pp. 277-290). Hoboken, NJ: John Wiley \& Sons, Inc.

Schifter, D. E., \& Ajzen, I. (1985). Intention, perceived, and weight loss: An application of the theory of planned behavior. Journal of Personality and Social Psychology, 49(3), 843851.

Simpson, R. D., Koballa, T. R., Oliver, J. S., \& Crawley, F. E. (1994). Research on the affective dimension of science learning. In D. L. Gabel (Ed.), Handbook of research on science teaching and learning (pp. 211-234). NY: Macmillan Publishing Company.

Smith, M. U., \& Siegel, H. (2004). Knowing, believing, and understanding: What goals for science education? Science and Education, 13, 553-582.

Stein, M. K., Smith, M. S., \& Silver, E. A. (1999). The development of professional developers learning to assist teachers in new settings in new ways. Harvard Educational Review, 69, $111-126$.

Sweeney, A. E. (2006). Social and ethical dimensions of nanoscale science and engineering research. Science \& Engineering Ethics, 12(3), 435-464. 
Taylor, A., Jones, G., \& Pearl, T. P. (2008). Bumpy, sticky, and shaky: Nanoscale science and the curriculum. Science Scope, 31(7), 28-35.

Telford, M. (2004). Building a nano workforce from the bottom up: Education. Materials Today, 718. doi:10.1016/S1369-7021(04)00625-X.

The Royal Academy of Engineering \& the Royal Society. (2004). Nanoscience and nanotechnology: Opportunities and uncertainties. Retrieved from http://www.nanotec.org.uk/finalReport.htm

van Aalderen-Smeets, S. T., Walma, van der Molen, J. H., \& Asma, L. J. F. (2012). Primary teachers' attitudes toward science: A new theoretical framework. Science Education, 96(1), 158-182.

Wesely, P. (2012). Learner attitudes, perceptions, and beliefs in language learning. Foreign Language Annals, 45(1), 98-117.

Xie, Y., \& Achen, A. (2009). Science on the decline? Educational outcomes of three cohorts of young Americans. Population Studies Center Research Report 09-684.

Yore, L. (1991). Secondary science teachers' attitudes towards and beliefs about science reading and science textbooks. Journal of Research in Science Teaching, 28(1), 55-72.

Zimmerman, B. J. (2000). Self-efficacy: An essential motive to learn. Contemporary Educational Psychology, 25, 82-91. 
Appendices 


\section{Appendix A}

\section{Securing Copyright Permission}

Confirmation Number: 11327586 Order Date: 03/27/2015

Print this page Customer Information

Customer: Nadira Ghattas Account Number: 3000903303 Organization: Nadira Ghattas Email: nissa@mix.wvu.edu Phone: +1 (703)5686739 Payment Method: Invoice

Organizational behavior and human decision processes

Order detail ID: 66583701

- ISSN: 0749-5978

- Publication Type: Journal

- Volume:

- Issue:

- Start page:

- Publisher: ACADEMIC PRESS

- Permission Status: Granted

- Permission type: Republish or display content

- Type of use: Thesis/Dissertation

Order License Id:

Requestor type

Format

Portion

Number of charts/graphs/tables/figures

Title or numeric reference of the portion(s)

Title of the article or chapter the portion is

from

Editor of portion(s)

Author of portion(s)

Volume of serial or monograph

Issue, if republishing an article from a

serial

Page range of portion

Publication date of portion

Rights for

Duration of use

Creation of copies for the disabled

With minor editing privileges

For distribution to

In the following language(s)

With incidental promotional use

Lifetime unit quantity of new product

Made available in the following markets

The requesting person/organization

Order reference number

Author/Editor

The standard identifier

Title

Publisher

Expected publication date

Estimated size (pages)
3597181041222

Academic institution

Print, Electronic

chart/graph/table/figure

1

Figure 1, p. 182

Theory of Planned Behavior

Icek Ajzen

Icek Ajzen

50

2

182

1991

Main product

Life of current edition

no

no

Worldwide

Original language of publication

no

Up to 9,999

education

Nadira Ghattas/West Virginia University

Icek Ajzen

$\mathrm{XXXXXXXX}$

The theory of planned behavior

West Virginia University

Aug 2015

200 


\section{Appendix B}

Science Teachers' Attitudes toward Nanotechnology (STAT-N) Survey

General Information

What is your gender?

O Male

O Female

Other

What science courses did you take when you were in high school? Please check all that apply.

$\square$ Chemistry

$\square$ Biology

$\square$ Physics

$\square$ Coordinated science I

a Coordinated science II

$\square$ Physical science

a Anatomy

D AP physics

a AP chemistry

$\square$ AP biology

$\square$ Other

What science courses have you taken in college? Please check all that apply.
$\square$ Chemistry
$\square$ Biology
$\square$ Physics
$\square$ Anatomy
$\square$ Astronomy
$\square$ Geology

$\square$ Other 
What is your undergraduate major area of study?

Chemistry

Biology

O Physics

A Astronomy

O Geology

Science education

Other

In what science area(s) are you certified to teach? Please check all that apply.

$\square$ Chemistry

$\square$ Biology

$\square$ Physics

$\square$ General science

$\square$ Other

How long have you been teaching?

O 0 -5 years

6-11 years

- 12-17 years

- 18-23 years

O 23-28 years

Greater than 28 years

Are you a middle or high school science teacher?

Middle school science teacher

High school science teacher

What grades do you teach?

What subjects do you teach? 
Have you taken course(s) with nanotechnology-related topic during your middle school, high school, undergraduate, or graduate studies?

O Yes

O No

Based on a 5-point Likert scale $(1=$ Strongly Disagree, $2=$ Disagree, $3=$ Neither Agree nor

Disagree, $4=$ Agree, and $5=$ Strongly Agree), please, respond to the following statements:

\begin{tabular}{|c|c|c|c|c|c|}
\hline Statement & $\begin{array}{c}\text { Strongly } \\
\text { Disagree (1) }\end{array}$ & $\begin{array}{l}\text { Disagree } \\
\text { (2) }\end{array}$ & $\begin{array}{l}\text { Neither } \\
\text { Agree nor } \\
\text { Disagree } \\
\text { (3) }\end{array}$ & $\begin{array}{l}\text { Agree } \\
(4)\end{array}$ & $\begin{array}{l}\text { Strongly } \\
\text { Agree (5) }\end{array}$ \\
\hline $\begin{array}{l}\text { 1-I am familiar with the concept } \\
\text { of nanotechnology. }\end{array}$ & 0 & O & O & 0 & 0 \\
\hline $\begin{array}{l}\text { 2-I am knowledgeable about } \\
\text { nanotechnology. }\end{array}$ & 0 & 0 & 0 & 0 & 0 \\
\hline $\begin{array}{l}\text { 3-Science courses in which I } \\
\text { have enrolled during my } \\
\text { undergraduate or graduate } \\
\text { studies, have helped me to learn } \\
\text { about nanotechnology-related } \\
\text { concepts. }\end{array}$ & 0 & 0 & 0 & 0 & 0 \\
\hline $\begin{array}{l}\text { 4-I have increased my } \\
\text { knowledge about } \\
\text { nanotechnology through } \\
\text { educational opportunities such } \\
\text { as professional development, } \\
\text { workshops, museums, etc. }\end{array}$ & 0 & 0 & O & 0 & 0 \\
\hline $\begin{array}{l}\text { 5-Nanotechnology is inherently } \\
\text { dangerous. }\end{array}$ & 0 & 0 & 0 & 0 & 0 \\
\hline $\begin{array}{l}\text { 6-Nanotechnology helps with } \\
\text { the nation's economic growth } \\
\text { and competitiveness. }\end{array}$ & 0 & 0 & 0 & 0 & 0 \\
\hline $\begin{array}{l}\text { 7-Students should learn about } \\
\text { nanotechnology in science } \\
\text { classrooms. }\end{array}$ & 0 & 0 & 0 & 0 & 0 \\
\hline $\begin{array}{l}\text { 8-I am confident about teaching } \\
\text { nanotechnology-related content } \\
\text { in my science classroom. }\end{array}$ & 0 & 0 & 0 & 0 & 0 \\
\hline
\end{tabular}




\begin{tabular}{|c|c|c|c|c|c|}
\hline $\begin{array}{l}\text { 9-I intend to integrate } \\
\text { nanotechnology-related content, } \\
\text { activities, and materials in my } \\
\text { science classroom within the } \\
\text { next one or two years. }\end{array}$ & 0 & 0 & 0 & 0 & 0 \\
\hline $\begin{array}{l}\text { 10-Professional development } \\
\text { opportunities on } \\
\text { nanotechnology education } \\
\text { should be promoted for science } \\
\text { teachers at the middle and high } \\
\text { school levels. }\end{array}$ & 0 & 0 & 0 & 0 & 0 \\
\hline $\begin{array}{l}\text { 11-Science teachers should } \\
\text { attend professional development } \\
\text { workshops on advanced } \\
\text { technology, such as } \\
\text { nanotechnology. }\end{array}$ & 0 & 0 & 0 & 0 & 0 \\
\hline $\begin{array}{l}\text { 12-I intend to attend } \\
\text { professional development } \\
\text { workshops on nanotechnology } \\
\text { to learn about nanotechnology } \\
\text { in the near future. }\end{array}$ & 0 & 0 & 0 & 0 & 0 \\
\hline $\begin{array}{l}\text { 13-My school administration is } \\
\text { supportive of integrating } \\
\text { nanotechnology-related content, } \\
\text { activities, and/ or materials in } \\
\text { science classrooms. }\end{array}$ & 0 & 0 & 0 & 0 & 0 \\
\hline $\begin{array}{l}\text { 14-My science teacher } \\
\text { colleagues at my school are } \\
\text { advocates of integrating } \\
\text { nanotechnology-related content } \\
\text { and activities, and/ or materials. }\end{array}$ & 0 & 0 & 0 & 0 & 0 \\
\hline $\begin{array}{l}\text { 15-My state science standards } \\
\text { include content standards } \\
\text { related to nanotechnology. }\end{array}$ & 0 & 0 & 0 & 0 & 0 \\
\hline $\begin{array}{l}\text { 16-My state science standards } \\
\text { allow me to include } \\
\text { nanotechnology-related content, } \\
\text { activities, and/ or materials in } \\
\text { my science classroom. }\end{array}$ & 0 & 0 & 0 & 0 & 0 \\
\hline $\begin{array}{l}\text { 17-Nanotechnology content, } \\
\text { activities and materials are } \\
\text { already integrated into my } \\
\text { curriculum. }\end{array}$ & 0 & 0 & 0 & 0 & 0 \\
\hline
\end{tabular}




\begin{tabular}{|c|c|c|c|c|c|}
\hline $\begin{array}{l}\text { 18-My students are allowed to } \\
\text { explore nanotechnology-related } \\
\text { projects or problems in my } \\
\text { science classroom. }\end{array}$ & 0 & 0 & 0 & 0 & 0 \\
\hline $\begin{array}{l}\text { 19-It is important for science } \\
\text { teachers to talk to their school } \\
\text { administration about the } \\
\text { importance of integrating the } \\
\text { topic of nanotechnology as part } \\
\text { of science curricula. }\end{array}$ & 0 & 0 & 0 & 0 & 0 \\
\hline $\begin{array}{l}\text { 20-Science teachers should talk } \\
\text { to their students about new } \\
\text { scientific and technological } \\
\text { discoveries and developments, } \\
\text { such as nanotechnology. }\end{array}$ & 0 & 0 & 0 & 0 & 0 \\
\hline $\begin{array}{l}\text { 21-My undergraduate or } \\
\text { graduate education included } \\
\text { significant research experiences } \\
\text { in science (e.g., undergraduate } \\
\text { research in chemistry, Master's } \\
\text { thesis in physics, biological } \\
\text { field study, etc.). }\end{array}$ & 0 & 0 & 0 & 0 & 0 \\
\hline $\begin{array}{l}\text { 22-I engage my students in } \\
\text { conducting scientific inquiry in } \\
\text { my science classroom or lab. }\end{array}$ & 0 & 0 & 0 & 0 & 0 \\
\hline $\begin{array}{l}\text { 23-Opportunities are available } \\
\text { for me to engage in scientific } \\
\text { research experience (s) (e.g., } \\
\text { summer research experience, } \\
\text { evening research at a local } \\
\text { university, etc.). }\end{array}$ & 0 & 0 & 0 & 0 & 0 \\
\hline $\begin{array}{l}\text { 24-Opportunities are available } \\
\text { for me to engage in } \\
\text { nanotechnology-related } \\
\text { research experience (e.g., } \\
\text { summer research experience. } \\
\text { etc). }\end{array}$ & 0 & 0 & 0 & 0 & 0 \\
\hline
\end{tabular}




\section{Appendix $C$}

\section{Semi-structured Interview Protocol}

1. Tell me about your familiarity with nanotechnology?

2. How would you describe the level of your knowledge about nanotechnology?

3. Describe your thoughts about nanotechnology as an advanced technology in our society?

4. Of what value to you is implementing nanotechnology in science classrooms?

a. What do you see to be advantages of implementing nanotechnology in science classrooms?

b. What do you see to be disadvantages of implementing nanotechnology in science classrooms?

5. Describe your own ability about teaching nanotechnology in science classrooms?

a. What do you think about your own confidence in teaching about nanotechnology in science classrooms?

6. What would influence your decision to implement nanotechnology in science classrooms?

7. What would you need to feel supported in teaching about nanotechnology or if you decided to integrate nanotechnology in your science classroom? (e.g., materials, support, PD training, standards, etc.)

8. What are some of the challenges that would face you and make you unable to teach about nanotechnology in science classrooms?

9. What suggestions do you have for overcoming some of these challenges in order to integrate nanotechnology in science classrooms?

10. Tell me about your plan/intention of implementing nanotechnology in your science classroom in the next year or next two years?

11. What other things that you would like to add about implementing nanotechnology in science classrooms? 


\section{Appendix D}

\section{STAT-N Invitation Email}

Dear middle/high school science teacher,

This email is a request for you to take part in a dissertation research study to measure science teachers' attitudes toward nanotechnology and intention of implementing it in science classrooms. Your participation in this research study is greatly appreciated. Because I know your time is valuable, the time I'm asking for your assistance is minimal. It will take approximately $\mathbf{5 - 1 0}$ minutes to fill out a questionnaire that will be available to you via the link that is provided below.

Your involvement in this study will be kept as confidential as legally as possible. All data will be reported anonymously. I will not ask any information that should lead back to your identity as a participant. You must be 18 years of age or older to participate. Your participation is completely voluntary. You may skip any question that you do not wish to answer and you may discontinue at any time. Your job or class status, if applicable, will not be affected if you decide either not to participate or to withdraw. West Virginia University's Institutional Review Board acknowledgement of this study is on file.

\section{Please click on the following link to access the Science Teachers' Attitudes toward Nanotechnology (STAT-N) survey:}

\section{https://wvuhre.az1.qualtrics.com/SE/?SID=SV_6hzdqDfmnRfVQSp}

I hope that you will participate in this research study, as it could be beneficial in understanding the attitudes of science teachers towards nanotechnology before enforcing or even expecting them teaching that subject in schools as part of science curricula. It also helps with providing effective professional training, preparation, and support for science teachers.

Thank you! Please see the attached cover letter and if you have any questions about this letter or the research study, please feel free to contact Nadira Ghattas at (703) 568-6739 or by e-mail at nissa@mix.wvu.edu or Jeffrey S. Carver at (304) 293-3841 or by email at jeffrey.carver@mail.wvu.edu.

Thank you so much for your time and help with this study.

Sincerely,

Nadira Ghattas

(703) 568-6739

nissa@mix.wvu.edu
Jeffrey S. Carver 609-E Allen Hall

P.O. BOX 6122

Morgantown, WV 26506

(304) 293-3841

jeffrey.carver@mail.wvu.edu 
Appendix E

STAT-N Survey Cover Letter

Dear participant,

This letter is a request for you to take part in a research study to measure science teachers' attitudes toward nanotechnology and intention to implement its related content, activities, and materials in science classrooms. This research study is being conducted by Nadira Ghattas, Doctoral Student in Curriculum and Instruction with an emphasis in Science Education at WVU with supervision of Dr. Jeffrey S. Carver, Ed.D., an associate professor in the College of Education and Human Services, for a pilot study for my dissertation. Your participation in this research study is greatly appreciated. It will take approximately 5-10 minutes to fill out a questionnaire that will be available to you online to complete. I will be the only person with access to your responses.

Your involvement in this study will be kept as confidential as legally as possible. You must be 18 years of age or older to participate. All data will be reported anonymously. I will not ask any information that should lead back to your identity as a participant. Your participation is completely voluntary. You may skip any question that you do not wish to answer and you may discontinue at any time. Your job or class status, if applicable, will not be affected if you decide either not to participate or to withdraw. West Virginia University's Institutional Review Board acknowledgement of this study is on file.

I hope that you will participate in this research study, as it could be beneficial in understanding science teachers' attitudes towards nanotechnology and intention to implement it before enforcing or even expecting them teaching that subject in schools as part of science curricula. It also helps with providing effective professional training, preparation, and support for science teachers. If you would like to participate, please click on the link provided in the email in which you received this letter. If at any time you choose to be withdrawn from the study contact Nadira Ghattas at (703) 568-6739 or by e-mail at nissa@mix.wvu.edu or Jeffrey S. Carver at (304) 293-3841 or by email at jeffrey.carver@mail.wvu.edu.

Upon the completion of this dissertation research study, you will have the opportunity to request a free copy of the results so that you may benefit from the findings.

Thank you for your time and help with this study.

Sincerely,

Nadira Ghattas

(703) 568-6739

nissa@mix.wvu.edu
Jeffrey S. Carver

604-K Allen Hall

P.O. BOX 6122

Morgantown, WV 26506

(304) 293-3841

jeffrey.carver@mail.wvu.edu 


\author{
Appendix $F$ \\ Interview Recruitment Survey \\ Semi-Structured Interview on Science Teachers' Attitudes toward Nanotechnology and \\ Implementing it in Science Classrooms
}

Attachment: Interview cover letter

Dear Participants,

This letter is a request for you to take part in a dissertation research study to measure teachers' attitudes and perceptions towards nanotechnology and implementing it in science classrooms. This study is being conducted by Nadira Ghattas, Doctoral Student in Curriculum and Instruction with an emphasis in Science Education at WVU with supervision of Dr. Jeffrey S. Carver, Ed.D., an assistant professor in the College of Education and Human Services, for a research study for my dissertation. Your participation in this study is greatly appreciated. It will take approximately 20-25 minutes to participate in this interview. Dr. Carver and I will be the only persons with access to your responses. This interview aims to address your personal attitudes toward nanotechnology and implementing it in science classrooms. In addition, it asks you about the facilitators that would help implementing nanotechnology in science classrooms. The interview responses will completely be kept confidential and names will be kept anonymous. All names will be stripped from the interview responses. The data collected from this study will be kept in a locked cabinet. Participation in this research is voluntary and you may refuse to participate without any consequences. West Virginia University Institutional Review Board acknowledgement of this study is on file. Please see attached interview cover letter. If at any time you choose to be withdrawn from the study contact Nadira Ghattas at (703) 568-6739 or by e-mail at nissa@mix.wvu.edu or Jeffrey S. Carver at (304) 381-2607 or by email at jeffrey.carver@mail.wvu.edu. Thank you for your consideration. Your help is highly appreciated. Sincerely, Nadira Ghattas 703-568-6739 nissa@mix.wvu.edu Jeffrey S. Carver 604K Allen Hall P.O. BOX 6122 Morgantown, WV 26506 (304) 293-3841 jeffrey.carver@mail.wvu.edu.

Have you ever participated in nanotechnology formal professional development opportunities (e.g., in-service nano workshops, nanotechnology program, nanotechnology research and development experience, etc.) or taken any nanotechnology course in your undergraduate or graduate studies?

Yes

No

If you answered Yes, please, provide your contact information (name, phone number, and mailing address, if possible) in order to be contacted for the interview purpose.

If you answered No, please, provide your contact information (name, phone number, and mailing address, if possible) in order to be contacted for the interview purpose. 


\title{
Appendix $G$
}

\author{
Interview Cover Letter
}

Dear science teacher,

This letter is a request for you to take part in a dissertation research study to measure science teachers' attitudes and perceptions toward integrating nanotechnology in science classrooms. This study is being conducted by Nadira Ghattas, Doctoral Student in Curriculum and Instruction with an emphasis in Science Education at WVU with supervision of Dr. Jeffrey S. Carver, Ed.D., an associate professor in the College of Education and Human Services, for a research study for my dissertation. Your participation in this study is greatly appreciated. You must be 18 years of age or older to participate. It will take approximately 20-25 minutes to participate in an interview on your attitudes and perceptions that will be conducted via telephone. I will be the only person with access to your responses.

This interview aims to address your personal attitudes toward nanotechnology and implementing it in science classrooms. In addition, it asks you about the facilitators that would help with implementing nanotechnology in science classroom. Your participation in this research is voluntary and you may refuse to participate without any consequences. You may choose to skip any questions that you do not wish to answer. You must be 18 years of age or older to participate. The interview responses will completely be kept confidential and names will be kept anonymous. All names will be stripped from the interview responses. The data collected from this study will be kept in a locked cabinet. West Virginia University's Institutional Review Board acknowledgement of this study is on file. If at any time you choose to be withdrawn from the study contact Nadira Ghattas at (703) 568-6739 or by e-mail at nissa@mix.wvu.edu or Jeffrey S. Carver at (304) 293-3841 or by email at jeffrey.carver@mail.wvu.edu.

Thank you for your consideration. Your help is greatly appreciated.

Sincerely,

Nadira Ghattas

(703) 568-6739

nissa@mix.wvu.edu
Jeffrey S. Carver

609-E Allen Hall

P.O. BOX 6122

Morgantown, WV 26506

(304) 293-3841

jeffrey.carver@mail.wvu.edu 


\title{
Appendix $H$
}

IRB Research Approval

\section{WestVurginiaUniversity. \\ Office of Research Integrity and Compliance \\ Acknowledgement Letter Exempt Initial Protocol Review}

\author{
To Jeffrey Carver \\ From WVU Office of Research Integrity and Compliance \\ Action Date $\quad 10 / 10 / 2014$ \\ Approval Period 10/10/2014 Expiration Date 10/09/2017 \\ Subject \\ Protocol Number \\ Title

\section{Acknowledgement Letter Exempt Initial Protocol Review} \\ 1409444165 \\ Science Teachers Intentions of Integrating Nanotechnology in Science \\ Classrooms
}

The above-referenced study was reviewed by the West Virginia University Institutional Review Board IRB and was granted exemption in accordance with 45 CFR 46.101.

- This research study was granted an exemption because the Research involves educational tests, survey procedures, interview procedures or observation of public behavior and (i) information obtained is recorded in such a manner that human subjects cannot be identified, directly or through identifiers linked to the subjects; and (ii) any disclosure of the human subjects responses outside the research could not reasonably place the subjects at risk of criminal or civil liability or be damaging to the subjects financial standing, employability, or reputation [45 CFR 46.101(2)]. All exemptions are only good for three years. If this research extends more than three years beyond the approved date, then the researcher will have to request another exemption. The following documents have been acknowledged for use in this study and are available in the WVU+kc system:

Documents for use in this study have been acknowledged and are available in the WVU+kc system in the Notes and Attachments section of your protocol.

The Office of Research Integrity and Compliance is here to provide assistance to you from the initial submission of an IRB protocol and all subsequent activity. Please feel free to contact us by phone at 304.293.7073 with any question you may have. Thank you. 
WVU Office of Research Integrity and Compliance

Date: $10 / 10 / 2014$

Signed:

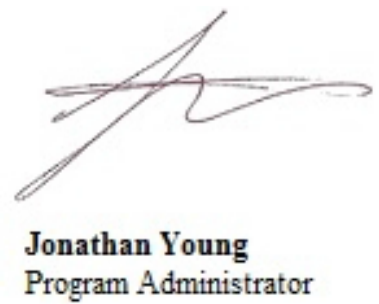




\section{Appendix I}

\section{Correlation Matrix of All Likert-type Survey Items}

\begin{tabular}{|c|c|c|c|c|c|c|c|c|c|c|c|c|c|c|c|c|c|c|c|c|c|c|c|}
\hline & $\begin{array}{l}\text { SS } \\
16\end{array}$ & SS1 & SS2 & SS3 & SS4 & SS5 & SS6 & SS 15 & SS7 & SS8 & Ss9 & SS10 & SS11 & SS12 & SS13 & SS14 & SS17 & SS18 & SS19 & SS20 & SS21 & SS22 & $\mathrm{SS} 23$ \\
\hline$\overline{S S 16}$ & & & & & & & & & & & & & & & & & & & & & & & \\
\hline SS1 & .19 & & & & & & & & & & & & & & & & & & & & & & \\
\hline SS2 & .18 & .76 & & & & & & & & & & & & & & & & & & & & & \\
\hline SS3 & .15 & .46 & .61 & & & & & & & & & & & & & & & & & & & & \\
\hline SS4 & .20 & .50 & .58 & .40 & & & & & & & & & & & & & & & & & & & \\
\hline SS6 & .28 & .47 & .41 & .29 & .38 & .37 & & & & & & & & & & & & & & & & & \\
\hline SS15 & .49 & .13 & .14 & .13 & .15 & -.014 & .19 & & & & & & & & & & & & & & & & \\
\hline SS7 & .28 & .36 & .29 & .20 & .36 & .29 & .55 & .28 & & & & & & & & & & & & & & & \\
\hline SS8 & .26 & .56 & .66 & .53 & .55 & .23 & .40 & .22 & .42 & & & & & & & & & & & & & & \\
\hline SS9 & .34 & .40 & .42 & .36 & .47 & .13 & .39 & .35 & .54 & .61 & & & & & & & & & & & & & \\
\hline SS10 & .30 & .28 & .19 & .15 & .36 & .20 & .41 & .27 & .65 & .27 & .52 & & & & & & & & & & & & \\
\hline SS12 & .24 & .25 & .28 & .26 & .41 & .07 & .31 & .31 & .48 & .39 & .62 & .55 & .59 & & & & & & & & & & \\
\hline SS13 & .46 & .19 & .25 & .24 & .25 & .12 & .26 & .34 & .33 & .37 & .47 & .33 & .28 & .38 & & & & & & & & & \\
\hline SS14 & .38 & .20 & .16 & .18 & .26 & -.001 & .26 & .46 & .35 & .31 & .45 & .36 & .42 & .46 & .59 & & & & & & & & \\
\hline SS17 & .35 & .23 & .36 & .38 & .40 & .03 & .23 & .43 & .31 & .48 & .53 & .29 & .29 & .39 & .37 & .39 & & & & & & & \\
\hline SS18 & .32 & .31 & .34 & .37 & .36 & .09 & .21 & .25 & .25 & .42 & .42 & .16 & .22 & .32 & .33 & .32 & .52 & & & & & & \\
\hline SS 19 & .23 & .13 & .12 & .15 & .25 & .07 & .29 & .29 & .52 & .24 & .48 & .55 & .56 & .53 & .32 & .43 & .33 & .22 & & & & & \\
\hline SS20 & .25 & .24 & .14 & .07 & .20 & .22 & .29 & .14 & .40 & .29 & .27 & .35 & .42 & .33 & .18 & .26 & .16 & .21 & .32 & & & & \\
\hline SS21 & .06 & .21 & .24 & .27 & .19 & .08 & .09 & .01 & .04 & .29 & .18 & .08 & .06 & .11 & .06 & .03 & .10 & .09 & .04 & .12 & & & \\
\hline SS22 & .18 & .16 & .15 & .06 & .14 & .11 & .16 & .09 & .22 & .19 & .21 & .17 & .18 & .13 & .17 & .17 & .12 & .14 & .13 & .28 & .16 & & \\
\hline SS23 & .15 & .15 & .16 & .14 & .17 & .06 & .07 & .05 & .04 & .10 & .09 & .09 & .06 & .07 & .18 & .12 & .11 & .21 & .10 & .14 & .22 & .23 & \\
\hline SS24 & .25 & .24 & .30 & .28 & .33 & .05 & .18 & .21 & .15 & .23 & .27 & .20 & .14 & .21 & .30 & .27 & .28 & .30 & .13 & .05 & .14 & .12 & .56 \\
\hline
\end{tabular}




\section{Appendix $J$}

\section{Total Variance Explained by Six-Factor Solution}

\begin{tabular}{|c|c|c|c|c|c|c|c|c|c|}
\hline \multirow[b]{4}{*}{ Component } & \multicolumn{9}{|c|}{ Extraction Sums of Squared } \\
\hline & \multicolumn{3}{|c|}{ Initial Eigenvalues } & \multicolumn{3}{|c|}{ Loadings } & \multicolumn{3}{|c|}{ Rotation Sums of Squared Loadings } \\
\hline & & $\%$ of & Cumulative & & $\%$ of & Cumulative & & $\%$ of & Cumulative \\
\hline & Total & Variance & $\%$ & Total & Variance & $\%$ & Total & Variance & $\%$ \\
\hline 1 & 7.657 & 31.904 & 31.904 & 7.657 & 31.904 & 31.904 & 3.946 & 16.443 & 16.443 \\
\hline 2 & 2.392 & 9.968 & 41.873 & 2.392 & 9.968 & 41.873 & 3.896 & 16.232 & 32.675 \\
\hline 3 & 1.826 & 7.607 & 49.479 & 1.826 & 7.607 & 49.479 & 2.938 & 12.240 & 44.915 \\
\hline 4 & 1.423 & 5.930 & 55.409 & 1.423 & 5.930 & 55.409 & 1.712 & 7.133 & 52.048 \\
\hline 5 & 1.150 & 4.790 & 60.200 & 1.150 & 4.790 & 60.200 & 1.586 & 6.609 & 58.657 \\
\hline 6 & 1.024 & 4.265 & 64.465 & 1.024 & 4.265 & 64.465 & 1.394 & 5.808 & 64.465 \\
\hline 7 & .837 & 3.489 & 67.954 & & & & & & \\
\hline 8 & .766 & 3.190 & 71.144 & & & & & & \\
\hline 9 & .735 & 3.064 & 74.208 & & & & & & \\
\hline 10 & .680 & 2.832 & 77.040 & & & & & & \\
\hline 11 & .599 & 2.498 & 79.538 & & & & & & \\
\hline 12 & .549 & 2.288 & 81.826 & & & & & & \\
\hline 13 & .516 & 2.149 & 83.975 & & & & & & \\
\hline 14 & .511 & 2.128 & 86.103 & & & & & & \\
\hline 15 & .468 & 1.949 & 88.052 & & & & & & \\
\hline 16 & .449 & 1.873 & 89.925 & & & & & & \\
\hline 17 & .424 & 1.765 & 91.690 & & & & & & \\
\hline 18 & .369 & 1.539 & 93.229 & & & & & & \\
\hline 19 & .344 & 1.432 & 94.660 & & & & & & \\
\hline 20 & .316 & 1.318 & 95.979 & & & & & & \\
\hline 21 & .304 & 1.268 & 97.247 & & & & & & \\
\hline 22 & .276 & 1.151 & 98.397 & & & & & & \\
\hline 23 & .212 & .885 & 99.282 & & & & & & \\
\hline 24 & .172 & .718 & 100.000 & & & & & & \\
\hline
\end{tabular}

Extraction Method: Principal Component Analysis. 


\section{Appendix $K$}

\section{Rotated Component Matrix of the Survey Items}

\begin{tabular}{|c|c|c|c|c|c|c|c|c|}
\hline & \multicolumn{6}{|c|}{ Component } & \multirow[t]{2}{*}{ Item } & \multirow[t]{2}{*}{$\begin{array}{l}\text { Factor } \\
\text { (FA) }\end{array}$} \\
\hline & 1 & 2 & 3 & 4 & 5 & 6 & & \\
\hline $\begin{array}{l}\text { My state science standards allow me to include } \\
\text { nanotechnology-related content, activities, and/ or materials in } \\
\text { my science classroom. }\end{array}$ & .050 & .059 & .752 & .248 & .089 & .141 & SS16 & 3 \\
\hline I am familiar with the concept of nanotechnology. & .695 & .094 & .041 & .418 & .074 & .091 & SS1 & 1 \\
\hline I am knowledgeable about nanotechnology. & .843 & .033 & .071 & .247 & .092 & .049 & SS2 & 1 \\
\hline $\begin{array}{l}\text { Science courses in which I have enrolled during my } \\
\text { undergraduate or graduate studies, have helped me to learn } \\
\text { about nanotechnology-related concepts. }\end{array}$ & .757 & .044 & .099 & .016 & .105 & -.005 & SS3 & 1 \\
\hline $\begin{array}{l}\text { I have increased my knowledge about nanotechnology through } \\
\text { educational opportunities such as professional development, } \\
\text { workshops, museums, etc. }\end{array}$ & 641 & .324 & .064 & .175 & .178 & -.003 & SS4 & 1 \\
\hline Nanotechnology is inherently dangerous. & .153 & .052 & -.036 & .738 & .030 & .090 & SS5 & 4 \\
\hline $\begin{array}{l}\text { Nanotechnology helps with the nation's economic growth and } \\
\text { competitiveness. }\end{array}$ & .317 & .331 & .160 & 629 & .012 & .032 & SS6 & 4 \\
\hline $\begin{array}{l}\text { My state science standards include content standards related to } \\
\text { nanotechnology. }\end{array}$ & .063 & .172 & .735 & -.011 & -.024 & -.022 & SS15 & 3 \\
\hline $\begin{array}{l}\text { Students should learn about nanotechnology in science } \\
\text { classrooms. }\end{array}$ & .197 & .651 & .206 & .410 & -.053 & .103 & SS7 & 2 \\
\hline $\begin{array}{l}\text { I am confident about teaching nanotechnology-related content } \\
\text { in my science classroom. }\end{array}$ & .754 & .203 & .239 & .121 & -.056 & .206 & SS8 & 1 \\
\hline I intend to integrate nanotechnology. & .494 & .533 & .371 & -.007 & -.10 & .109 & SS9 & 2 \\
\hline $\begin{array}{l}\text { Professional development opportunities on nanotechnology } \\
\text { education should be promoted for science teachers at the } \\
\text { middle and high school levels. }\end{array}$ & .087 & .793 & .143 & .245 & .085 & .043 & SS10 & 2 \\
\hline $\begin{array}{l}\text { Science teachers should attend professional development } \\
\text { workshops on advanced technology, such as nanotechnology. }\end{array}$ & .065 & .819 & .116 & .126 & .033 & .109 & SS11 & 2 \\
\hline $\begin{array}{l}\text { I intend to attend professional development workshops on } \\
\text { nanotechnology to learn about nanotechnology in the near } \\
\text { future. }\end{array}$ & .292 & .734 & .219 & -.097 & .026 & .047 & $\mathrm{SS} 12$ & 2 \\
\hline $\begin{array}{l}\text { My school administration is supportive of integrating } \\
\text { nanotechnology-related content, activities, and/ or materials in } \\
\text { science classrooms. }\end{array}$ & .167 & .237 & .651 & .083 & .172 & .044 & $\mathrm{SS} 13$ & 3 \\
\hline
\end{tabular}




\begin{tabular}{|c|c|c|c|c|c|c|c|c|}
\hline $\begin{array}{l}\text { My science teacher colleagues at my school are advocates of } \\
\text { integrating nanotechnology-related content and activities, and/ } \\
\text { or materials. }\end{array}$ & .099 & .409 & .627 & -.044 & 109 & .046 & SS14 & 3 \\
\hline $\begin{array}{l}\text { Nanotechnology content, activities and materials are already } \\
\text { integrated into my curriculum. }\end{array}$ & .479 & .251 & .531 & -.193 & .017 & .010 & SS17 & 3 \\
\hline $\begin{array}{l}\text { My students are allowed to explore nanotechnology-related } \\
\text { projects or problems in my science classroom. }\end{array}$ & .462 & 109 & .444 & -.079 & .147 & .083 & SS18 & 1,3 \\
\hline $\begin{array}{l}\text { It is important for science teachers to talk to their school } \\
\text { administration about the importance of integrating the topic of } \\
\text { nanotechnology as part of science curricula. }\end{array}$ & .051 & .762 & .208 & -.026 & .046 & .048 & SS19 & 2 \\
\hline $\begin{array}{l}\text { Science teachers should talk to their students about new } \\
\text { scientific and technological discoveries and developments, such } \\
\text { as nanotechnology. }\end{array}$ & .020 & .392 & .141 & .268 & -.048 & .556 & SS20 & 6 \\
\hline $\begin{array}{l}\text { My undergraduate or graduate education included significant } \\
\text { research experiences in science (e.g., undergraduate research in } \\
\text { chemistry, Master's thesis in physics, biological field study, } \\
\text { etc.). }\end{array}$ & .376 & .009 & -.144 & -.182 & .142 & .568 & $\mathrm{SS} 21$ & 6 \\
\hline $\begin{array}{l}\text { I engage my students in conducting scientific inquiry in my } \\
\text { science classroom or lab. }\end{array}$ & .015 & .068 & .158 & .128 & .104 & .748 & $\mathrm{SS} 22$ & 6 \\
\hline $\begin{array}{l}\text { Opportunities are available for me to engage in scientific } \\
\text { research experience (s) (e.g., summer research experience, } \\
\text { evening research at a local university, etc.). }\end{array}$ & .061 & .012 & .051 & .020 & .864 & .248 & $\mathrm{SS} 23$ & 5 \\
\hline $\begin{array}{l}\text { Opportunities are available for me to engage in } \\
\text { nanotechnology-related research experience (e.g., summer } \\
\text { research experience, etc.). }\end{array}$ & .245 & .096 & .237 & .029 & .812 & -.070 & $\mathrm{SS} 24$ & 5 \\
\hline
\end{tabular}

Extraction Method: Principal Component Analysis.

Rotation Method: Varimax with Kaiser Normalization.

a. Rotation converged in 7 iterations. 


\section{Appendix L}

Detailed Alignment of the Survey Statements into Six Different Subscales

\begin{tabular}{|c|c|c|c|}
\hline Subscale & $\begin{array}{l}\text { No. of } \\
\text { items }\end{array}$ & $\begin{array}{l}\text { Survey } \\
\text { statement } \\
\text { (SS) No. }\end{array}$ & Survey statements included \\
\hline \multirow[t]{3}{*}{$\begin{array}{l}\text { Professional } \\
\text { Development }\end{array}$} & \multirow[t]{3}{*}{3} & SS10 & $\begin{array}{l}\text { Professional development opportunities on } \\
\text { nanotechnology education should be promoted for } \\
\text { science teachers at the middle and high school } \\
\text { levels. }\end{array}$ \\
\hline & & SS11 & $\begin{array}{l}\text { Science teachers should attend professional } \\
\text { development workshops on advanced technology, } \\
\text { such as nanotechnology. }\end{array}$ \\
\hline & & SS12 & $\begin{array}{l}\text { I intend to attend professional development } \\
\text { workshops on nanotechnology to learn about } \\
\text { nanotechnology in the near future. }\end{array}$ \\
\hline \multirow[t]{4}{*}{$\begin{array}{l}\text { Professional } \\
\text { Context }\end{array}$} & \multirow[t]{4}{*}{4} & SS13 & $\begin{array}{l}\text { My school administration is supportive of } \\
\text { integrating nanotechnology-related content, } \\
\text { activities, and/ or materials in science classrooms. }\end{array}$ \\
\hline & & SS14 & $\begin{array}{l}\text { My science teacher colleagues at my school are } \\
\text { advocates of integrating nanotechnology-related } \\
\text { content and activities, and/ or materials. }\end{array}$ \\
\hline & & SS15 & $\begin{array}{l}\text { My state science standards include content } \\
\text { standards related to nanotechnology. }\end{array}$ \\
\hline & & SS16 & $\begin{array}{l}\text { My state science standards allow me to include } \\
\text { nanotechnology-related content, activities, and/ or } \\
\text { materials in my science classroom. }\end{array}$ \\
\hline \multirow[t]{4}{*}{ Practice } & \multirow[t]{4}{*}{4} & SS17 & $\begin{array}{l}\text { Nanotechnology content, activities and materials } \\
\text { are already integrated into my curriculum. }\end{array}$ \\
\hline & & SS18 & $\begin{array}{l}\text { My students are allowed to explore } \\
\text { nanotechnology-related projects or problems in my } \\
\text { science classroom. }\end{array}$ \\
\hline & & SS19 & $\begin{array}{l}\text { It is important for science teachers to talk to their } \\
\text { school administration about the importance of } \\
\text { integrating the topic of nanotechnology as part of } \\
\text { science curricula. }\end{array}$ \\
\hline & & SS20 & $\begin{array}{l}\text { Science teachers should talk to their students about } \\
\text { new scientific and technological discoveries and } \\
\text { developments, such as nanotechnology. }\end{array}$ \\
\hline Research & 4 & SS21 & $\begin{array}{l}\text { My undergraduate or graduate education included } \\
\text { significant research experiences in science (e.g., } \\
\text { undergraduate research in chemistry, Master's }\end{array}$ \\
\hline
\end{tabular}


S22

SS23

$\mathrm{SS} 24$

Knowledge and self-confidence

Attitude
5

SS1

SS2

SS3

SS4

SS8

SS6
$3 \quad$ SS5 thesis in physics, biological field study, etc.). I engage my students in conducting scientific inquiry in my science classroom or lab.

Opportunities are available for me to engage in scientific research experience (s) (e.g., summer research experience, evening research at a local university, etc.).

Opportunities are available for me to engage in nanotechnology-related research experience (e.g., summer research experience, etc.).

I am familiar with the concept of nanotechnology. I am knowledgeable about nanotechnology. Science courses in which I have enrolled during my undergraduate or graduate studies, have helped me to learn about nanotechnology-related concepts.

I have increased my knowledge about nanotechnology through educational opportunities such as professional development, workshops, museums, etc.

I am confident about teaching nanotechnologyrelated content in my science classroom.

Nanotechnology is inherently dangerous. Nanotechnology helps with the nation's economic growth and competitiveness.

SS7 Students should learn about nanotechnology in science classrooms. 
Appendix $M$

Reliability Statistics (Cronbach's Alpha Coefficients)

CRONBACH'S ALPHA COEFFICIENT FOR SUBSCALE \#1 (PROFESSIONAL DEVELOPMENT)

\begin{tabular}{|r|r|}
\hline \multicolumn{2}{|c|}{ Reliability Statistics } \\
\hline \multicolumn{2}{|c|}{$\begin{array}{c}\text { Cronbach's } \\
\text { Alpha }\end{array}$} \\
\hline .818 & N of Items \\
\hline
\end{tabular}

\begin{tabular}{|c|c|c|c|c|}
\hline \multicolumn{5}{|c|}{ Item-Total Statistics } \\
\hline & $\begin{array}{l}\text { Scale Mean if } \\
\text { Item Deleted }\end{array}$ & $\begin{array}{c}\text { Scale Variance if } \\
\text { Item Deleted } \\
\end{array}$ & $\begin{array}{l}\text { Corrected Item- } \\
\text { Total Correlation } \\
\end{array}$ & $\begin{array}{c}\text { Cronbach's Alpha if Item } \\
\text { Deleted } \\
\end{array}$ \\
\hline $\begin{array}{l}\text { Professional development } \\
\text { opportunities on } \\
\text { nanotechnology education } \\
\text { should be promoted for science } \\
\text { teachers at the middle and high } \\
\text { school levels. }\end{array}$ & 6.67 & 3.264 & .686 & .737 \\
\hline $\begin{array}{l}\text { Science teachers should attend } \\
\text { professional development } \\
\text { workshops on advanced } \\
\text { technology, such as } \\
\text { nanotechnology. }\end{array}$ & 6.68 & 3.212 & .722 & .703 \\
\hline $\begin{array}{l}\text { I intend to attend professional } \\
\text { development workshops on } \\
\text { nanotechnology to learn about } \\
\text { nanotechnology in the near } \\
\text { future. }\end{array}$ & 7.52 & 2.955 & .620 & .815 \\
\hline
\end{tabular}


CRONBACH'S ALPHA COEFFICIENT FOR SUBSCALE \#2 (PROFESSIONAL CONTEXT)

\begin{tabular}{|r|r|}
\hline \multicolumn{2}{|c|}{ Reliability Statistics } \\
\hline Cronbach's Alpha & N of Items \\
\hline .762 & \\
\hline
\end{tabular}

\begin{tabular}{|c|c|c|c|c|}
\hline \multicolumn{5}{|c|}{ Item-Total Statistics } \\
\hline & $\begin{array}{l}\text { Scale Mean if } \\
\text { Item Deleted }\end{array}$ & $\begin{array}{l}\text { Scale Variance } \\
\text { if Item Deleted }\end{array}$ & $\begin{array}{l}\text { Corrected } \\
\text { Item-Total } \\
\text { Correlation } \\
\end{array}$ & $\begin{array}{c}\text { Cronbach's Alpha if Item } \\
\text { Deleted }\end{array}$ \\
\hline $\begin{array}{l}\text { My school administration is } \\
\text { supportive of integrating } \\
\text { nanotechnology-related } \\
\text { content, activities, and/ or } \\
\text { materials in science } \\
\text { classrooms. }\end{array}$ & 7.78 & 5.454 & .578 & .698 \\
\hline $\begin{array}{l}\text { My science teacher } \\
\text { colleagues at my school are } \\
\text { advocates of integrating } \\
\text { nanotechnology-related } \\
\text { content and activities, and/ } \\
\text { or materials. }\end{array}$ & 8.08 & 5.410 & .588 & .692 \\
\hline $\begin{array}{l}\text { My state science standards } \\
\text { include content standards } \\
\text { related to nanotechnology. }\end{array}$ & 8.36 & 5.551 & .538 & .718 \\
\hline $\begin{array}{l}\text { My state science standards } \\
\text { allow me to include } \\
\text { nanotechnology-related } \\
\text { content, activities, and/ or } \\
\text { materials in my science } \\
\text { classroom. }\end{array}$ & 7.68 & 4.942 & .550 & .717 \\
\hline
\end{tabular}


CRONBACH'S ALPHA COEFFICIENT FOR SUBSCALE \#3 (PRACTICE)

Reliability Statistics

\begin{tabular}{|r|r|}
\hline Cronbach's Alpha & N of Items \\
\hline .621 & 4 \\
\hline
\end{tabular}

\begin{tabular}{|c|c|c|c|c|}
\hline \multicolumn{5}{|c|}{ Item-Total Statistics } \\
\hline & $\begin{array}{l}\text { Scale Mean if } \\
\text { Item Deleted }\end{array}$ & $\begin{array}{c}\text { Scale Variance if } \\
\text { Item Deleted }\end{array}$ & $\begin{array}{l}\text { Corrected Item- } \\
\text { Total Correlation }\end{array}$ & $\begin{array}{c}\text { Cronbach's Alpha if Item } \\
\text { Deleted }\end{array}$ \\
\hline $\begin{array}{l}\text { Nanotechnology content, } \\
\text { activities and materials are } \\
\text { already integrated into my } \\
\text { curriculum. }\end{array}$ & 9.63 & 3.955 & .497 & .474 \\
\hline $\begin{array}{l}\text { My students are allowed to } \\
\text { explore nanotechnology-related } \\
\text { projects or problems in my } \\
\text { science classroom. }\end{array}$ & 9.12 & 3.792 & .460 & .506 \\
\hline $\begin{array}{l}\text { It is important for science } \\
\text { teachers to talk to their school } \\
\text { administration about the } \\
\text { importance of integrating the } \\
\text { topic of nanotechnology as part } \\
\text { of science curricula. }\end{array}$ & 8.49 & 4.756 & .376 & .569 \\
\hline $\begin{array}{l}\text { Science teachers should talk to } \\
\text { their students about new } \\
\text { scientific and technological } \\
\text { discoveries and developments, } \\
\text { such as nanotechnology. }\end{array}$ & 7.38 & 5.201 & .282 & .627 \\
\hline
\end{tabular}




\section{CRONBACH'S ALPHA COEFFICIENT FOR SUBSCALE \#4 (RESEARCH)}

Reliability Statistics

\begin{tabular}{|r|r|}
\hline Cronbach's Alpha & N of Items \\
\hline .563 & 4 \\
\hline
\end{tabular}

\begin{tabular}{|c|c|c|c|c|}
\hline \multicolumn{5}{|c|}{ Item-Total Statistics } \\
\hline & $\begin{array}{l}\text { Scale Mean if } \\
\text { Item Deleted }\end{array}$ & $\begin{array}{l}\text { Scale Variance if } \\
\text { Item Deleted }\end{array}$ & $\begin{array}{l}\text { Corrected Item- } \\
\text { Total Correlation }\end{array}$ & $\begin{array}{c}\text { Cronbach's Alpha if Item } \\
\text { Deleted }\end{array}$ \\
\hline $\begin{array}{l}\text { My undergraduate or graduate } \\
\text { education included significant } \\
\text { research experiences in science } \\
\text { (e.g., undergraduate research in } \\
\text { chemistry, Master's thesis in } \\
\text { physics, biological field study, } \\
\text { etc.). }\end{array}$ & 10.32 & 5.029 & .265 & .605 \\
\hline $\begin{array}{l}\text { I engage my students in } \\
\text { conducting scientific inquiry in } \\
\text { my science classroom or lab. }\end{array}$ & 9.18 & 7.227 & .252 & .560 \\
\hline $\begin{array}{l}\text { Opportunities are available for } \\
\text { me to engage in scientific } \\
\text { research experience (s) (e.g., } \\
\text { summer research experience, } \\
\text { evening research at a local } \\
\text { university, etc.). }\end{array}$ & 10.09 & 5.094 & .517 & .345 \\
\hline $\begin{array}{l}\text { Opportunities are available for } \\
\text { me to engage in } \\
\text { nanotechnology-related } \\
\text { research experience (e.g., } \\
\text { summer research experience, } \\
\text { etc.). }\end{array}$ & 10.84 & 5.708 & .419 & .436 \\
\hline
\end{tabular}


CRONBACH'S ALPHA COEFFICIENT FOR SUBSCALE \#5 (KNOWLEDGE and SELF-CONFIDENCE)

Reliability Statistics

\begin{tabular}{|r|r|}
\hline Cronbach's Alpha & N of Items \\
\hline .866 & 5 \\
\hline
\end{tabular}

\begin{tabular}{|c|c|c|c|c|}
\hline \multicolumn{5}{|c|}{ Item-Total Statistics } \\
\hline & $\begin{array}{l}\text { Scale Mean if } \\
\text { Item Deleted }\end{array}$ & $\begin{array}{l}\text { Scale Variance } \\
\text { if Item Deleted }\end{array}$ & $\begin{array}{l}\text { Corrected } \\
\text { Item-Total } \\
\text { Correlation }\end{array}$ & $\begin{array}{c}\text { Cronbach's Alpha if Item } \\
\text { Deleted }\end{array}$ \\
\hline $\begin{array}{l}\text { I am familiar with the } \\
\text { concept of nanotechnology. }\end{array}$ & 9.44 & 15.752 & .695 & .835 \\
\hline $\begin{array}{l}\text { I am knowledgeable about } \\
\text { nanotechnology. }\end{array}$ & 10.14 & 15.322 & .824 & .805 \\
\hline $\begin{array}{l}\text { Science courses in which I } \\
\text { have enrolled during my } \\
\text { undergraduate or graduate } \\
\text { studies, have helped me to } \\
\text { learn about nanotechnology- } \\
\text { related concepts. }\end{array}$ & 10.77 & 17.001 & .599 & .858 \\
\hline $\begin{array}{l}\text { I have increased my } \\
\text { knowledge about } \\
\text { nanotechnology through } \\
\text { educational opportunities } \\
\text { such as professional } \\
\text { development, workshops, } \\
\text { museums, etc. }\end{array}$ & 10.34 & 15.590 & .623 & .856 \\
\hline $\begin{array}{l}\text { I am confident about } \\
\text { teaching nanotechnology- } \\
\text { related content in my science } \\
\text { classroom. }\end{array}$ & 10.38 & 15.523 & .715 & .830 \\
\hline
\end{tabular}


CRONBACH'S ALPHA COEFFICIENT FOR SUBSCALE \#6 (ATTITUDE)

\begin{tabular}{|r|r|}
\hline \multicolumn{2}{|c|}{ Reliability Statistics } \\
\hline Cronbach's Alpha & N of Items \\
\hline .650 & 3 \\
\hline
\end{tabular}

\begin{tabular}{|l|r|r|r|r|}
\hline \multicolumn{7}{|c|}{ Item-Total Statistics } \\
\hline & $\begin{array}{c}\text { Scale Mean if } \\
\text { Item Deleted }\end{array}$ & $\begin{array}{c}\text { Scale Variance if } \\
\text { Item Deleted }\end{array}$ & $\begin{array}{c}\text { Corrected Item- } \\
\text { Total Correlation }\end{array}$ & $\begin{array}{c}\text { Cronbach's Alpha if Item } \\
\text { Deleted }\end{array}$ \\
\hline $\begin{array}{l}\text { Nanotechnology is inherently } \\
\text { dangerous. }\end{array}$ & 7.39 & 2.142 & .346 & .708 \\
\hline $\begin{array}{l}\text { Nanotechnology helps with the } \\
\text { nation's economic growth and } \\
\text { competitiveness. }\end{array}$ & 7.69 & 1.838 & .555 & \\
\hline $\begin{array}{l}\text { Students should learn about } \\
\text { nanotechnology in science } \\
\text { classrooms. }\end{array}$ & 7.62 & 1.978 & .492 & \\
\hline
\end{tabular}




\section{Appendix $N$}

Histograms of all Variables Included in the Factor Analysis

Histogram of Attitude: This histogram shows a normal distribution of the attitude toward nanotechnology and its implementation in science classrooms.

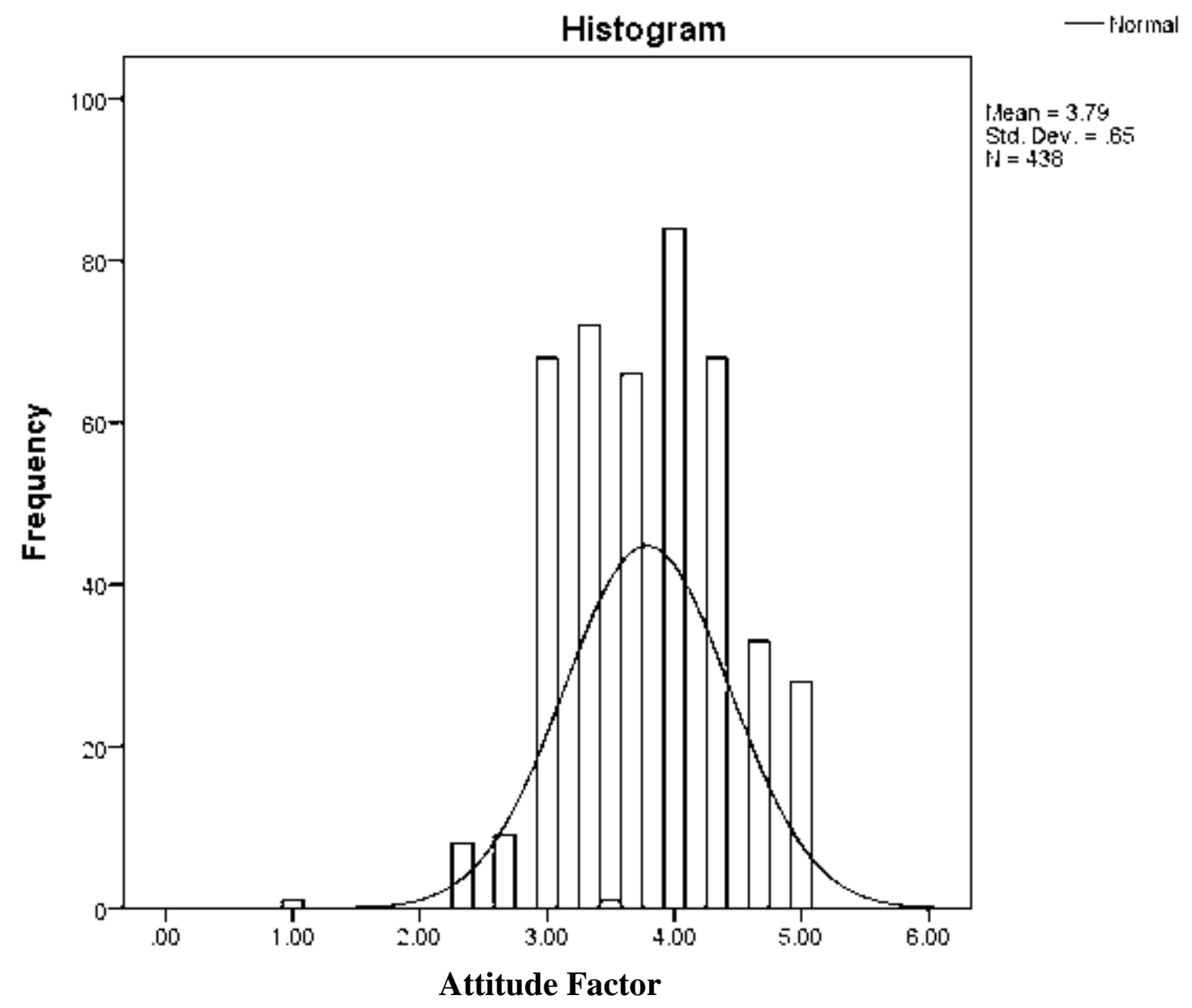


Histogram of Professional Development: This histogram that shows a normal distribution of the professional development factor.

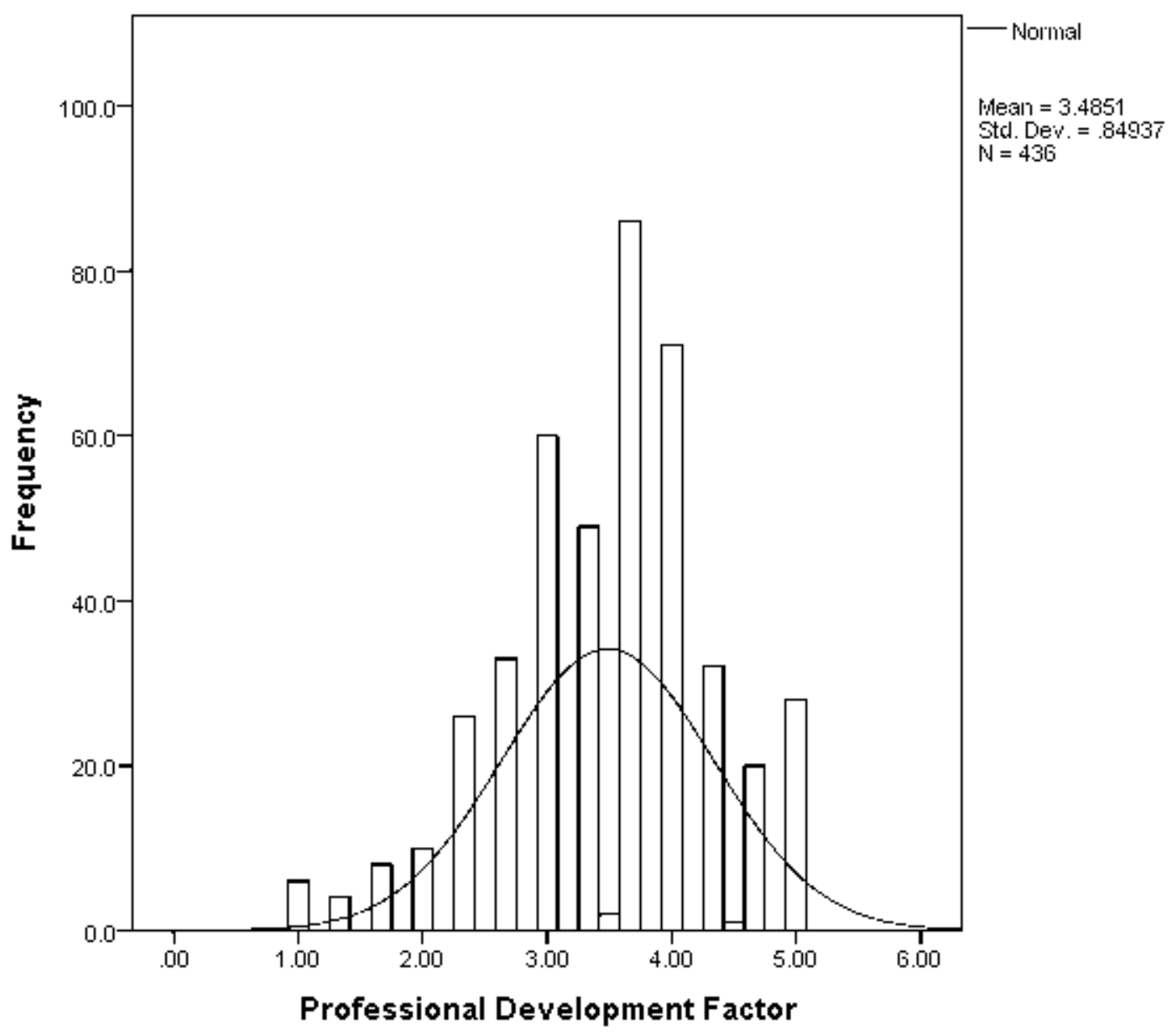


Histogram of Professional Context: This histogram that shows a normal distribution of the professional context factor.

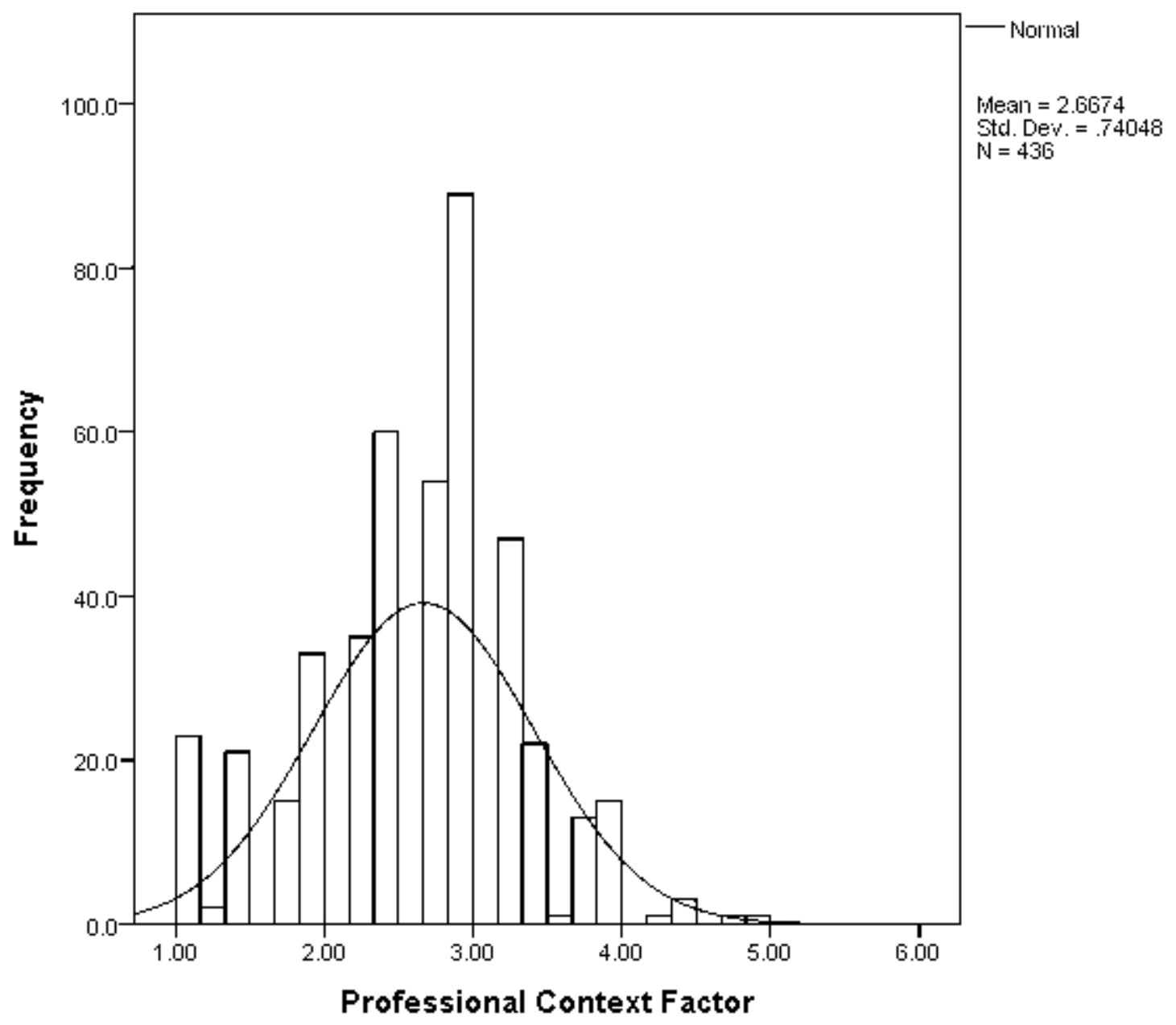


Histogram of Personal Practice: This histogram that shows a normal distribution of the practice factor.

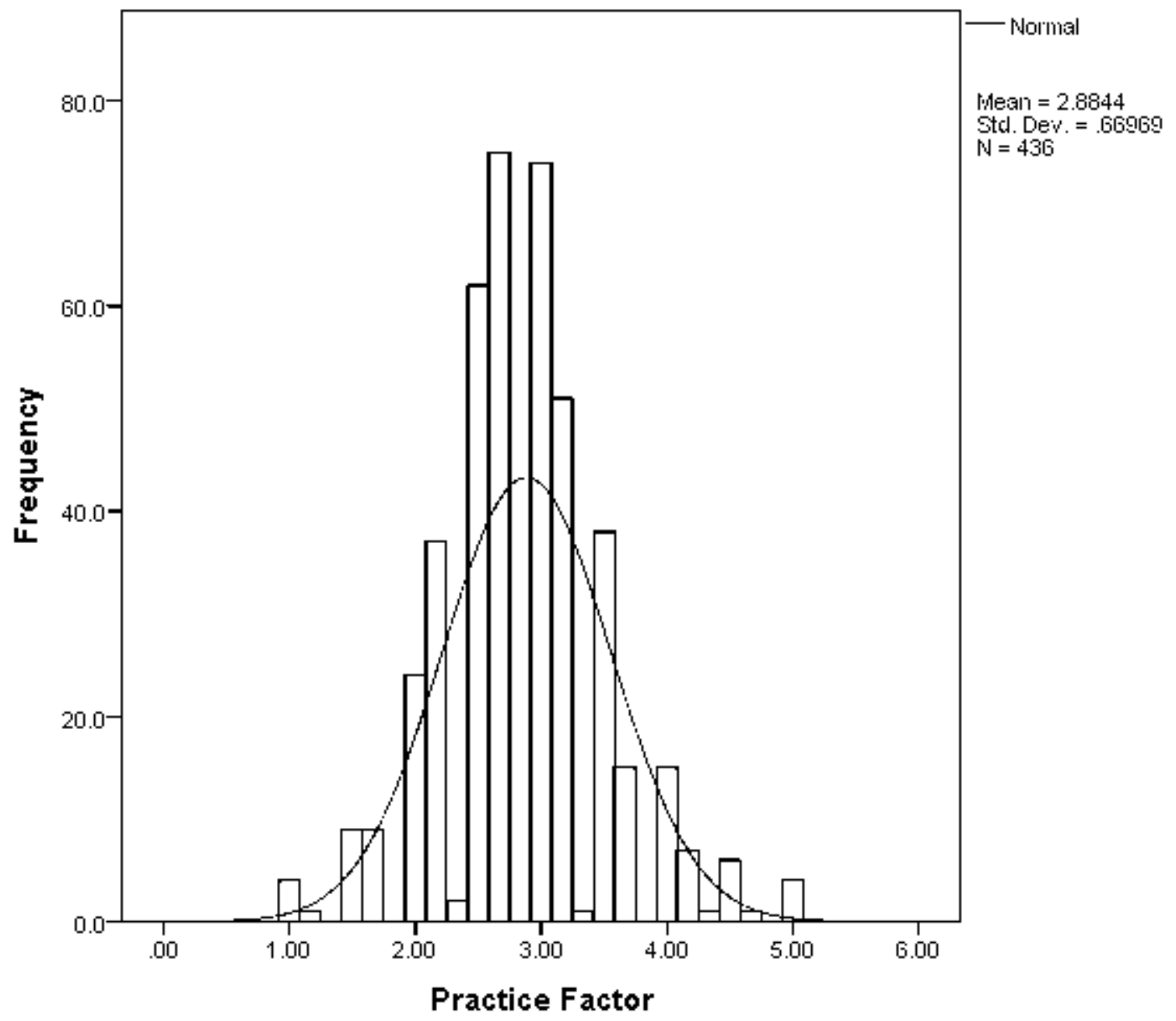


Histogram of Knowledge and Self-confidence: This histogram shows a normal distribution of knowledge and self-confidence factor.

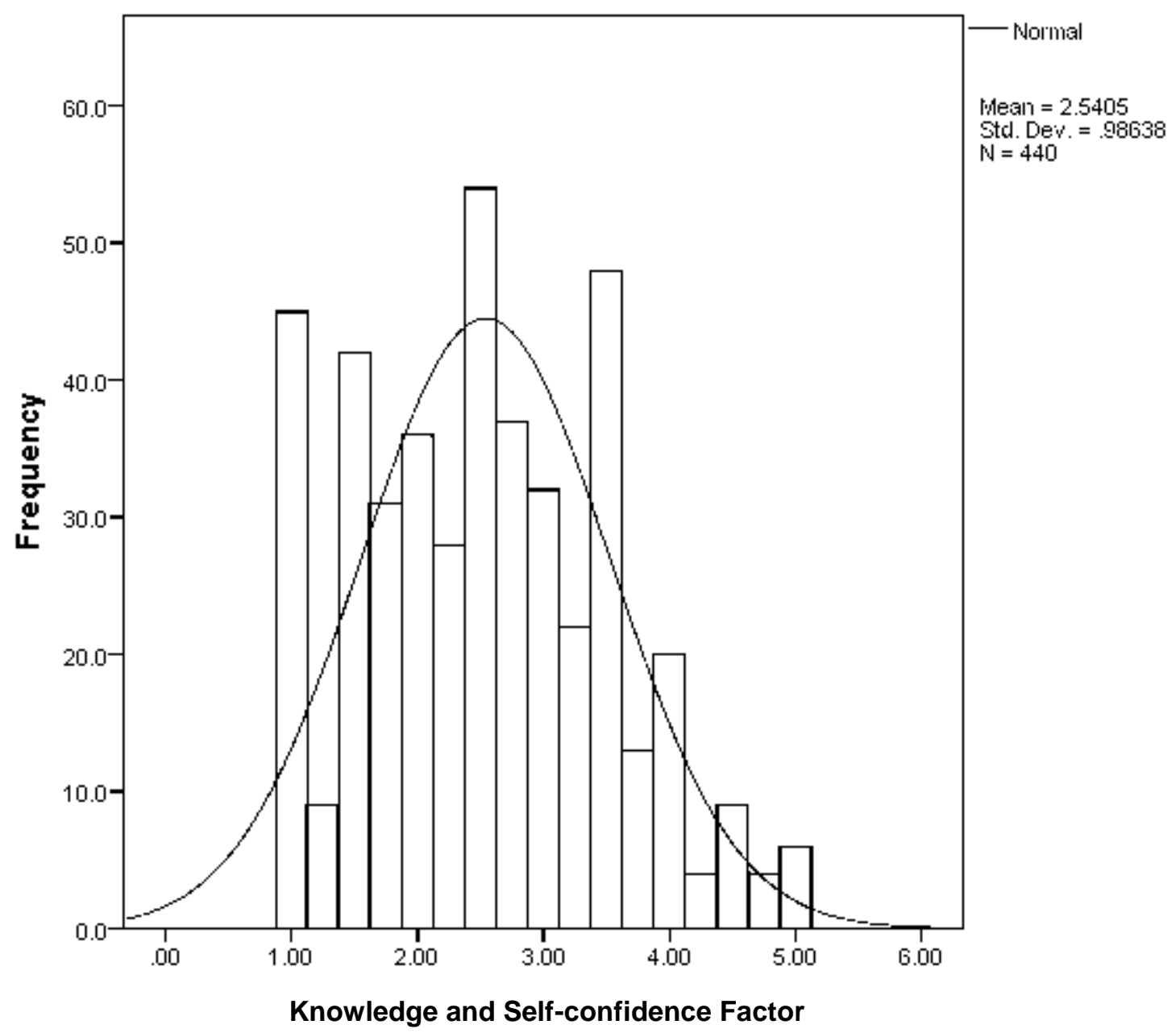


Histogram of Research: This histogram shows a normal distribution of the research factor.

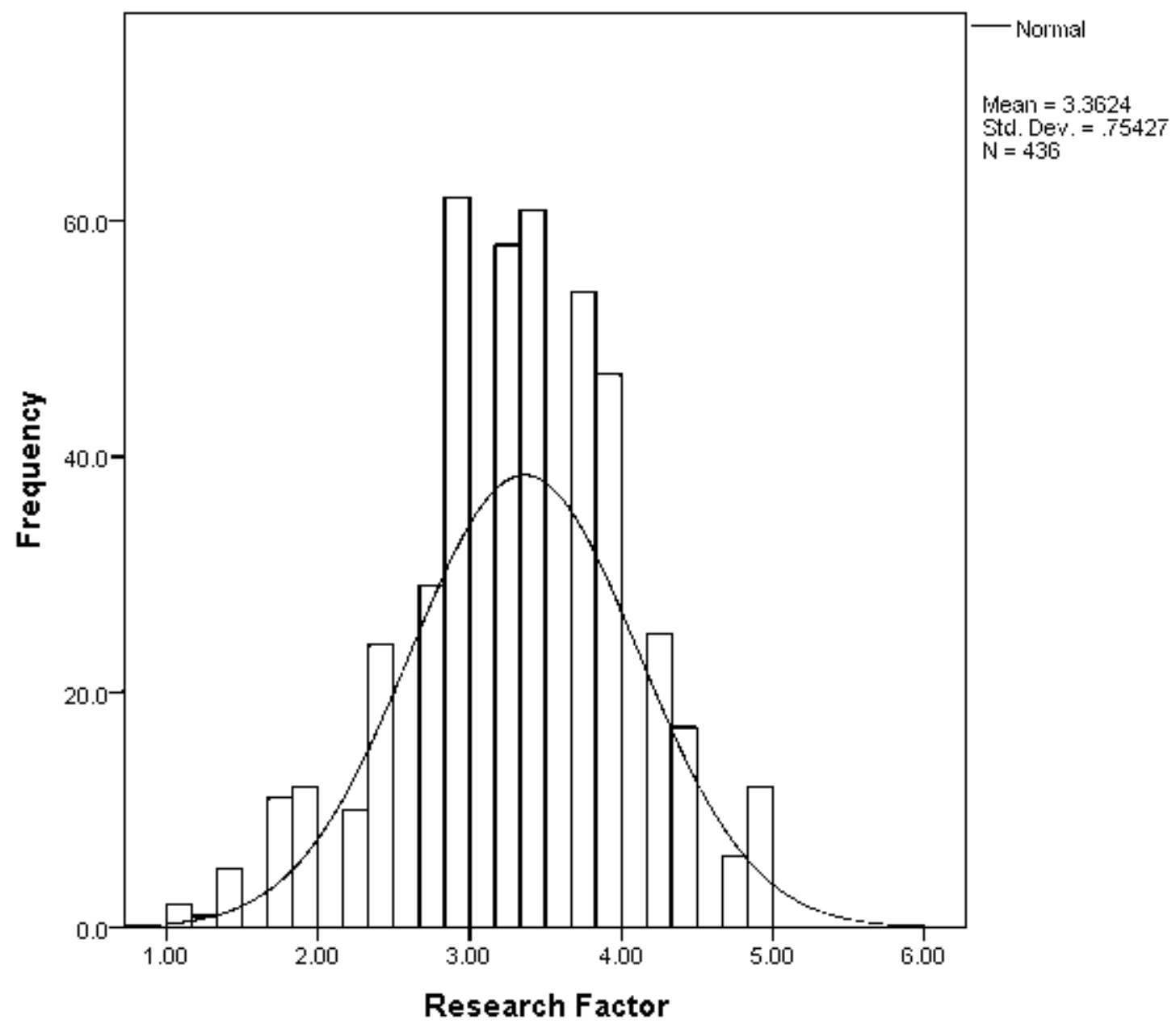


Histogram of Intention: This histogram shows a normal distribution of the intention factor.

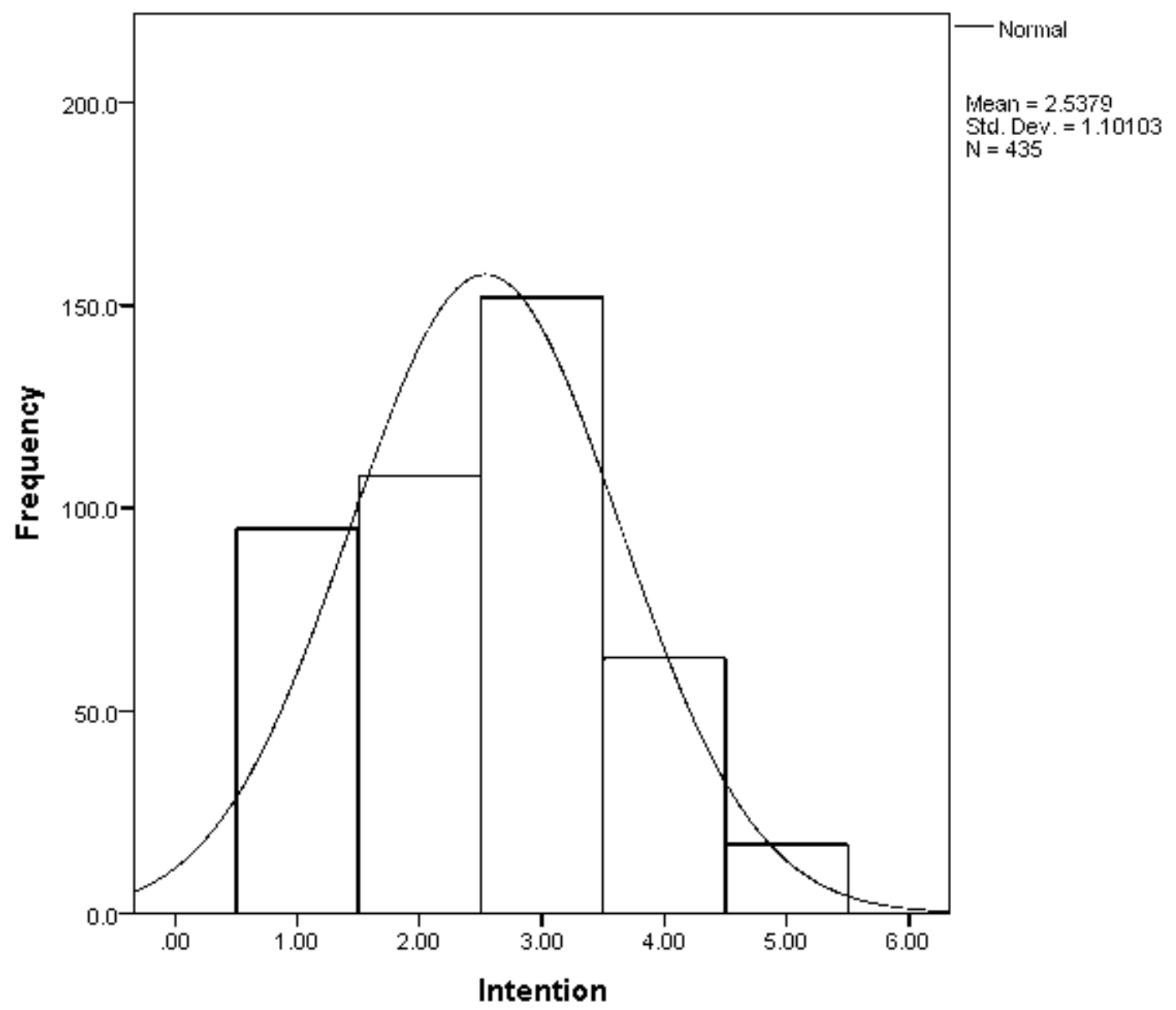

